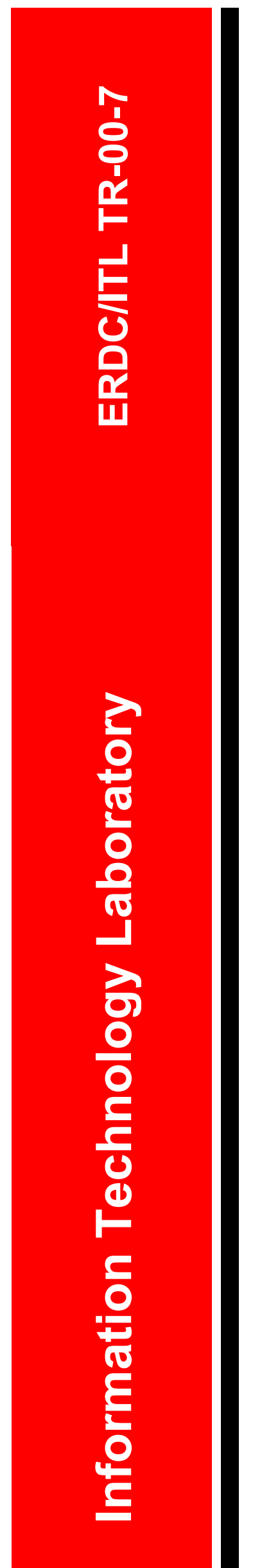

Innovations for Navigation Projects Research Program

Extended Load/Unload/Reload Hyperbolic Model for Interfaces: Parameter Values and Model Performance for the Contact Between Concrete and Coarse Sand

Jesús E. Gómez, George M. Filz, and Robert M. Ebeling

December 2000

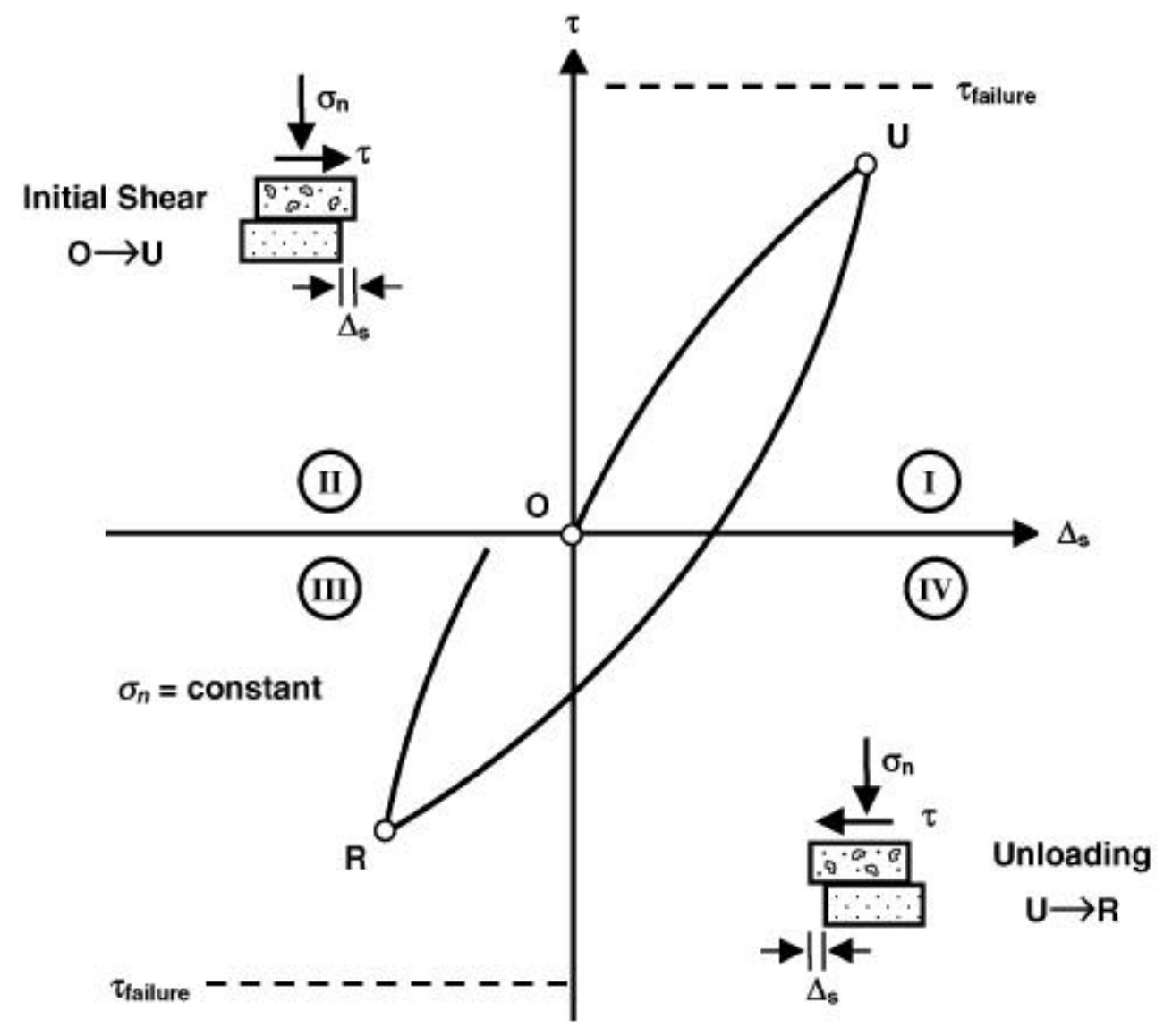


The contents of this report are not to be used for advertising, publication, or promotional purposes. Citation of trade names does not constitute an official endorsement or approval of the use of such commercial products.

The findings of this report are not to be construed as an official Department of the Army position, unless so designated by other authorized documents. 


\section{Extended Load/Unload/Reload Hyperbolic Model for Interfaces: Parameter Values and Model Performance for the Contact Between Concrete and Coarse Sand}

by Jesús E. Gómez, George M. Filz

Virginia Polytechnic Institute and State University

Blacksburg, VA 24061-0105

Robert M. Ebeling

Information Technology Laboratory

U.S. Army Engineer Research and Development Center

3909 Halls Ferry Road

Vicksburg, MS 39180-6199

Final report

Approved for public release; distribution is unlimited

Prepared for

Under
U.S. Army Corps of Engineers

Washington, DC 20314-1000

INP Work Unit 33272 


\section{Contents}

Preface ................. v

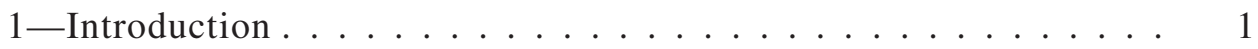

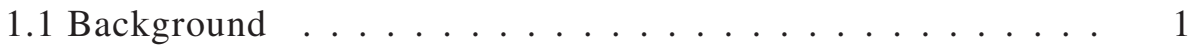

1.2 Common Types of Multi-Anchored Systems _... . . . . 2

1.3 Response to Soil-to-Wall Interfaces in Multi-Anchored

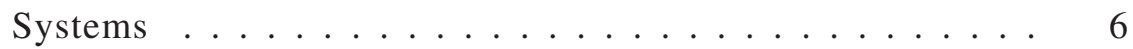

1.4 The Gómez-Filz-Ebeling Interface Model $\ldots \ldots \ldots \ldots$. . . 9

1.5 Scope of the Investigation $\ldots \ldots \ldots \ldots$

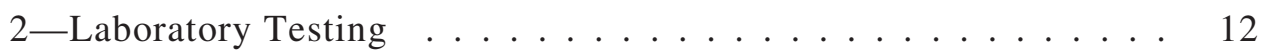

2.1 Properties of Blacksburg Sand . . . . . . . . . . . . 12

2.1 .1 Triaxial testing . . . . . . . . . . . . . . 14

2.1.2 Consolidation testing . . . . . . . . . . . . 15

2.1.3 Hyperbolic parameters . . . . . . . . . . . . . 15

2.2 Interface Testing $\ldots \ldots \ldots \ldots \ldots \ldots \ldots \ldots$

2.2.1 Interface testing program $\ldots \ldots \ldots \ldots \ldots$

2.2.2 Results of interface tests . . . . . . . . . . . 17

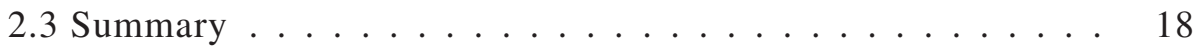

3-Evaluation of the Gómez-Filz-Ebeling Model for Interfaces . . . . 20

3.1 The Gómez-Filz-Ebeling Model for Interfaces _ . . . . . . . . 21

3.1 .1 Yield surfaces and loading regions . . . . . . . . 21

3.1.2 Formulation of extended hyperbolic model for interfaces at yield .................... 23

3.1.3 Formulation for unloading-reloading of the

Gómez-Filz-Ebeling model . . . . . . . . . . . . 25

3.1.4 Determination of the model parameter values . . . . . 31

3.2 Interface Hyperbolic Parameter Values . . . . . . . . . . . 32

3.3 Evaluation of the Extended Hyperbolic Model . . . . . . . 36

3.4 Input of Model Parameters in SOILSTRUCT-ALPHA . . . . . 39

3.4 .1 Soil parameter input . . . . . . . . . . . . . 40

3.4.2 Interface parameter input . . . . . . . . . . . 41

3.5 Summary and Conclusions . . . . . . . . . . . . 41 
4 -Summary and Conclusions . . . . . . . . . . . . . . 43

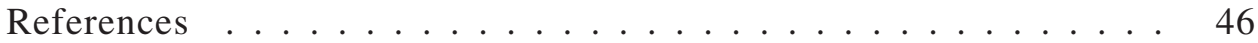

Appendix A: Results of Triaxial and Consolidation Tests and

Determination of Hyperbolic Parameter Values . . . . . . . . . . A1

Appendix B: Results of Interface Tests and Determination of Interface

Hyperbolic Parameter Values . . . . . . . . . . . . . B1

Appendix C: Notation . . . . . . . . . . . . . . . C C1

SF 298 


\section{Preface}

The work described in this report was authorized by Headquarters, U.S. Army Corps of Engineers (HQUSACE), as part of the Innovations for Navigation Projects (INP) Research Program. The work was performed under Work Unit 33272, "Soil-Structure Interaction Studies of Walls with Multiple Rows of Anchors."

Dr. Tony C. Liu was the INP Coordinator at the Directorate of Research and Development, HQUSACE; Research Area Manager was Mr. Barry Holliday, HQUSACE; and Program Monitor was Mr. Bruce Riley, HQUSACE. Mr. William H. McAnally of the U.S. Army Engineer Research and Development Center (ERDC) Coastal and Hydraulics Laboratory was the Lead Technical Director for navigation systems research; Dr. Stanley C. Woodson, ERDC Geotechnical and Structures Laboratory (GSL), was the INP Program Manager.

This report was prepared by Mr. Jesús E. Gómez, doctoral student, and Dr. George M. Filz, Associate Professor, Virginia Polytechnic Institute and State University, Blacksburg, and by Dr. Robert M. Ebeling, ERDC Information Technology Laboratory (ITL). The work was monitored by Dr. Ebeling, Principal Investigator for INP Work Unit 33272, under the supervision of Mr. H. Wayne Jones, Chief, Computer-Aided Engineering Division, ITL; Mr. Tim Ables, Acting Director, ITL; and Dr. Michael J. O’Connor, Director, GSL.

At the time of publication of this report, Dr. James R. Houston was Director of ERDC, and COL James S. Weller, EN, was Commander.

The contents of this report are not to be used for advertising, publication, or promotional purposes. Citation of trade names does not constitute an official endorsement or approval of the use of such commercial products. 


\section{Introduction}

\subsection{Background}

Multi-anchored or tieback wall systems are often used for temporary support of excavations that have space restrictions due to adjacent structures, highways, railroads, etc. In some cases, multi-anchored systems may remain as permanent structures after construction. In Corps of Engineers projects, permanent tieback wall systems are used as guide walls and approach walls on navigation projects, and as retaining walls on highway and railroad protection and relocation projects.

The behavior of multi-anchored systems may be strongly influenced by factors such as the sequence of excavation and installation of anchors, and by fluctuations in the water table. Therefore, to obtain accurate predictions of the magnitudes of stresses and deformations in the structure and the surrounding soil, it is necessary to perform soil-structure interaction (SSI) analyses that model the construction and operation stages of the system. For such analyses, adequate models for soils and soil-to-structure interfaces are required.

A substantial amount of research has been performed in recent years on lock walls, which are an important type of earth-retaining structure for navigation projects. These studies have included SSI analyses of the Red River Lock and Dam No. 1 (Ebeling et al. 1993; Ebeling and Mosher 1996; and Ebeling, Peters, and Mosher 1997), the North Lock Wall at McAlpine Locks (Ebeling and Wahl 1997), and Locks 27 (Ebeling, Pace, and Morrison 1997), and are good examples of available state-of-the-art techniques. These studies showed that the behavior of the soil-structure interface has a significant influence on the magnitudes of the loads acting against lock walls. They also illustrated that the preconstruction and postconstruction stress paths followed by interface elements are complex, often involving simultaneous changes in normal and shear stresses, as well as unloadingreloading due to postconstruction fluctuations of the groundwater level.

Gómez, Filz, and Ebeling (2000) developed an extended hyperbolic model for interfaces and implemented it into the finite element program SOILSTRUCT-ALPHA. The model is based on the Clough and Duncan 
(1971) hyperbolic formulation, which was extended to model a variety of stress paths. Gómez, Filz, and Ebeling (2000) performed a series of interface tests between uniform, fine sands and concrete. Some of these tests followed complex stress paths that included unloading-reloading and simultaneous changes in normal and shear stresses. They also carried out a pilotscale lock wall simulation that modeled placement and compaction of the backfill, surcharge application, and changes in the elevation of the water table behind the wall. By comparing model predictions to interface test results, and results of SOILSTRUCT-ALPHA analyses to measurements from the lock wall simulation, they concluded that the extended load/ unload/reload hyperbolic model may provide accurate estimates of the response of backfill-to-lock wall interfaces.

Important similarities exist between the types of loading that occur at structure-to-soil interfaces in both multi-anchored systems and lock walls. Therefore, it is possible that the Gómez-Filz-Ebeling model for interfaces could also be used for SSI analyses of multi-anchored systems. However, the model was developed based on the results of interface tests performed using uniform fine sands, and the model performance has not been evaluated using coarser soils.

The purpose of this investigation is to evaluate the accuracy of the extended hyperbolic model in predicting the response of the interface between concrete and coarse sand. A series of virgin shear tests were performed under constant stress at the interface between a coarse sand and concrete. The results of these tests were used to determine the hyperbolic parameter values of the interface following the recommendations given by Gómez, Filz, and Ebeling (2000). An interface test was performed following a complex stress path that included unloading-reloading as well as simultaneous changes in shear and normal stresses. The interface response measured during this test was compared to the response calculated using the extended hyperbolic model. It was found that the Gómez-Filz-Ebeling interface model provided accurate estimates of the response of this type of interface. Therefore, it can be concluded that the extended hyperbolic model can be used for prediction of the response of interfaces between concrete and a variety of granular soils. The hyperbolic parameter values of the interface tested also add to the database of interface properties available in the literature. The extended hyperbolic model, together with the interface data that have been generated, provide useful tools for analyses of multi-anchored retaining systems and other U.S. Army Corps of Engineers structures.

\subsection{Common Types of Multi-Anchored Systems}

Multi-anchored systems can be constructed using different materials and configurations. The following are the most common types found in practice: 
- Vertical sheet pile systems with wales and posttensioned tieback anchors.

- Soldier beam systems with wood or reinforced concrete lagging and posttensioned tieback anchors.

- Secant cylinder pile systems with posttensioned tieback anchors.

- Continuous reinforced concrete slurry wall systems with posttensioned tieback anchors.

- Discrete concrete slurry wall systems (soldier beams with concrete lagging) with posttensioned tieback anchors.

Figure 1-1 illustrates the use of a multi-anchored system for a typical navigation project. Because of the space restrictions imposed by an adjacent railroad, excavation for the expansion of the waterway requires the use of a multi-anchored system. For simplicity, it is assumed that the multi-anchored system depicted in the figure corresponds to a continuous, reinforced concrete slurry wall with tieback anchors. Tiebacks consist of posttensioned tendons with a grouted anchor region. A berm of granular material or riprap is placed at the toe of the wall to minimize erosion and improve stability.

Figure 1-2 illustrates the typical construction sequence of a reinforced concrete slurry wall. Initially, a trench is excavated using a clamshell-type tool. The excavation is stabilized by the use of mud slurry. The finished trench acts as formwork for the reinforced concrete panel. Placement of the concrete using a tremie pipe displaces the mud slurry and leaves a structural concrete wall that can be excavated and tied back in much the same manner as the other tieback wall systems. The walls are reinforced using preassembled cages, which are dropped into the slurry trench just before concrete placement. Slurry wall systems are usually 0.6 to 0.9 m thick and can be placed to depths of $30 \mathrm{~m}$ or more. The construction process can be summarized as follows:

a. Guide walls are constructed to facilitate positioning and alignment of the clamshell during the excavation process. To stabilize the excavation, mud slurry is kept inside the excavation to a level above the water table. As illustrated in Figure 1-2a, the excavation for each panel follows a staggered sequence. Two end excavations are performed first, leaving a central core intact. After the end excavations are completed, the central core is removed.

$b$. A stop end tube is placed at one end of the panel excavation. This tube is extracted after concrete placement leaving a semicircular indentation. This indentation serves as a guide for the excavation of the adjacent panel and allows the creation of a shear key between the panels.

$c$. Once the panel has been excavated to the desired depth and the slurry cleaned of fine excavation material (desanded), the reinforcement cage is lowered into the excavation. 


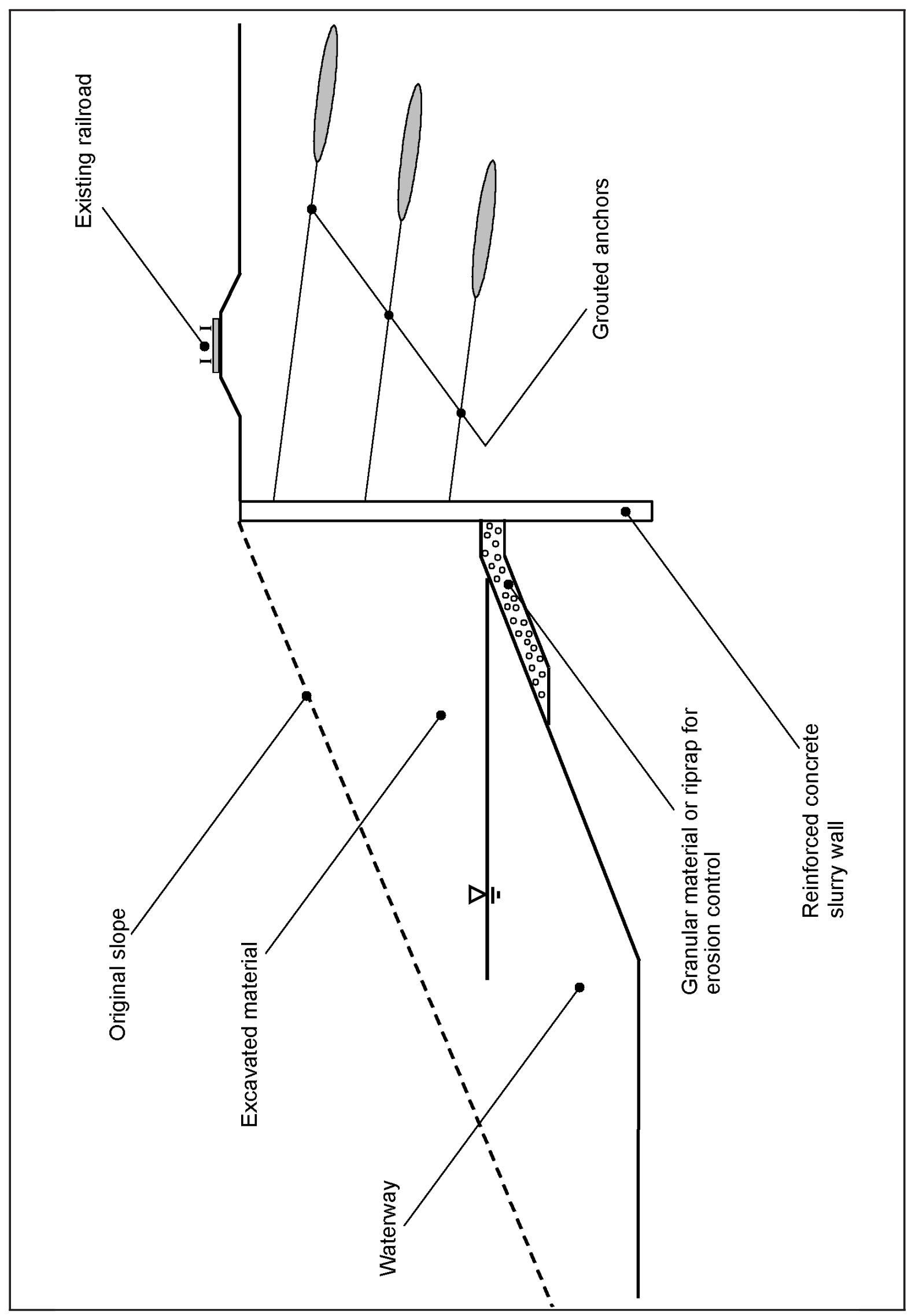

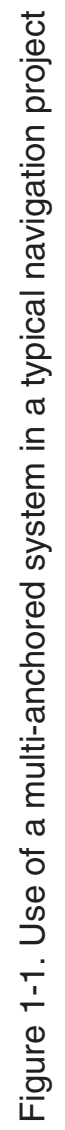



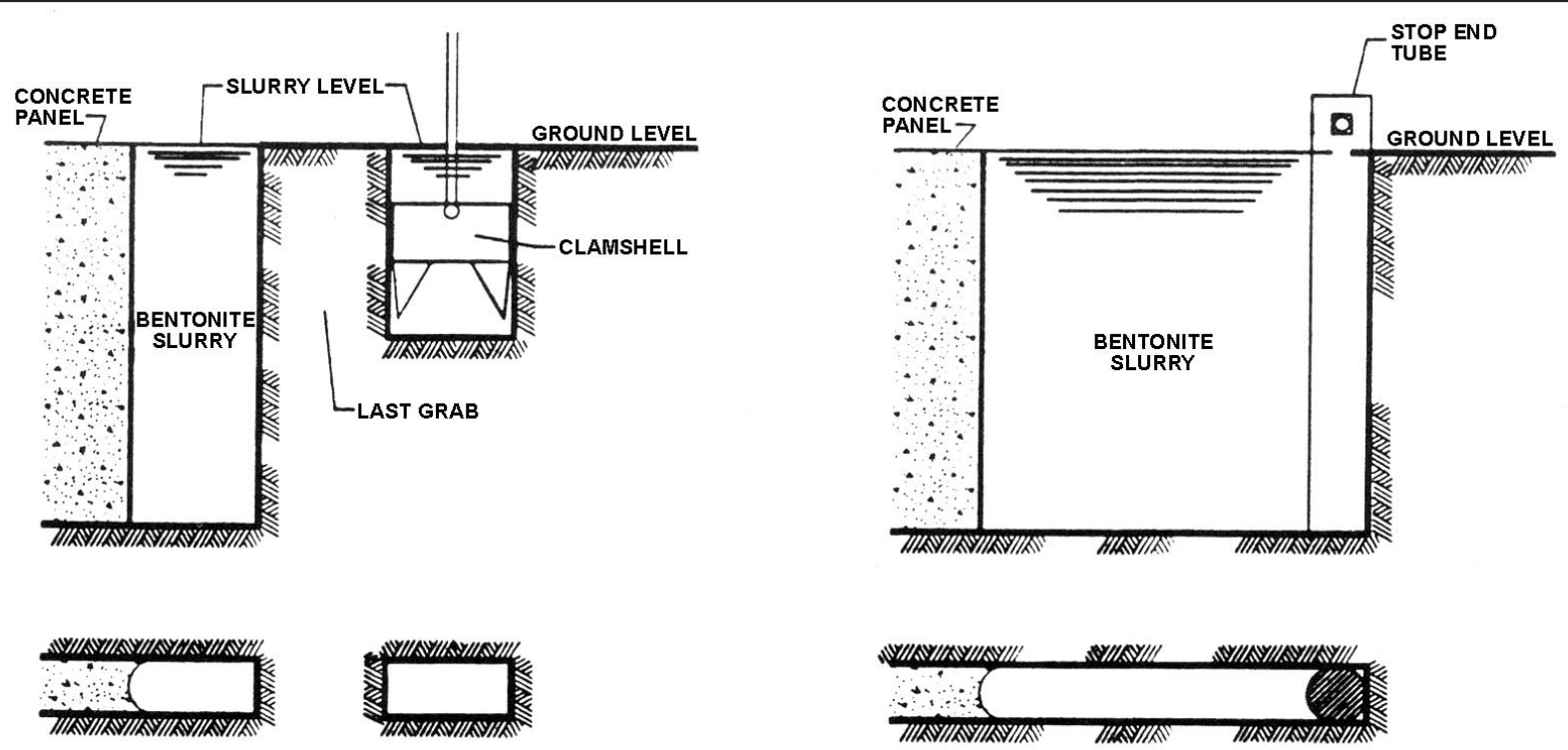

a. Excavation under mud slurry

b. Placement of stop end tube
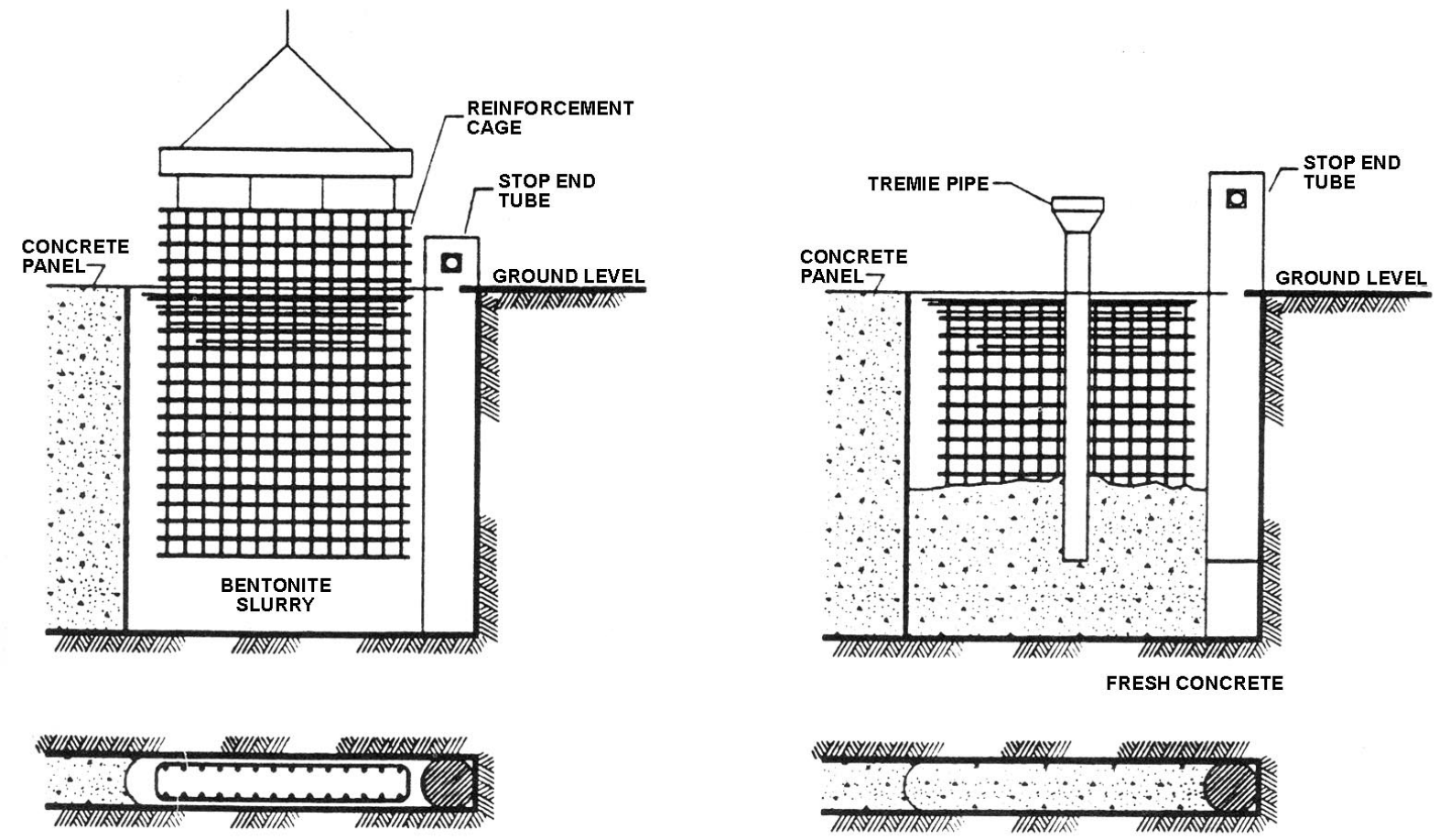

c. Placement of reinforcement cage

d. Placement of concrete

Figure 1-2. Typical construction sequence of a reinforced-concrete slurry wall (Maurseth and Sedey 1992) 
$d$. One or more tremie pipes are used to place the concrete without contamination from the slurry.

$e$. Once the wall is finished and the concrete reaches its desired strength, the excavation and tieback installation process can begin.

Construction of the second navigation lock at Bonneville Lock and Dam required the use of concrete slurry walls to retain the foundation of an adjacent railroad line. Detailed descriptions of construction procedures for the continuous reinforced-concrete slurry wall and for the discrete slurry wall systems used at Bonneville Lock are presented by Munger, Jones, and Johnson (1990, 1992) and Maurseth and Sedey (1992), respectively.

\subsection{Response of Soil-to-Wall Interfaces in Multi-Anchored Systems}

A waterways expansion project, such as that presented in Figure 1-1, requires performing SSI analyses to determine the magnitude of the deformations of the soil above the excavation, and the bending moments and stresses in the retaining wall. Such analyses require close modeling of the construction stages of the multi-anchored system, as well as adequate constitutive models for the soil and for the interfaces between soil and structural components. The finite element analyses performed by Mosher and Knowles (1990) for the tieback walls at Bonneville Lock and Dam are a good example of the available techniques that can be used in SSI analyses of multi-anchored systems.

Figure 1-3 illustrates some of the construction and operation stages of the hypothetical navigation project shown in Figure 1-1. For simplicity, it is assumed that construction is performed in the dry. After completion of the continuous reinforced concrete slurry wall (Figure 1-3b), the soil in front of the wall is excavated to an elevation slightly below the position of the first row of anchors. The anchors are then installed and tensioned according to the project specifications (Figure 1-3c). Once these anchors are tensioned and tested, excavation continues until reaching the position of the second row of anchors. The process is repeated until reaching the bottom of the excavation (Figures 1-3d and 1-3e). Once the excavation is completed, the granular toe berm is placed against the toe of the wall (Figure 1-3f). During operation of the navigation facility, the water level outside the wall reaches its normal elevation, which may fluctuate periodically during the life of the structure (Figure 1-3g).

Figure 1-4 illustrates the type of loading expected to occur on a soil-towall interface element during construction of such multi-anchored systems. Immediately after construction of the slurry wall, the interface element is 


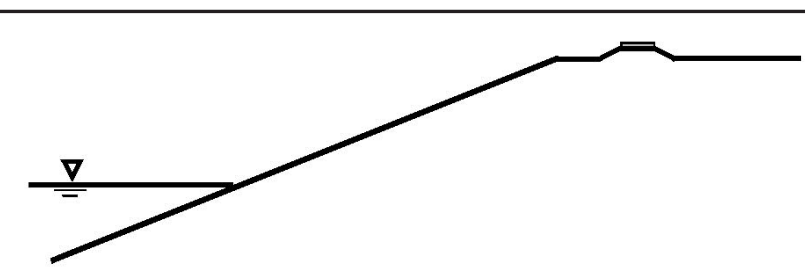

a. Initial state

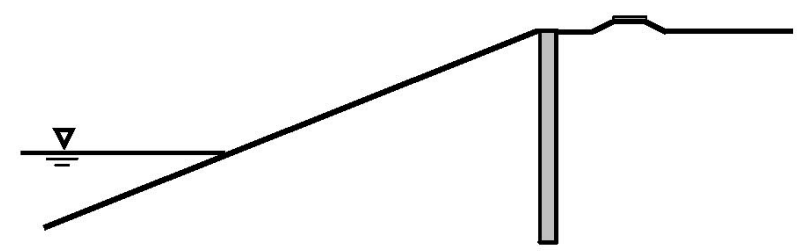

b. Construction of reinforced concrete slurry wall

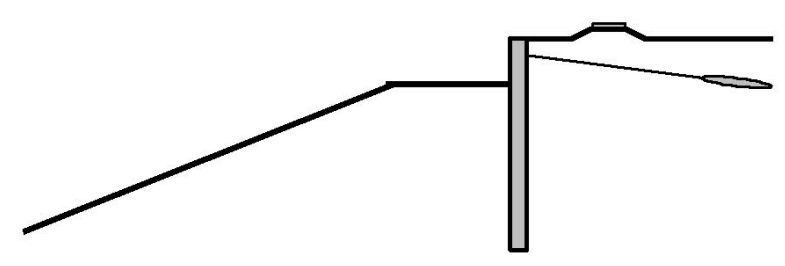

c. First stage of excavation and installation of anchors

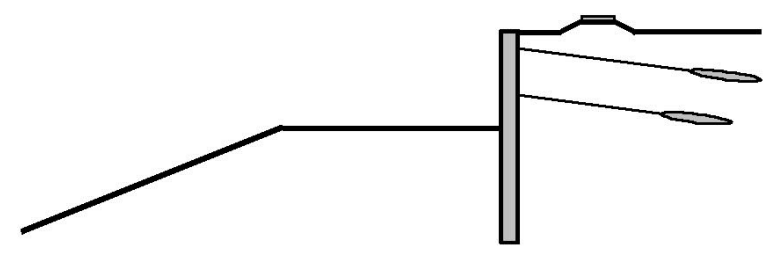

d. Intermediate stage of excavation and installation of anchors

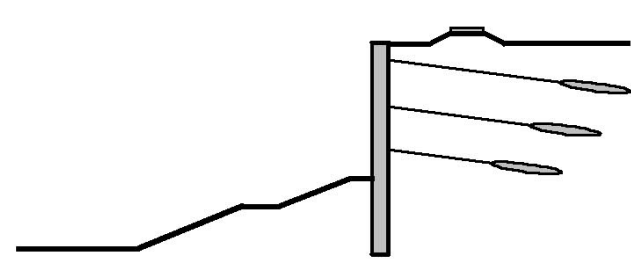

e. Final excavation and installation of bottom row of anchors

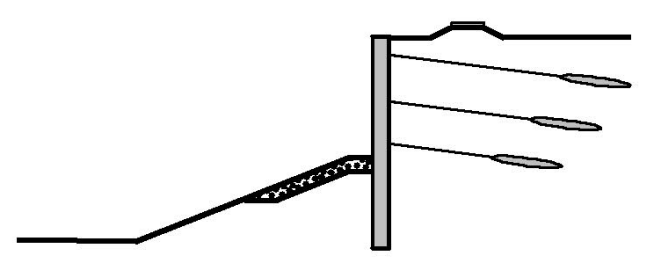

f. Construction of riprap blanket

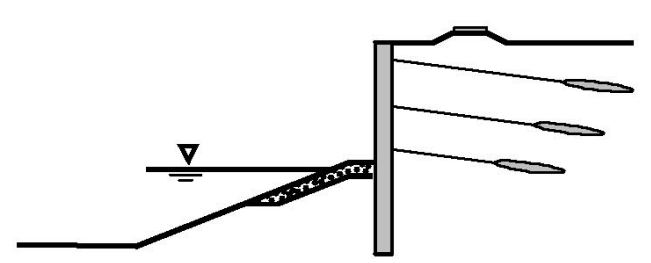

g. Operational stage

Figure 1-3. Stages of construction that can be modeled in SOILSTRUCT-ALPHA analyses 


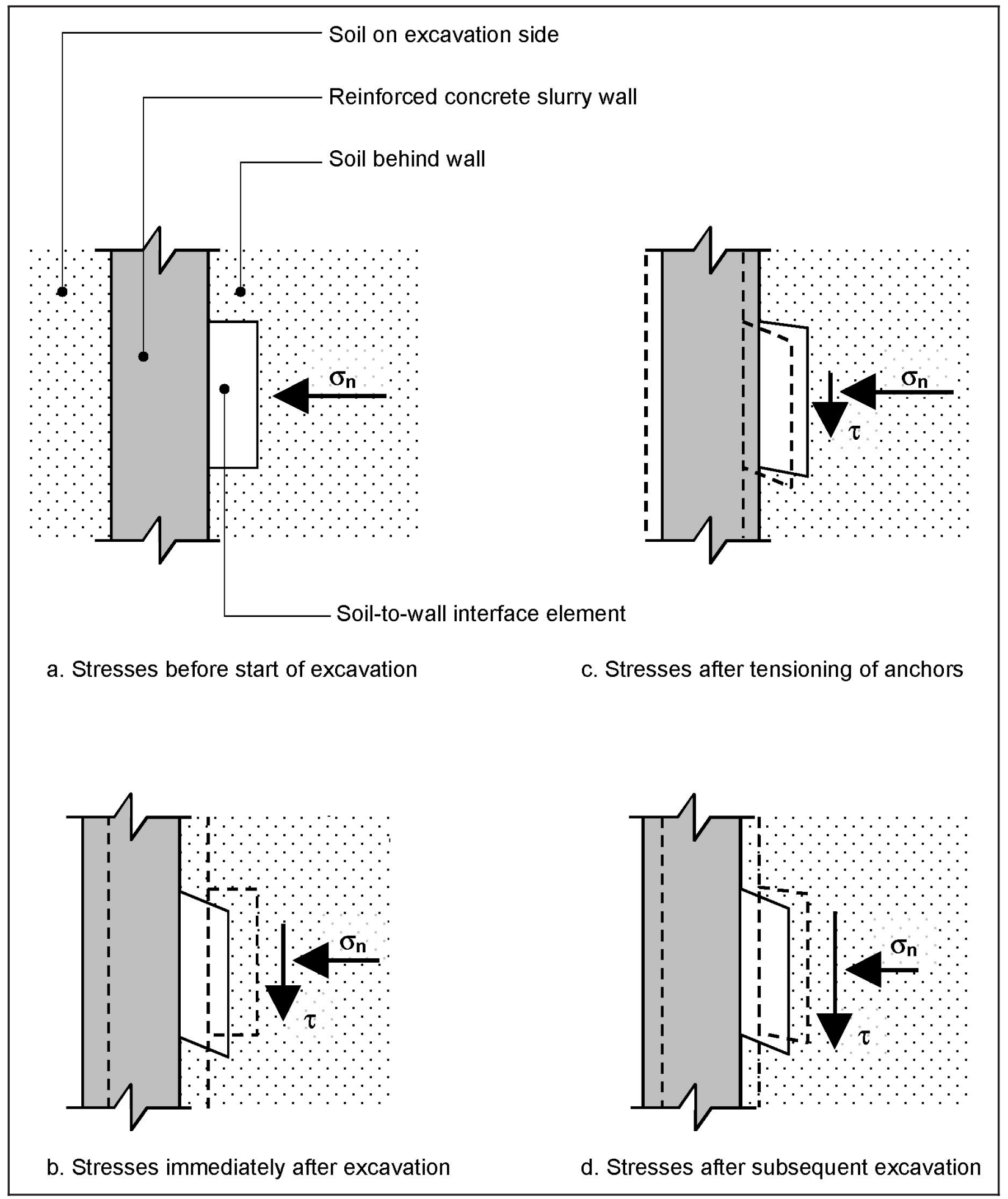

Figure 1-4. Evolution of stresses on a soil-to-wall interface element during construction of a multi-anchored system 
subjected to a normal stress $\sigma_{n}$ (Figure 1-4a). ${ }^{1}$ Because little or no relative movement has taken place between the soil and the wall, the shear stress acting on the interface element at this stage may be assumed zero.

Excavation of the soil in front of the structure may induce outward deformations of the wall and reduction in the lateral stresses within the soil mass behind the wall. The relative settlement of the soil behind the wall, which may take place as a consequence of the reduction in lateral stresses, induces shear on the soil-to-wall interface element (Figure 1-4b). Subsequent installation and tensioning of a row of anchors may increase the normal stresses acting on the interface element. Tensioning of anchors may also induce relative heave of the soil mass behind the wall and a consequent reduction in the shear stress acting on the interface (Figure 1-4c).

Subsequent stages of excavation and installation of anchors may produce progressive shearing of the interface element under varying normal stress with intermediate cycles of unloading-reloading. During the life of the structure, fluctuations of the water level on both sides of the wall may induce further cycles of unloading and reloading of the wall-soil interface.

The type of loading imposed on the soil-to-wall interface of a multi-anchored system may differ from the simplified loading mechanisms illustrated in Figure 1-4. Factors such as the sequence of excavation, the distribution of anchors, the stiffness of the wall, and the response of the foundation soil will influence the behavior of the soil-wall system.

\subsection{The Gómez-Filz-Ebeling Interface Model}

A number of interface constitutive models have been developed by different authors. Quasi-linear models have been used by Goodman, Taylor, and Brekke (1968); Desai, Muqtadir, and Scheele (1986); Matsui and San (1989); and Wong, Kulhawy, and Ingraffea (1989). Nonlinear models have been used by Clough and Duncan (1971); Zaman, Desai, and Drumm (1984); and Desai, Drumm and Zaman (1985), among others.

Clough and Duncan (1971) developed the hyperbolic model for interfaces. This model has been used extensively in SSI analyses and design of geotechnical structures, including analyses of lock wall behavior (Ebeling et al. 1993; Ebeling and Mosher 1996; Ebeling, Peters and Mosher 1997; Ebeling and Wahl 1997; and Ebeling, Pace, and Morrison 1997). The hyperbolic model can provide an accurate approximation of the interface response under monotonic loading at constant normal stress. A recent study by Gómez, Filz, and Ebeling (2000) has shown that the original Clough and Duncan (1971) interface model is not accurate for modeling the interface response under simultaneous changes in shear and normal stresses or for unloading-reloading.

1 For convenience, symbols and abbreviations are listed in the notation (Appendix C). 
Gómez, Filz, and Ebeling (2000) introduced the extended hyperbolic model for interfaces and implemented it into the finite element program SOILSTRUCT-ALPHA. The model is based on the Clough and Duncan (1971) hyperbolic formulation and incorporates new features to model a variety of stress paths. The Gómez-Filz-Ebeling model does not require any interface parameter values in addition to those used in the Clough and Duncan (1971) hyperbolic model. Therefore, hyperbolic parameter values available in the literature (Clough and Duncan 1969, Peterson et al. 1976, Lee et al. 1989) for a variety of interfaces can be used with the Gómez-FilzEbeling model.

Gómez, Filz, and Ebeling (2000) performed a series of interface tests between uniform, fine sands and concrete. Some of their tests followed complicated stress paths that included unloading-reloading and simultaneous changes in normal and shear stresses. Comparisons between test results and model predictions showed that the extended hyperbolic model can predict accurately the response of interfaces of the types tested.

Gómez, Filz, and Ebeling (2000) also carried out a pilot-scale lock wall simulation that modeled placement and compaction of backfill, surcharge application, and changes in the elevation of the water table behind the wall. The backfill consisted of a uniform, fine sand identical to one of the soils used for interface testing. The lock wall simulation test was also modeled using SOILSTRUCT-ALPHA. Comparison between the data from the lock wall simulation and the results of the SOILSTRUCT-ALPHA analyses confirmed the accuracy of the extended hyperbolic model and its applicability for SSI analyses of lock walls.

The Gómez-Filz-Ebeling model is also presumed to be applicable for SSI analyses of multi-anchored systems. As illustrated by the simplified interface loading mechanism in Figure 1-4, the soil-to-wall interface in a reinforced concrete slurry wall may be subject to simultaneous changes in shear and normal stresses as well as unloading-reloading. The Gómez-FilzEbeling model is accurate for predicting the response of interfaces to this type of loading. While the model has been verified against the results of tests performed on interfaces between fine sands and concrete, it has not been evaluated against results of tests performed on interfaces between coarse sands and concrete. In addition, further work on interface testing is required to expand the existing database on interface hyperbolic parameter values.

\subsection{Scope of the Investigation}

The purpose of this investigation is the validation of the Gómez-FilzEbeling model against results of shear tests performed at the interface between a coarse sand and concrete. Hyperbolic parameter values of the interface between the coarse sand and concrete were determined from the results of initial loading tests under constant normal stress. In addition, an 
interface test was performed following a complex stress path that included simultaneous changes in shear and normal stresses as well as unloadingreloading of the interface. The Gómez-Filz-Ebeling model, with hyperbolic parameter values determined from the initial loading tests, was used to estimate the response of the interface under this complex stress path. The calculated response was compared with the test measurements to evaluate the accuracy of the model.

It was found that the Gómez-Filz-Ebeling model provides accurate estimates for the coarse sand-to-concrete interface. It can be concluded from this result and previous work that the Gómez-Filz-Ebeling model provides accurate predictions of the response of interfaces between concrete and a variety of granular soils. The hyperbolic parameters for the coarse sand-toconcrete interface, determined from the tests, also add to the database of interface parameter values.

The results of the laboratory tests performed for this investigation are presented in Chapter 2. Results include those tests performed to characterize the coarse sand used for the interface tests, as well as from the interface tests.

Chapter 3 contains a brief description of the Gómez-Filz-Ebeling interface model. The hyperbolic parameter values for the coarse sand-toconcrete interface are determined and added to the database of interface parameter values. The model performance is evaluated against the results of the interface tests described in Chapter 2.

Chapter 4 contains a summary of the work performed and relevant conclusions obtained from this investigation.

This report also includes three appendixes. Appendix A contains the results of the triaxial and consolidation tests performed on the coarse sand used for interface testing. It also contains a description of the procedure followed for determining the hyperbolic parameter values of the coarse sand, as well as a compilation of hyperbolic parameter values for different soils. Appendix B contains the results of the interface tests performed and a description of the procedure for determining the hyperbolic parameter values of the coarse sand-to-concrete interface. Finally, all the symbols and abbreviations used in this report are defined in Appendix C. 


\section{Laboratory Testing}

A series of shear tests were performed on the interface between a coarse, well-graded sand and concrete using the Large Displacement Shear Box (LDSB). The objective of the tests was to compile additional experimental data on the response of soil-to-concrete interfaces, and to further validate the Gómez-Filz-Ebeling extended hyperbolic model.

This chapter contains a description of the properties of the sand used for this investigation and results of the interface tests performed. Details of the techniques for preparation of the concrete and soil specimens, and of the interface testing procedures, are given by Gómez, Filz, and Ebeling (2000).

\subsection{Properties of Blacksburg Sand}

A processed, well-graded sand, commercially available for the preparation of concrete in Blacksburg, VA, was used for the interface tests. This sand is referred to as "Blacksburg Sand" throughout this report. Table 2-1 summarizes the results of a series of laboratory tests performed to determine the gradation, maximum/minimum density, and specific gravity of Blacksburg Sand. Its grain size distribution is presented in Figure 2-1, which shows that the particle sizes range from 0.2 to $5 \mathrm{~mm}$. According to ASTM D2487, a sand must have a value of the coefficient of uniformity, $C_{u}$, greater than or equal to 6 to be well graded. The value of $C_{u}$ for the Blacksburg Sand is 3; therefore, according to ASTM D2487, it is poorly graded. However, Blacksburg Sand includes a wider range of grain sizes than did the sands used in the previous study (Gómez, Filz, and Ebeling 2000). 


\section{Table 2-1 \\ Properties of Blacksburg Sand}

\begin{tabular}{|l|l|l||}
\hline \hline Parameter $^{1}$ & Value & Relevant Standard \\
\hline \hline$D_{10}$ & $0.27 \mathrm{~mm}$ & ASTM D2487 \\
$D_{30}$ & $0.45 \mathrm{~mm}$ & \\
$D_{60}$ & $0.82 \mathrm{~mm}$ & \\
$C_{u}$ & 3 & \\
$C_{c}$ & 0.9 & ASTM D4253 \\
\hline$\gamma_{\max }$ & $18 \mathrm{kN} / \mathrm{m}^{3}$ & ASTM D4254 \\
\hline$\gamma_{\min }$ & $14.5 \mathrm{kN} / \mathrm{m}^{3}$ & ASTM D854 \\
\hline$G_{S}$ & 2.65 & \\
\hline \hline
\end{tabular}

${ }^{1}$ Parameters are listed and defined in the notation (Appendix $\left.C\right)$.

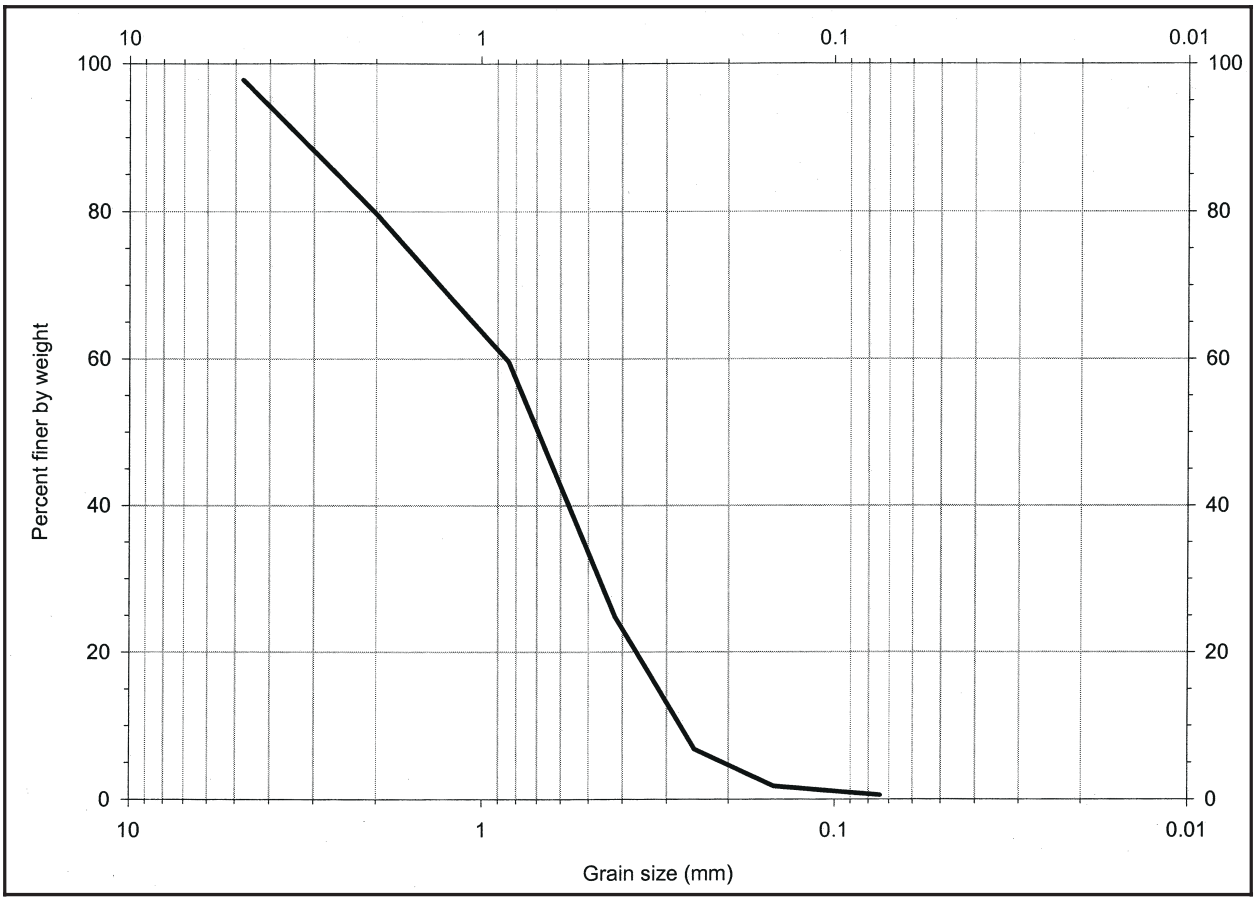

Figure 2-1. Grain size distribution of Blacksburg Sand

Examination under an optical microscope revealed that the sand grains smaller than $1 \mathrm{~mm}$ are predominantly subangular, with length-to-width ratios ranging from 1 to 3 . The larger grains tend to be more angular and flat (ASTM D2488). 


\subsubsection{Triaxial testing}

Drained triaxial (CD) tests were performed to determine the internal friction angle and hyperbolic parameter values of Blacksburg Sand in a dense condition. The specimens for the tests were prepared by compaction to a relative density of 80 percent, and subjected to an internal manometric pressure of -15 to $-20 \mathrm{kPa}$, which was gradually removed during application of the cell pressure. The samples were de-aired using carbon dioxide, inundated with de-aired distilled water, and back-pressure saturated. The samples in each set were consolidated under effective confining pressures ranging from 69 to $276 \mathrm{kPa}$. Shearing was performed at a strain rate of 0.25 percent per minute, which was found to be appropriate for pore pressure dissipation during previous trials.

The results of the tests are presented graphically in Figure A1 of Appendix A and are summarized in Table 2-2.

\section{Table 2-2}

Summary of Results of CD Triaxial Tests on Dense Blacksburg Sand $\left(D_{r}=80 \%\right)$

\begin{tabular}{|l|l||}
\hline \hline Parameter $^{1}$ & Value \\
\hline \hline$\phi_{O}$ & $43.4 \mathrm{deg}$ \\
\hline$\Delta \phi$ & $7.4 \mathrm{deg}$ \\
\hline$\phi_{C V}$ & $30.7 \mathrm{deg}$ \\
\hline Reference (Figure No.) & A1 \\
\hline \hline \multicolumn{2}{|l|}{ Parameters are listed and defined in the notation (Appendix C). } \\
\hline
\end{tabular}

All the specimens exhibited dilation during shear and strain-softening after mobilization of the peak strength. The peak strength values measured during the tests defined curved strength envelopes. The value of the peak secant friction angle $\phi$ for a given effective confining stress $\sigma_{3}{ }^{\prime}$ can be calculated from the following expression (Duncan et al. 1980):

$$
\phi=\phi_{o}-\Delta \phi \cdot \log _{10}\left(\frac{\sigma_{3}{ }^{\prime}}{p_{a}}\right)
$$

where

$$
\begin{aligned}
\phi_{o}= & \text { peak secant friction angle at a confining pressure of } \\
& 101.3 \mathrm{kPa}(1 \mathrm{~atm}) \\
\Delta \phi= & \text { reduction in peak secant friction angle value for a } 10 \text {-fold } \\
& \text { increase in } \sigma_{3}^{\prime} \\
\sigma_{3}^{\prime}= & \text { minor principal effective stress } \\
p_{a}= & \text { atmospheric pressure }(101.3 \mathrm{kPa})
\end{aligned}
$$


The values of $\phi_{o}$ and $\Delta \phi$ were determined as shown in Appendix A and are given in Table 2-2. The strength envelopes corresponding to the strength measured at a 15-percent strain are linear, and the corresponding friction angle $\phi_{c v}$ value is also given in Table 2-2.

\subsubsection{Consolidation testing}

Consolidation tests were performed on specimens of Blacksburg Sand to provide additional data on its mechanical properties. The specimens were prepared at a relative density of 75 percent in a dry condition. Each specimen was consolidated under a series of vertical stress increments. The tests included a stage of inundation of the specimens to determine the susceptibility of Blacksburg Sand to hydrocompression. The results of these tests are presented in Figure A2 of Appendix A.

\subsubsection{Hyperbolic parameters}

The procedure for determining the hyperbolic parameter values listed in Table 2-3 is described in detail in Appendix A. The triaxial test data were used to obtain the parameter values for initial loading, according to the procedures described by Duncan et al. (1980). Parameter values obtained from the results from drained CD triaxial tests on a variety of soils are reported in Table 5 of Duncan et al. (1980). These values are reproduced in Table A2 of Appendix A.

\section{Table 2-3 \\ Hyperbolic Parameter Values of Dense Blacksburg Sand}

\begin{tabular}{|c|c|c|}
\hline Hyperbolic Parameters ${ }^{1}$ & $\begin{array}{l}\text { Dense Blacksburg Sand } \\
\left(D_{r}=80 \%\right)\end{array}$ & $\begin{array}{l}\text { Reference Values for Soils of } \\
\text { Similar Gradation (from } \\
\text { Duncan et al. 1980) }\end{array}$ \\
\hline$K$ & 642 & $340-650$ \\
\hline$n$ & 0.25 & $0.38-0.45$ \\
\hline$R_{f}$ & 0.55 & $0.7-0.77$ \\
\hline$K_{b}$ & 567 & $230-280$ \\
\hline$m$ & 0.01 & $0.05-0.06$ \\
\hline$\phi_{0}$ & 43.4 & $48-49$ \\
\hline$\Delta \phi$ & 7.4 & $10-12$ \\
\hline
\end{tabular}

Table 2-3 shows ranges of values for the modulus exponent $n$, failure ratio $R_{f}$, bulk modulus exponent $m$, and the parameter $\Delta \phi$, which were reported by Duncan et al. (1980) for soils of similar gradation (Table A2). Some of the hyperbolic parameter values for the dense Blacksburg Sand are outside the range of values obtained from Duncan et al. (1980), but they do not differ by much. 
A comparison between the hyperbolic stress-strain relationships calculated using the parameters in Table 2-3 and the data from the triaxial tests is presented in Figure A7 of Appendix A. The hyperbolic model provides a good fit of the laboratory data, but it does not model the post-peak strainsoftening behavior or shear-induced dilation of the soil.

\subsection{Interface Testing}

A set of tests were performed at the interface between a concrete specimen and dense Blacksburg Sand using the LDSB. The purposes of the tests were:

a. To collect additional experimental data for assessing the accuracy of the extended hyperbolic model developed by Gómez, Filz, and Ebeling (2000). This model was developed based on the results of tests performed at the interface between concrete and uniform, fine sands. An important objective of the current research was to validate the model against the results of interface testing between concrete and a well-graded, coarse sand, such as Blacksburg Sand.

$b$. To add to the database on interface properties available in the literature.

For each of the tests, the soil specimen was densified by vibration to a relative density of 80 percent, following the procedures described by Gómez, Filz, and Ebeling (2000). All the tests were performed at a displacement rate of $1 \mathrm{~mm} / \mathrm{min}$ (0.04 in./min), under normal pressures ranging from 38 to $292 \mathrm{kPa}$.

A set of preliminary tests were performed to study the influence of inundation of the interface on the test results. The results showed that inundation does not induce any significant effect on the response of the interface. All subsequent tests were performed in a dry condition.

Additional details pertaining to the equipment, specimen preparation, and testing procedures are given by Gómez, Filz, and Ebeling (2000).

\subsubsection{Interface testing program}

Two types of interface tests were performed for this report. Four initial loading tests were performed to determine the peak and residual friction angle values and hyperbolic parameter values of the interface. These tests consisted of shearing the newly prepared interface under constant normal stress. In some of the tests, shearing continued until the residual strength was mobilized. 
A multidirectional stress path test was performed in which the interface was sheared following a stress path that involved simultaneous changes in normal and shear stresses, as well as unloading-reloading. It was intended to model loading conditions similar to those expected at soil-to-wall interfaces, and to provide a basis for evaluating the Gómez-Filz-Ebeling model. Table 2-4 summarizes the types of tests performed during this investigation.

\section{Table 2-4 \\ Summary of Tests Performed at the Interface Between Concrete and Dense Blacksburg Sand}

\begin{tabular}{|c|c|c|c|c|}
\hline Type of Test & Specimen & Test Number & $\begin{array}{l}\text { Normal Stress } \\
(\mathrm{kPa})\end{array}$ & Figure No. ${ }^{1}$ \\
\hline $\begin{array}{l}\text { Initial loading } \\
\text { (virgin shear) }\end{array}$ & $\begin{array}{l}\text { S2001 } \\
\text { S2002 } \\
\text { S2003 } \\
\text { S2004 }\end{array}$ & $\begin{array}{l}\text { T2001_5 } \\
\text { T2002_10 } \\
\text { T2003_20 } \\
\text { T2004_40 }\end{array}$ & $\begin{array}{l}38 \\
69 \\
141 \\
292\end{array}$ & B1, B2 \\
\hline $\begin{array}{l}\text { Multidirectional } \\
\text { stress path }\end{array}$ & S2005 & T2005 & 80 to 280 & B3 \\
\hline
\end{tabular}

\subsubsection{Results of interface tests}

The results of the interface tests performed for this investigation are presented in the figures of Appendix B. Table 2-4 lists the figures in Appendix B that are relevant to each interface test.

The results of the initial loading tests are presented in Figures B1 and B2, and are summarized in Table 2-5. It can be seen that the peak shear strength was mobilized at small displacements ranging from 1 to $5 \mathrm{~mm}$. After mobilization of the initial peak strength, shear stresses remained practically constant before displacement softening took place.

\section{Table 2-5}

Summary of Results of Initial Loading Tests on the Interface Between Concrete and Dense Blacksburg Sand

\begin{tabular}{|c|c|c|c|c|c|}
\hline \multicolumn{2}{|c|}{ Displacement ${ }^{1}(\mathrm{~mm})$} & \multicolumn{2}{|c|}{ Interface Friction Angle ${ }^{1}$} & \multicolumn{2}{|c|}{$\begin{array}{c}\text { Interface/Soil Friction Angle } \\
\text { Ratio }\end{array}$} \\
\hline to Peak $\Delta_{s p}$ & to Residual $\Delta_{s r}$ & Peak $\delta$ & Residual $\delta_{r}$ & $\delta / \phi_{o}$ & $\delta_{\mathrm{r}} / \phi_{c v}$ \\
\hline $1-5$ & 6-10 & $32 \mathrm{deg}$ & $29.5 \mathrm{deg}$ & 0.74 & 0.96 \\
\hline
\end{tabular}

This plateau of relatively constant shear stress may exist up to displacements as large as $10 \mathrm{~mm}$, as evidenced by test T2003_20, after which the residual condition is attained. In some cases, a secondary peak is observed in the shear stress-displacement curve. For the purposes of this investigation, the peak strength was assumed to correspond to the first peak that 
occurred during the test. These observations are consistent with the results of the previous interface tests reported by Gómez, Filz, and Ebeling (2000).

The peak and residual interface strength envelopes, which are shown in Figure B2 (Appendix B), are both represented as straight lines out of the origin. As shown in Figure A1 for the Blacksburg Sand itself, the peak soil strength envelope is curved. This difference between the curvature of the peak soil strength envelope and the linearity of the peak interface strength envelope was also observed for other sands tested in the previous study (Gomez, Filz, and Ebeling 2000). Figure A1 also shows that the soil strength envelope for the Blacksburg Sand at 15 percent strain is a straight line out of the origin, which is a characteristic similar to the linearity of the residual strength of the interface.

The values of peak and residual friction angle, $\delta$ and $\delta_{r}$, for the interface between Blacksburg Sand and concrete are presented in Table 2-5. These values are compared to the peak secant friction at 1 atmosphere confining pressure, $\phi_{o}$, and the 15-percent strain friction angle, $\phi_{c v}$, of the soil. It can be seen that the values of $\delta$ and $\delta_{r}$ correspond to approximately 74 and 96 percent of $\phi_{o}$ and $\phi_{c v}$, respectively.

The results of the initial loading tests were used to determine the hyperbolic parameter values of the interface between concrete and dense Blacksburg Sand, following the procedure described in Appendix B.

Figure B3 shows the results of multidirectional stress path test T2005. The test consisted of the application of a complex stress path that included simultaneous changes in shear and normal stresses and unloadingreloading. The purpose of this test was to provide a basis for a performance evaluation of the extended hyperbolic model.

\subsection{Summary}

The following laboratory activities were performed for this investigation:

a. Selection of a coarse sand specimen for interface testing.

$b$. Grain size distribution, minimum/maximum density, specific gravity, consolidation testing, and triaxial testing on Blacksburg Sand.

c. Initial loading tests to determine the hyperbolic parameter values of the interface between concrete and dense Blacksburg Sand.

d. A multidirectional stress path test to obtain data for the validation of the extended hyperbolic model. 
A coarse, well-graded sand (Blacksburg Sand) was selected for interface testing. The basic properties of Blacksburg Sand were determined from a series of laboratory tests, such as minimum/maximum density and grain size analyses. CD triaxial tests were performed to determine hyperbolic parameter values for this soil (Appendix A). These hyperbolic parameter values are consistent with values reported by Duncan et al. (1980) for soils of similar gradation.

Initial loading tests were performed at the interface between concrete and dense Blacksburg Sand using the LDSB. The interface hyperbolic parameter values were determined from the results of these tests as indicated in Appendix B.

A multidirectional stress path test was performed on the dense Blacksburg Sand against concrete interface. The purpose of this test was to obtain data for evaluating the accuracy of the extended hyperbolic model for predicting interface response under complex stress paths, as discussed in Chapter 3. 


\section{Evaluation of the Gómez-Filz-Ebeling Model for Interfaces}

A new model for interfaces was developed in a previous investigation by Gómez, Filz, and Ebeling (2000). The model is based on the Clough and Duncan (1971) hyperbolic formulation, which was extended to model the response of interfaces under general field loading conditions in lock walls. The model captures important aspects of interface response while retaining much of the simplicity of the original Clough and Duncan (1971) formulation.

The model incorporates three new elements into the hyperbolic formulation: (1) a yield surface, (2) a formulation for virgin shear under continuously changing normal stress, and (3) a formulation for unloadingreloading of the interface. Gómez, Filz, and Ebeling (2000) evaluated the performance of the extended hyperbolic model against the results of tests performed at the interfaces between concrete and two uniform, fine sands. They found that the model provides an accurate estimate of interface response for stress paths such as those expected to occur at the interface between a lock wall and the backfill.

In this investigation, the performance of the extended hyperbolic model is evaluated against the results of tests performed at the interface between coarse, well-graded sand (Blacksburg Sand) and concrete. These interface tests were described in Chapter 2. It was found that predictions of the extended hyperbolic model are also accurate for this type of interface. This suggests that the model is applicable for interfaces between concrete and a variety of granular soils. Consequently, it is possible that the model can be used for routine SSI analyses of multi-anchored systems in granular soils, and lock walls with granular backfills.

This chapter contains a brief review of the formulation of the extended hyperbolic model for interfaces. The model is used to obtain an estimated response of the interface between concrete and dense Blacksburg Sand for the complex stress path applied during multidirectional stress path 
test T2005, described in Chapter 2. The estimated response is compared to the response measured during the test. Additionally, a summary is presented of hyperbolic parameter values of different interfaces, including those reported by Gómez, Filz, and Ebeling (2000).

\subsection{The Gómez-Filz-Ebeling Model for Interfaces}

This section contains a summary of the extended hyperbolic model for interfaces developed by Gómez, Filz, and Ebeling (2000), who present a more complete description of the model formulation and its implementation.

\subsubsection{Yield surfaces and loading regions}

Based on analyses of the results of staged interface tests, Gómez, Filz, and Ebeling (2000) developed a formulation for yield surfaces in interface shear. According to their observations, two yield surfaces can be defined as illustrated in Figure 3-1. An upper yield surface $S L+$ is contained in the

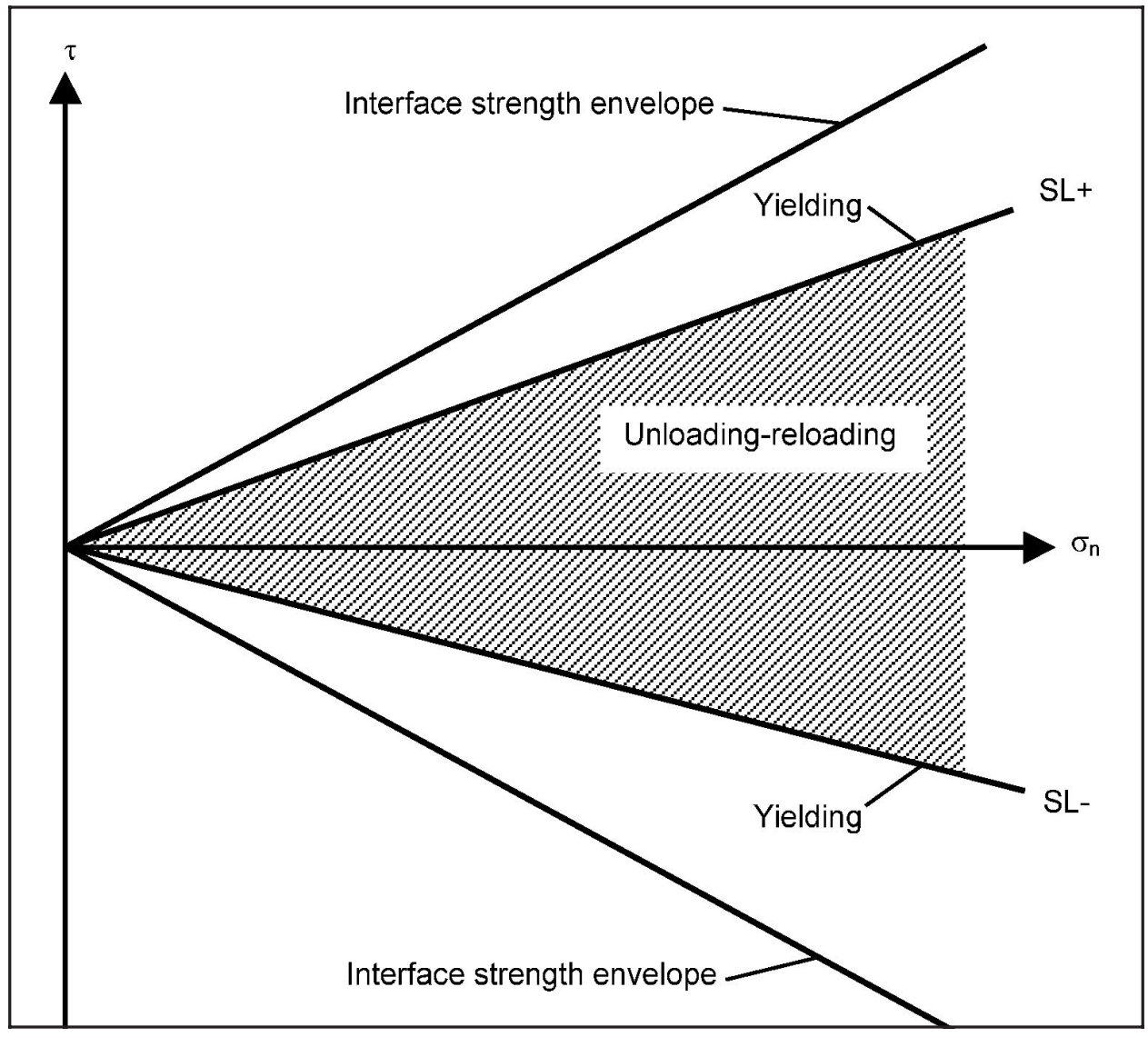

Figure 3-1. Loading regions for Versions I and II of the Gómez-Filz-Ebeling model for interfaces 
first quadrant of the $\sigma_{n}-\tau$ plane and is defined by the past maximum shear stress level reached during shear. A lower yield surface $S L$ - is contained in the fourth quadrant and is defined by the past minimum shear stress level. The shear stress level is defined as the ratio of shear stress to shear strength of the interface (Clough and Duncan 1971). For an interface with zero adhesion intercept, the yield surfaces thus defined are straight lines passing through the origin of the $\sigma_{n}-\tau$ plane.

Two types of loading are defined as illustrated in Figure 3-1. Unloadingreloading takes place along any stress path that is contained within the region defined by the $S L+$ and $S L$ - surfaces. Yielding occurs when a stress path reaches one of the two yield surfaces. As will be discussed in Section 3.3, this definition of loading regions is used in Versions I and II of the Gómez-Filz-Ebeling model.

In some cases where very accurate predictions of the interface response are required, it is convenient to introduce additional loading regions. Two transition surfaces, $\tau+$ and $\tau$-, are illustrated in Figure 3-2. They are defined by the past maximum and past minimum values of shear stress, and consist of straight lines parallel to the $\sigma_{n}$ axis in the $\sigma_{n}-\tau$ plane. The transition regions are defined as the areas delimited by the $S L+$ and $\tau+$ surfaces and by the $S L$ - and $\tau$ - surfaces. A stress path corresponds to transition loading if it lies within any of the two transition regions. The definition of

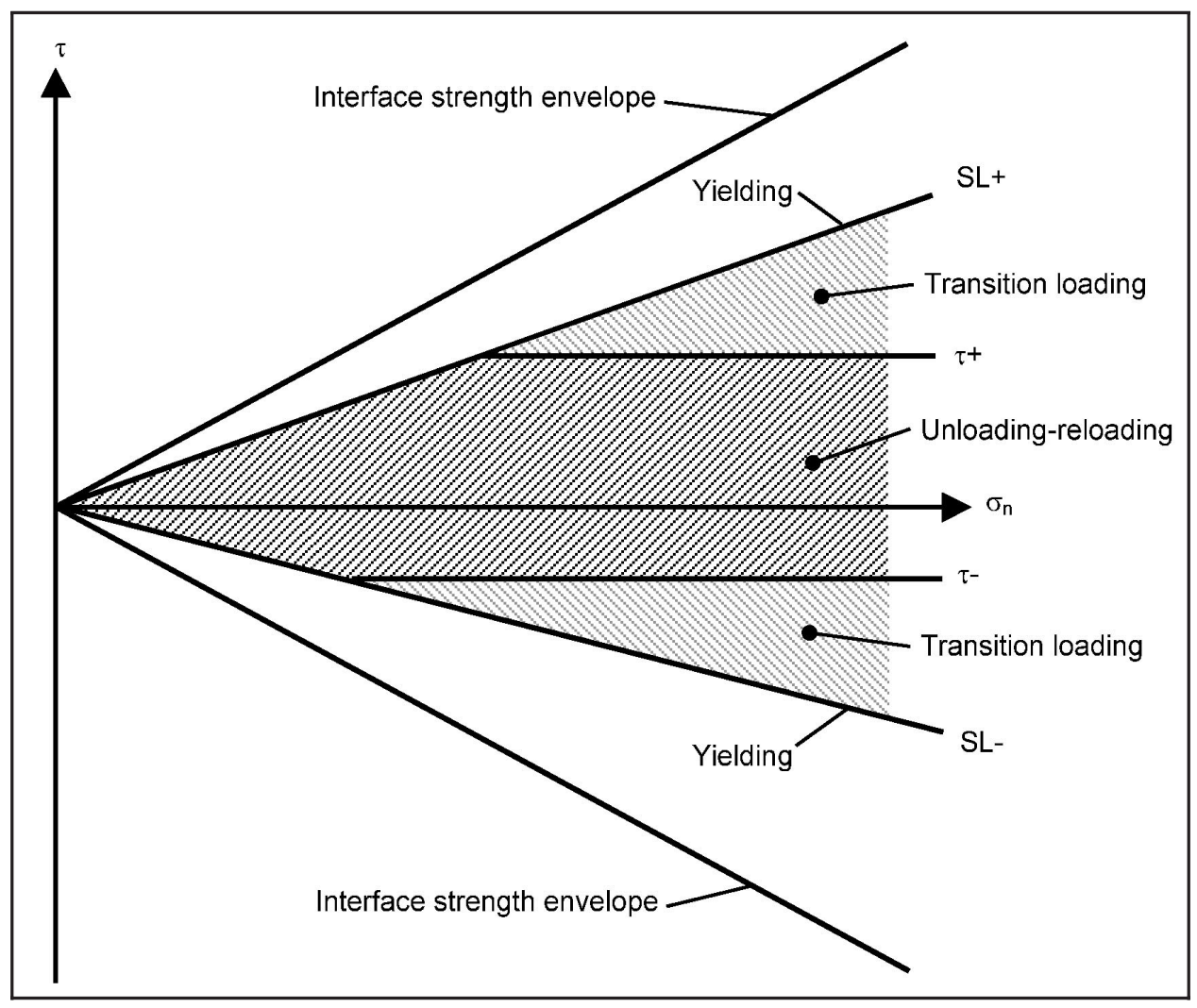

Figure 3-2. Loading regions for Version III of the Gómez-Filz-Ebeling model for interfaces 
transition loading is used in Version III of the Gómez-Filz-Ebeling model as discussed in Section 3.3. Table 3-1 summarizes the definition of loading regions.

\begin{tabular}{|c|c|}
\hline Type of loading & Condition \\
\hline Yield-inducing shear & $\begin{array}{l}S L=S L+ \\
o r \\
S L=S L-\end{array}$ \\
\hline Unloading-reloading & $\begin{array}{l}S L<S L+\text { and } \tau<\tau+ \\
\text { and } \\
S L>S L-\text { and } \tau>\tau-\end{array}$ \\
\hline Transition loading & $\begin{array}{l}S L<S L+\text { and } \tau \geq \tau+ \\
\text { or } \\
S L>S L-\text { and } \tau \leq \tau-\end{array}$ \\
\hline
\end{tabular}

\subsubsection{Formulation of extended hyperbolic model for interfaces at yield}

The hyperbolic model for interface shear by Clough and Duncan (1971) was developed for initial loading into the first quadrant under constant normal stress. Gómez, Filz, and Ebeling (2000) extended the Clough and Duncan (1971) constitutive equation to loading into the fourth quadrant as follows:

$$
\tau=\frac{\Delta_{s}}{K_{I} \cdot \gamma_{w} \cdot\left(\frac{\sigma_{n}}{p_{a}}\right)^{n_{j}}}+q \cdot \frac{R_{f j} \cdot \Delta_{s}}{\sigma_{n} \cdot \tan \delta}
$$

where

$$
\begin{aligned}
\tau & =\text { interface shear stress } \\
\Delta_{s} & =\text { displacement along the interface } \\
K_{I} & =\text { stiffness number } \\
\gamma_{w} & =\text { unit weight of water } \\
n_{j} & =\text { stiffness exponent } \\
q & =\text { shear direction parameter } \\
R_{f j} & =\text { failure ratio }
\end{aligned}
$$


The shear direction parameter, $q$, is equal to +1 if shearing takes place into the first quadrant $(\tau>0)$, and equal to -1 if shearing takes place into the fourth quadrant $(\tau<0)$.

Equation 3-1 defines a three-dimensional surface in the $\Delta_{s}-\sigma_{n}-\tau$ space. Gómez, Filz, and Ebeling (2000) hypothesized that the interface response during shearing along any yield-inducing stress path is uniquely defined by this initial loading surface. For initial loading under constant normal stress, the following expression for the interface shear stiffness $K_{s t}$ is obtained by differentiation of Equation 3-1 with respect to the interface displacement, $\Delta_{S}$ :

$$
K_{s t}=K_{I} \cdot \gamma_{w} \cdot\left(\frac{\sigma_{n}}{p_{a}}\right)^{n_{j}} \cdot\left(1-q \cdot R_{f j} \cdot S L\right)^{2}
$$

For initial loading where simultaneous changes in shear and normal stresses take place, i.e. shearing along inclined stress paths, the interface stiffness, $K_{s t}^{\prime}$, is determined from the following equation:

$$
K_{s t}^{\prime}=K_{s t} \cdot I
$$

where $I$ is the correction factor for the inclination of the stress path. Gómez, Filz, and Ebeling (2000) derived mathematically the following equation for the correction factor:

$$
I=\frac{1}{1+S L \cdot\left[n_{j}\left(q \cdot R_{f j} \cdot S L-1\right)-q \cdot R_{f j} \cdot S L\right] \tan (\delta) \tan (\theta)}
$$

where

$$
\begin{aligned}
S L= & \text { stress level } \\
\tan (\theta)= & \text { inclination of the stress path in the } \sigma_{n}-\tau \text { plane with respect } \\
& \text { to the } \tau \text {-axis }
\end{aligned}
$$

The formulation for interface yielding of the extended hyperbolic model is given by Equations 3-2, 3-3, and 3-4. Table 3-2 summarizes the state variables, interface material properties, and equations necessary for implementing this formulation into SSI analyses. This formulation does not require any interface properties in addition to those defined in the Clough and Duncan (1971) hyperbolic model. 


\section{Table 3-2 \\ Summary of the Formulation for Interfaces at Yield in the Gómez-Filz-Ebeling Model}

\begin{tabular}{||l|l|}
\hline \hline Conditions for & $S L=S L-$ \\
application & $S L=S L+$
\end{tabular}

\subsubsection{Formulation for unloading-reloading of the Gómez-Filz-Ebeling model}

Three different versions of the unload-reload formulation were included in the Gómez-Filz-Ebeling model:

a. Version I. The interface response is assumed to be linear and normal stress-dependent. No differentiation is made between unloadingreloading and transition loading. This version was intended for use in cases where unloading-reloading takes place along simple stress paths, or where a high degree of accuracy is not required for the analyses.

$b$. Version II. The interface response is assumed to be nonlinear and normal stress-dependent. It follows a hyperbolic shear stressdisplacement relationship. No differentiation is made between unloading-reloading and transition loading. This formulation is simple to implement in finite element programs, yet it is accurate for most loading conditions. 
c. Version III. As in Version II, the interface response is assumed to be nonlinear and normal stress-dependent. However, the mathematical expressions used to convey this nonlinear response are more complex than those of Version II. Version III is the most accurate version of the model. It is also the most complex because it introduces additional sets of state variables that are needed to differentiate between unloading-reloading and transition loading.

In all three versions of the unload-reload formulation, the interface response is independent of the orientation of the stress path. In SSI analyses, any of the versions of the unload-reload formulation can be applied in conjunction with the formulation for interfaces at yield introduced previously. The following sections describe the mathematical formulation of the three versions of the unload-reload formulation.

3.1.3.1 Version I. In this version, the interface response is assumed linear and normal stress-dependent in both unloading-reloading and transition regions. The interface tangent stiffness is determined from the following expression:

$$
K_{s t}^{\prime}=K_{u r j} \cdot \gamma_{w} \cdot\left(\frac{\sigma_{n}}{p_{a}}\right)^{n_{j}}
$$

where $K_{u r j}$ is the interface stiffness number for unloading-reloading.

Table 3-3 contains a summary of this version of the model. The formulation is applicable if the stress-state is inside the region limited by the yield surfaces $S L+$ and $S L-$, in the $\sigma_{n}-\tau$ plane. There are no new state variables to be considered for this formulation in addition to those listed in Table 3-2. The application of the model is very simple once a value of $K_{u r j}$ is selected. It is noted that the interface response during unloading-reloading is assumed to be independent of the inclination of the stress path.

This formulation is appropriate for analyses that do not require a high degree of accuracy. In cases where the interface may be subjected to complex unloading-reloading paths, a single value of $K_{u r j}$ may not provide an accurate approximation to the nonlinear response of the interface. Version II, described in the following section, accounts for nonlinearity of the interface response during unloading-reloading.

3.1.3.2 Version II. In Version II, the tangent interface stiffness during unloading-reloading is determined from the following expression:

$$
K_{s t}^{\prime}=K_{u r j} \cdot \gamma_{w} \cdot\left(\frac{\sigma_{n}}{p_{a}}\right)^{n_{j}} \cdot\left[1-\frac{q}{\alpha} R_{f j} \cdot\left(S L-S L_{o}\right)\right]^{2}
$$




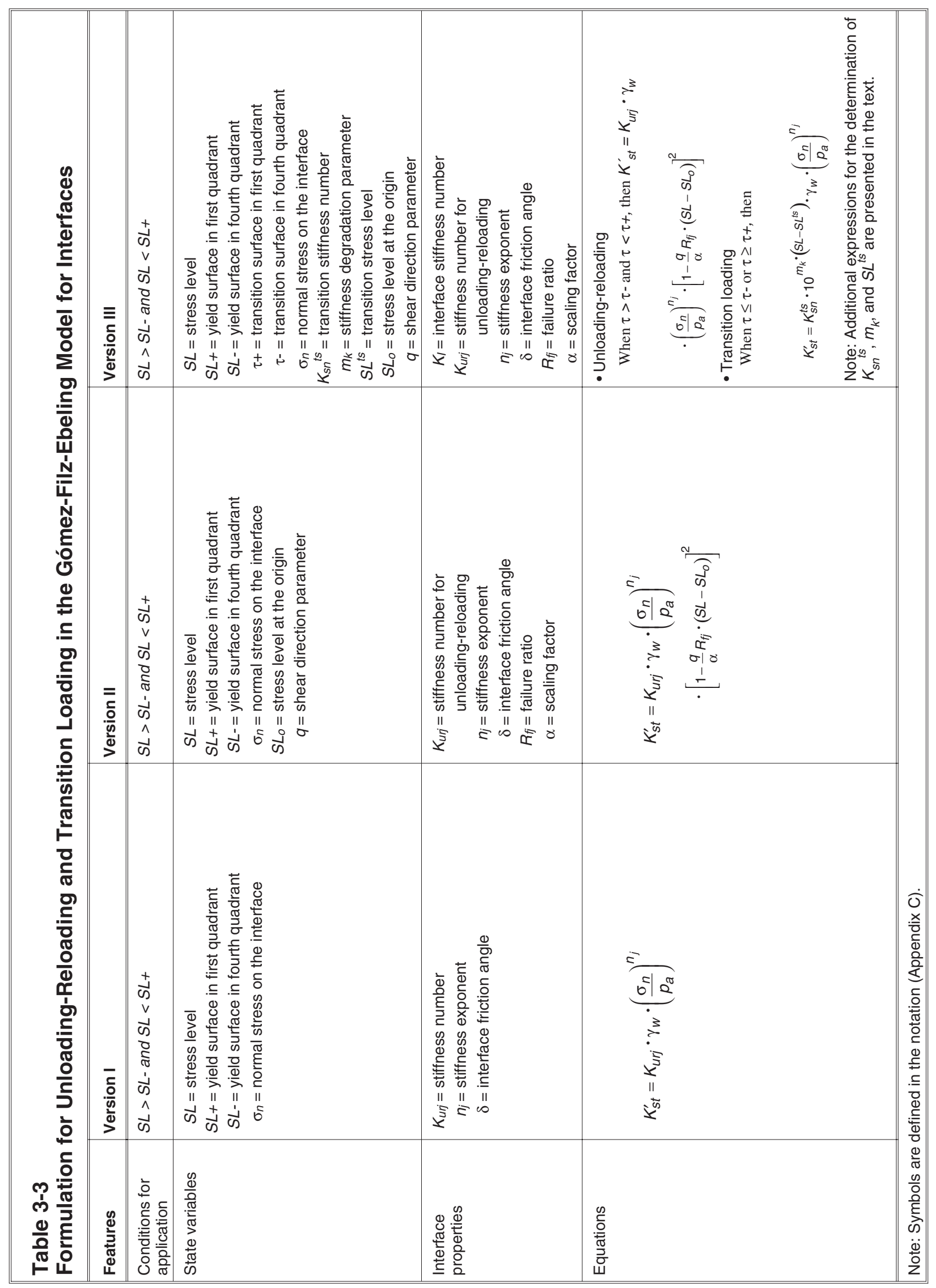


where

$$
\begin{aligned}
S L_{o} & =\text { shear stress level at the origin } \\
\alpha & =\text { dimensionless scaling factor for unloading-reloading }
\end{aligned}
$$

The origin of unloading-reloading is defined as the last point where a change in the direction of shear took place. The stress level at the origin $S L_{o}$ is calculated from the following expression:

$$
S L_{o}=\frac{\tau_{o}}{\sigma_{n o} \cdot \tan (\delta)}
$$

where

$$
\begin{gathered}
\tau_{o}=\text { shear stress at the origin } \\
\sigma_{n o}=\text { normal stress at the origin }
\end{gathered}
$$

According to this formulation, the interface response during unloadingreloading is characterized by a hyperbolic shear stress-displacement relationship that is qualitatively identical to that assumed for yield-inducing shear. However, the interface response during unloading-reloading is assumed to be independent of the inclination of the stress path. In Version II, Expression 3-6 is assumed applicable to both unloading-reloading and transition loading.

As can be seen in Table 3-3, this version of the model introduces two new interface properties: the stiffness number for unloading-reloading, $K_{u r j}$, and the scaling factor, $\alpha$. These property values can be determined through a trial-and-error process from the results of unload-reload interface tests. They can also be related to other interface properties without the need for their experimental determination. A procedure for the determination of $\alpha$ and $K_{u r j}$ from other interface properties was proposed by Gómez, Filz, and Ebeling (2000). This procedure is summarized in Section 3.1.4 (Determination of the model parameter values).

3.1.3.3 Version III. This version is intended for use in analyses where very accurate modeling of the interface response is required. It is a more sophisticated formulation that accounts for the type of interface response observed in the transition region. From a practical point of view, it is not known whether Version III introduces significant gains in accuracy for the modeling of soil-to-wall interfaces with respect to Versions I and II. Additional studies would be necessary to investigate the comparative advantages of Version III for practical problems. 
In Version III, the interface response during unloading-reloading is identical to Version II. Therefore, for stress paths contained inside the unloading-reloading region defined in Figure 3-2, the tangent interface stiffness can be determined from Equation 3-6.

The difference between the formulations of Versions II and III corresponds to the transition region. In Version II, the formulations for the unloading-reloading and the transition regions are identical (Equations 3-6 and 3-7). In Version III, the interface stiffness at any point inside the transition region is calculated using the following expression:

$$
K_{s t}^{\prime}=K_{S n}{ }^{t s} \cdot 10^{m_{k} \cdot\left(S L-S L^{t s}\right)} \cdot \gamma_{w} \cdot\left(\frac{\sigma_{n}}{p_{a}}\right)^{n_{j}}
$$

where

$$
\begin{aligned}
K_{s n}{ }^{t s} & =\text { transition stiffness number } \\
m_{k} & =\text { stiffness degradation parameter } \\
S L^{t s} & =\text { transition stress level }
\end{aligned}
$$

Equation 3-8 represents the formulation for transition loading in Version III of the Gómez-Filz-Ebeling model. The transition stiffness number $K_{s n}{ }^{t s}$, stiffness degradation parameter $m_{k}$, and transition stress level $S L^{t s}$ are three of the additional state variables required for implementation of this formulation.

The transition stiffness number can be determined from the following expression:

$$
K_{s n}{ }^{t s}=\frac{K_{s n}^{\prime t s}}{\gamma_{w} \cdot\left(\frac{\sigma_{n}{ }^{t s}}{p_{a}}\right)^{n_{j}}}
$$

where

$$
\begin{aligned}
K_{s t}^{\prime}{ }_{s t}= & \text { interface stiffness at the point where the stress path intersects } \\
& \text { the transition surface upon entering the corresponding } \\
& \text { transition region } \\
\sigma_{n}{ }^{t s}= & \text { normal stress at the point where the stress path intersects the } \\
& \text { transition surface upon entering the corresponding transition } \\
& \text { region }
\end{aligned}
$$


The stiffness degradation parameter, $m_{k}$, is determined from the following expression:

$$
m_{k}=\left[\frac{\log \left(K_{s n}{ }^{t s}\right)-\log \left(K_{s n}{ }^{y s}\right)}{S L^{t s}-S L^{y s}}\right]
$$

where

$$
\begin{aligned}
K_{s n}{ }^{y s} & =\text { yield stiffness number } \\
S L^{y s} & =\text { stress level for the current position of the yield surface }
\end{aligned}
$$

The yield stiffness number, $K_{s n}{ }^{y s}$, is the value of normalized stiffness corresponding to the current position of the yield surface, $S L^{y s}$, and is calculated from the following equation:

$$
K_{s n}{ }^{y s}=K_{I} \cdot\left(1-q \cdot R_{f j} \cdot S L^{y s}\right)^{2}
$$

The current position of the yield surface, $S L^{y s}$, is defined mathematically as

$$
\begin{aligned}
S L^{y s} & =S L+\text { for shear inside the transition zone of the first quadrant } \\
& =S L-\text { for shear inside the transition zone of the fourth quadrant }
\end{aligned}
$$

The value of the transition stress level, $S L^{t s}$, is determined from the following expression:

$$
S L^{t s}=\frac{\tau^{t s}}{\sigma_{n}{ }^{t s} \tan (\delta)}
$$

where $\tau^{t s}$ is the shear stress at the point where the stress path intersects the transition surface upon entering the corresponding transition region.

Table 3-3 summarizes the formulation of Version III. This version of the model does not introduce any new interface properties with respect to those required in Version II. A total of five additional state variables are required for Version III. 


\subsubsection{Determination of the model parameter values}

The application of the extended hyperbolic model requires the determination of the values of the interface parameters listed in Table 3-4. Gómez, Filz, and Ebeling (2000) presented a detailed description of the procedure for the determination of these parameter values, which is summarized in the following paragraphs.

\section{Table 3-4 \\ Summary of Material Properties Required in the Gómez-Filz-Ebeling Model for Interfaces}

\begin{tabular}{|c|c|c|}
\hline Type of Loading & Formulation & Parameters $^{1}$ \\
\hline Yield-inducing shear & $\begin{array}{l}\text { Formulation for yield-inducing } \\
\text { shear }\end{array}$ & $\begin{aligned} K_{l} & =\text { stiffness number } \\
n_{j} & =\text { stiffness exponent } \\
R_{f j} & =\text { failure ratio } \\
\delta & =\text { interface friction angle }\end{aligned}$ \\
\hline \multirow[t]{2}{*}{ Unloading-reloading } & Version I & $\begin{aligned} K_{u r j}= & \text { stiffness number for } \\
& \text { unloading-reloading } \\
n_{j}= & \text { stiffness exponent } \\
\delta & =\text { interface friction angle }\end{aligned}$ \\
\hline & Version II & $\begin{aligned} K_{u r j}= & \text { stiffness number for } \\
& \text { unloading-reloading } \\
n_{j}= & \text { stiffness exponent } \\
\delta= & \text { interface friction angle } \\
R_{f j}= & \text { failure ratio } \\
\alpha= & \text { scaling factor }\end{aligned}$ \\
\hline Transition loading & Version III & $\begin{aligned} K_{u r j}= & \text { stiffness number for } \\
& \text { unloading-reloading } \\
n_{j}= & \text { stiffness exponent } \\
\delta= & \text { interface friction angle } \\
R_{f j}= & \text { failure ratio } \\
\alpha= & \text { scaling factor }\end{aligned}$ \\
\hline
\end{tabular}

\subsubsection{Determination of parameter values for interfaces at yield.}

The implementation of the formulation for yield-inducing shear of the extended hyperbolic model does not require any parameters in addition to those considered in the Clough and Duncan (1971) hyperbolic model. A detailed description of the procedure for determining the hyperbolic parameter values is presented in Appendix B.

Gómez, Filz, and Ebeling (2000) observed that the simple procedure for determining the hyperbolic parameter values developed by Clough and Duncan (1971) is accurate enough for implementation of the hyperbolic model in cases of shear under constant normal stress. However, for shear along inclined stress paths, it is convenient to verify and, if necessary, to adjust the hyperbolic parameter values before application of the extended hyperbolic model. The procedure for adjusting the hyperbolic parameters is based on normalization of the test data. This procedure is summarized in 
Appendix B. Further details on normalization of interface test data and adjustment of the hyperbolic parameters can be found in Gómez, Filz, and Ebeling (2000).

3.1.4.2 Determination of interface parameter values for unloadingreloading. The stiffness number for unloading-reloading, $K_{u r j}$, is required for Versions I, II, and III of the model. The value of $K_{u r j}$ can be determined experimentally from the results of unload-reload tests, or can be estimated using the following equation:

$$
K_{u r j}=C_{k} \cdot K_{I}
$$

where $C_{k}$ is the interface stiffness ratio. The value of the stiffness ratio can be estimated according to the expressions presented in Table 3-5.

\section{Table 3-5 \\ Recommended Values of the Stiffness Ratio $C_{k}$ (Gómez, Filz, and Ebeling 2000)}

\begin{tabular}{|l|l|l||}
\hline \hline Version of the Model & Correlation with $\boldsymbol{R}_{f j}$ & Expected Range \\
\hline \hline I & $C_{k}=0.5 \cdot\left(1+R_{f j}\right)^{2}$ & 1 to 2 \\
\hline II and III & $C_{k}=\left(1+R_{f j}\right)^{2}$ & 2 to 4 \\
\hline
\end{tabular}

The scaling factor, $\alpha$, is used in Versions II and III of the model. Its value can also be determined experimentally from the results of unloadreload tests, or it can be estimated according to the expression presented in Table 3-6.

\section{Table 3-6}

Recommended Values of the Scaling Factor $\alpha$ (Gómez, Filz, and Ebeling 2000)

\begin{tabular}{|l|l|l||}
\hline \hline Version of the Model & Correlation with $\boldsymbol{R}_{\boldsymbol{f}}$ & Expected Range \\
\hline \hline I & Not applicable & - \\
\hline II and III & $\alpha=1+R_{f j}$ & 1.4 to 2 \\
\hline
\end{tabular}

\subsection{Interface Hyperbolic Parameter Values}

Hyperbolic parameter values for the interface between dense Blacksburg Sand and concrete were determined from the results of the initial loading tests described in Chapter 2, as described in Appendix B. These values are summarized in Table 3-7. 


\begin{tabular}{|c|c|}
\hline \multicolumn{2}{|c|}{$\begin{array}{l}\text { Table 3-7 } \\
\text { Hyperbolic Parameter Values for the Interface Between Dense } \\
\text { Blacksburg Sand and Concrete }\end{array}$} \\
\hline Parameter & Parameter Value \\
\hline$K_{l}$ & 23000 \\
\hline$n_{j}$ & 0.8 \\
\hline$R_{f j}$ & 0.76 \\
\hline$\delta$ & $31.6 \mathrm{deg}$ \\
\hline
\end{tabular}

The parameter values for the interface between dense Blacksburg Sand and concrete are reproduced in Table 3-8, together with the parameter values reported in the literature for other interfaces. This table may be useful for the selection of parameter values in cases where results of initial loading tests are not available.

\section{Table 3-8}

Summary of Hyperbolic Parameter Values for Interfaces between Concrete and Different Types of Soils

\begin{tabular}{|c|c|c|c|c|c|c|}
\hline Soil & Concrete Surface & $\begin{array}{l}\text { Relative Density of } \\
\text { Soil }\end{array}$ & $K_{I}$ & $n_{j}$ & $R_{f j}$ & $\delta$ (deg) \\
\hline Well-graded Blacksburg Sand & Cast against plywood & $80 \%$ (dense) & 23000 & 0.8 & 0.76 & 31.6 \\
\hline \multirow{2}{*}{$\begin{array}{l}\text { Uniform density sand (Gómez, Filz, } \\
\text { and Ebeling 2000) }\end{array}$} & \multirow[t]{2}{*}{ Cast against plywood } & $49 \%$ (medium dense) & 21800 & 0.81 & 0.88 & 29.3 \\
\hline & & $75 \%$ (dense) & 26600 & 0.83 & 0.85 & 31 \\
\hline $\begin{array}{l}\text { Uniform Light Castle Sand (Gómez, } \\
\text { Filz, and Ebeling 2000) }\end{array}$ & Cast against plywood & $80 \%$ (dense) & 20700 & 0.79 & 0.79 & 33.7 \\
\hline \multirow[t]{6}{*}{ Uniform sand (Peterson et al. 1976) } & \multirow{3}{*}{$\begin{array}{l}\text { Smooth (cast against } \\
\text { glass plate) }\end{array}$} & Loose & 10200 & 0.87 & 0.71 & 30 \\
\hline & & Medium dense & 12700 & 0.84 & 0.62 & 28.7 \\
\hline & & Dense & 8400 & 1.17 & 0.40 & 31.2 \\
\hline & \multirow[t]{3}{*}{ Rough } & Loose & 10000 & 0.83 & 0.85 & 31.6 \\
\hline & & Medium dense & 11900 & 0.71 & 0.78 & 29.8 \\
\hline & & Dense & 10400 & 0.70 & 0.41 & 32.9 \\
\hline \multirow{6}{*}{$\begin{array}{l}\text { Well-graded sand (Peterson et al. } \\
\text { 1976) }\end{array}$} & \multirow{3}{*}{$\begin{array}{l}\text { Smooth (cast against } \\
\text { glass plate) }\end{array}$} & Loose & 12000 & 0.83 & 0.89 & 30.4 \\
\hline & & Medium dense & 9200 & 0.94 & 0.69 & 30.7 \\
\hline & & Dense & 10500 & 1.11 & 0.75 & 31.4 \\
\hline & \multirow[t]{3}{*}{ Rough } & Loose & 7700 & 0.70 & 0.78 & 34.8 \\
\hline & & Medium dense & 13100 & 0.67 & 0.69 & 32.9 \\
\hline & & Dense & 14800 & 0.51 & 0.74 & 37 \\
\hline $\begin{array}{l}\text { Poorly graded sand (Clough and } \\
\text { Duncan 1969) }\end{array}$ & Smooth & Dense & 75000 & 1 & 0.87 & 33 \\
\hline \multirow[t]{2}{*}{ Ottawa Sand 50-60 (Lee et al. 1989) } & Smooth & Dense & 19500 & 0.35 & 0.89 & 26.3 \\
\hline & Rough & Dense & 19200 & 0.82 & 0.95 & 30.4 \\
\hline
\end{tabular}


There are a larger number of reference values of hyperbolic parameters for soils than there are for interfaces. If neither interface test results nor reference parameters are available, it may be possible to relate the interface parameter values to the hyperbolic parameter values of the soil. Table 3-9 compares the hyperbolic parameter values for the interface between dense Blacksburg Sand and concrete, and for the three interfaces tested by Gómez, Filz, and Ebeling (2000), to the hyperbolic parameter values obtained from CD triaxial tests on isotropically consolidated soil specimens.

\section{Table 3-9 \\ Comparison of the Hyperbolic Parameter Values of Several Interfaces to Hyperbolic Parameter Values of the Soils}

\begin{tabular}{|c|c|c|c|}
\hline \multirow[b]{2}{*}{ Type of Interface } & \multicolumn{2}{|c|}{ Hyperbolic Parameter Values } & \multirow{2}{*}{$\begin{array}{l}\text { Interface-to-Soil } \\
\text { Parameter Ratio }\end{array}$} \\
\hline & Interface & Soil & \\
\hline Dense Blacksburg Sand & $\begin{aligned} K_{l} & =23000 \\
n_{j} & =0.8 \\
R_{f j} & =0.76 \\
\delta & =31.6 \mathrm{deg}\end{aligned}$ & $\begin{aligned} K & =642 \\
n & =0.25 \\
R_{f} & =0.55 \\
\phi_{o} & =43.4 \mathrm{deg}\end{aligned}$ & $\begin{array}{l}36 \\
3.2 \\
1.37 \\
0.73\end{array}$ \\
\hline $\begin{array}{l}\text { Dense density } \\
\text { sand-to-concrete } \\
\text { (Gómez, Filz, and } \\
\text { Ebeling 2000) }\end{array}$ & $\begin{aligned} K_{l} & =26600 \\
n_{j} & =0.83 \\
R_{f j} & =0.85 \\
\delta & =31 \mathrm{deg}\end{aligned}$ & $\begin{aligned} K & =870 \\
n & =0.63 \\
R_{f} & =0.85 \\
\phi_{o} & =36 \mathrm{deg}\end{aligned}$ & $\begin{array}{l}31 \\
1.32 \\
0.99 \\
0.86\end{array}$ \\
\hline $\begin{array}{l}\text { Medium density } \\
\text { sand-to-concrete } \\
\text { (Gómez, Filz, and } \\
\text { Ebeling 2000) }\end{array}$ & $\begin{aligned} K_{l} & =21900 \\
n_{j} & =0.83 \\
R_{f j} & =0.85 \\
\delta & =31 \mathrm{deg}\end{aligned}$ & $\begin{aligned} K & =1200 \\
n & =0.63 \\
R_{f} & =0.85 \\
\phi_{o} & =41 \mathrm{deg}\end{aligned}$ & $\begin{array}{l}18 \\
1.32 \\
1.03 \\
0.71\end{array}$ \\
\hline $\begin{array}{l}\text { Dense Light Castle } \\
\text { sand-to-concrete } \\
\text { (Gómez, Filz, and } \\
\text { Ebeling 2000) }\end{array}$ & $\begin{aligned} K_{l} & =20700 \\
n_{j} & =0.79 \\
R_{f j} & =0.79 \\
\delta & =33.7 \mathrm{deg}\end{aligned}$ & $\begin{aligned} K & =690 \\
n & =0.79 \\
R_{f} & =0.81 \\
\phi_{o} & =42.4 \mathrm{deg}\end{aligned}$ & $\begin{array}{l}30 \\
1.0 \\
0.97 \\
0.79\end{array}$ \\
\hline
\end{tabular}

Ratios of interface-to-soil hyperbolic parameter values are presented in Table 3-9. These ratios are based on a limited database, and they should not be used as a reference for interfaces that differ substantially from the interfaces tested during this investigation.

Table 3-10 summarizes the values of parameters $K_{u r j}$ and $\alpha$ for the interface between dense Blacksburg Sand and for other types of interfaces. These are estimated values, determined using the criteria presented in Tables 3-5 and 3-6, the hyperbolic parameter values listed in Table 3-8, and Equation 3-14. 
Table 3-10

Summary of Values of Model Parameters $K_{u r j}$ and $\alpha$ for Several Interfaces

\begin{tabular}{|c|c|c|c|c|c|}
\hline \multirow[b]{2}{*}{ Soil } & \multirow[b]{2}{*}{ Concrete Surface } & \multirow{2}{*}{$\begin{array}{l}\text { Relative Density of } \\
\text { Soil }\end{array}$} & \multirow{2}{*}{$\begin{array}{l}\text { Version I } \\
\boldsymbol{K}_{\text {urj }}\end{array}$} & \multicolumn{2}{|c|}{ Versions II and III } \\
\hline & & & & $K_{u r j}$ & $\alpha$ \\
\hline Well-graded Blacksburg Sand & $\begin{array}{l}\text { Cast against } \\
\text { plywood }\end{array}$ & $80 \%$ (dense) & 35700 & 71440 & 1.76 \\
\hline \multirow{2}{*}{$\begin{array}{l}\text { Uniform density sand (Gómez, Filz, } \\
\text { and Ebeling 2000) }\end{array}$} & \multirow{2}{*}{$\begin{array}{l}\text { Cast against } \\
\text { plywood }\end{array}$} & $49 \%$ (medium dense) & 38400 & 76900 & 1.88 \\
\hline & & $75 \%$ (dense) & 45400 & 90730 & 1.85 \\
\hline $\begin{array}{l}\text { Uniform Light Castle Sand (Gómez, } \\
\text { Filz, and Ebeling 2000) }\end{array}$ & $\begin{array}{l}\text { Cast against } \\
\text { plywood }\end{array}$ & $80 \%$ (dense) & 33200 & 66320 & 1.79 \\
\hline \multirow[t]{6}{*}{ Uniform sand (Peterson et al. 1976) } & \multirow{3}{*}{$\begin{array}{l}\text { Smooth (cast } \\
\text { against glass } \\
\text { plate) }\end{array}$} & Loose & 14900 & 29825 & 1.71 \\
\hline & & Medium dense & 16700 & 33330 & 1.62 \\
\hline & & Dense & 8200 & 16460 & 1.4 \\
\hline & \multirow[t]{3}{*}{ Rough } & Loose & 17100 & 34220 & 1.85 \\
\hline & & Medium dense & 18800 & 37700 & 1.78 \\
\hline & & Dense & 10300 & 20680 & 1.41 \\
\hline \multirow{6}{*}{$\begin{array}{l}\text { Well-graded sand (Peterson et al. } \\
\text { 1976) }\end{array}$} & \multirow{3}{*}{$\begin{array}{l}\text { Smooth (cast } \\
\text { against glass } \\
\text { plate) }\end{array}$} & Loose & 21400 & 42860 & 1.89 \\
\hline & & Medium dense & 13100 & 26280 & 1.69 \\
\hline & & Dense & 16100 & 32160 & 1.75 \\
\hline & \multirow[t]{3}{*}{ Rough } & Loose & 12200 & 24400 & 1.78 \\
\hline & & Medium dense & 18700 & 37420 & 1.69 \\
\hline & & Dense & 22400 & 44800 & 1.74 \\
\hline $\begin{array}{l}\text { Poorly graded sand (Clough and } \\
\text { Duncan 1969) }\end{array}$ & Smooth & Dense & 131100 & 262260 & 1.87 \\
\hline \multirow[t]{2}{*}{ Ottawa Sand 50-60 (Lee et al. 1989) } & Smooth & Dense & 34800 & 69550 & 1.89 \\
\hline & Rough & Dense & 36600 & 73180 & 1.95 \\
\hline \multicolumn{6}{|c|}{$\begin{array}{l}\text { Notes: } \\
\text { The values of parameters } K_{u r j} \text { and } \alpha \text { are used for modeling unloading-reloading and transition loading in the Gómez-Filz-Ebeling } \\
\text { model. } \\
\text { The parameter values presented in this table were estimated using the criteria in Tables 3-5 and 3-6, the parameter values for } K \\
\text { and } R_{f j} \text { in Table 3-8, and Equation 3-14. }\end{array}$} \\
\hline
\end{tabular}




\subsection{Evaluation of the Extended Hyperbolic Model}

Gómez, Filz, and Ebeling (2000) carried out comparisons between the interface response calculated using the extended hyperbolic model and the results of interface tests. They found that the model was accurate to predict the response of interfaces between uniform, fine sands and concrete subjected to complex stress paths. In this section, further evaluation of the model is carried out using the results of interface test T2005 performed during this investigation using the coarse, well-graded Blacksburg Sand.

Figure 3-3a shows the stress path applied during interface test T2005. The following types of loading can be identified on this stress path:

a. Initial loading to point $A$ : yield inducing-shear.

$b$. Path $A-B$ : yield-inducing shear.

c. Path $B-C-T 1$ : unloading-reloading.

d. Path T1-Y1: transition loading.

e. Path Y1-D: yield-inducing shear.

f. Path $D-E$ : unloading.

g. Path $E-F$ : yield-inducing shear.

h. Path F-Y2: unloading-reloading.

$i$. Path $Y 2-G-H$ : yield-inducing shear to failure.

The shear stress-displacement response was estimated using all versions of the Gómez-Filz-Ebeling model. The interface parameter values used are those listed in Table 3-7. Comparisons between the measured interface response and the results obtained from Versions I, II, and III are presented in Figures 3-3b, 3-3c, and 3-3d, respectively.

All three versions of the model provide good approximations of the interface response for this stress path. The most significant differences between the three versions correspond to the calculated interface response during transition loading from $T 1$ to $Y 1$, and during unloading-reloading from $D$ to $E$ and from $F$ to $Y 2$. The interface response from $T 1$ to $Y 1$, estimated from Versions I and II, is stiffer than the measured interface response. A sharp break in the shear stress-displacement curve is obtained at point $Y 1$ from the model calculations, which does not fit the observed response. Version III provides a more accurate estimate of the interface stiffness during transition loading, and a smoother transition from transition loading to initial loading at point $Y 1$. 


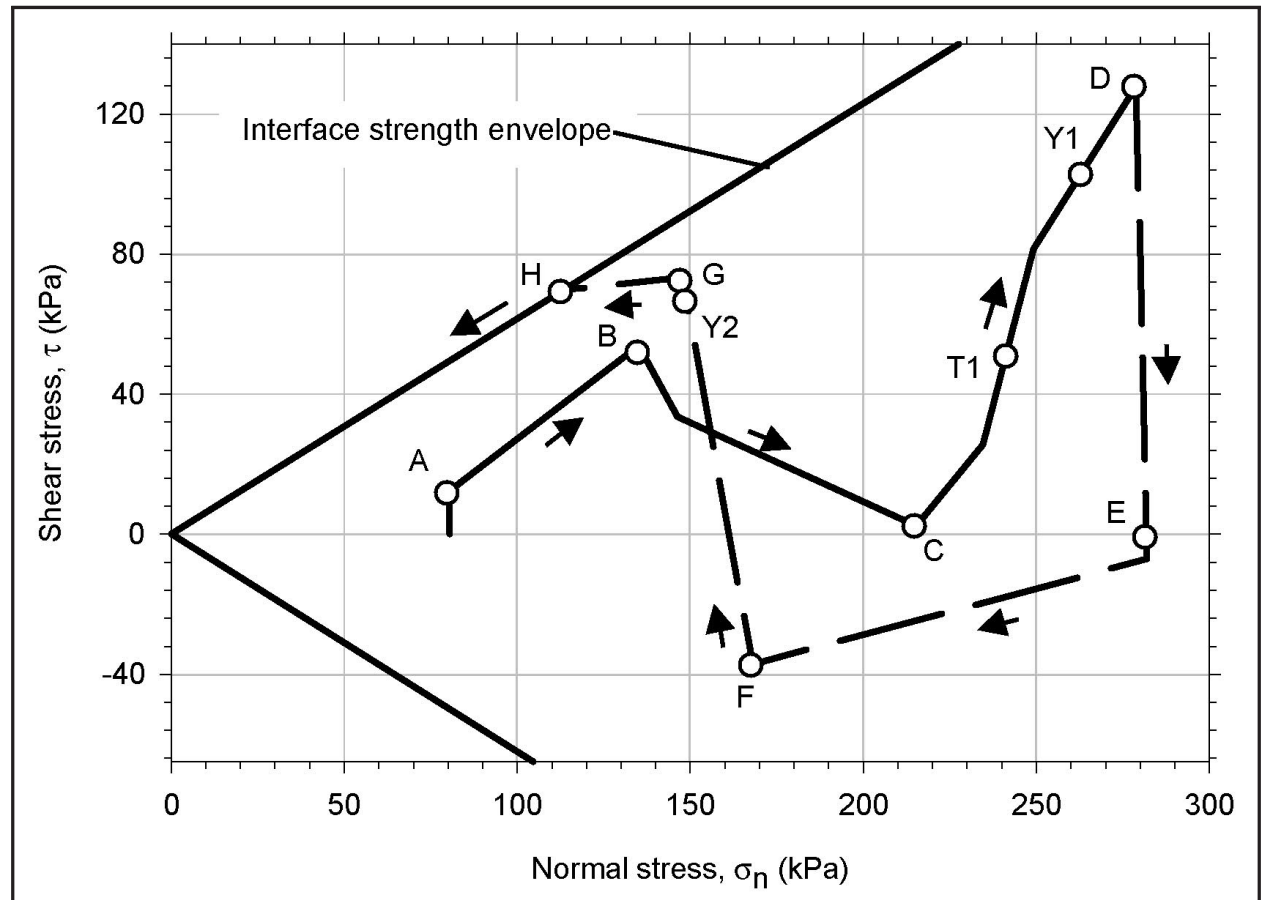

a. Stress path followed during the test

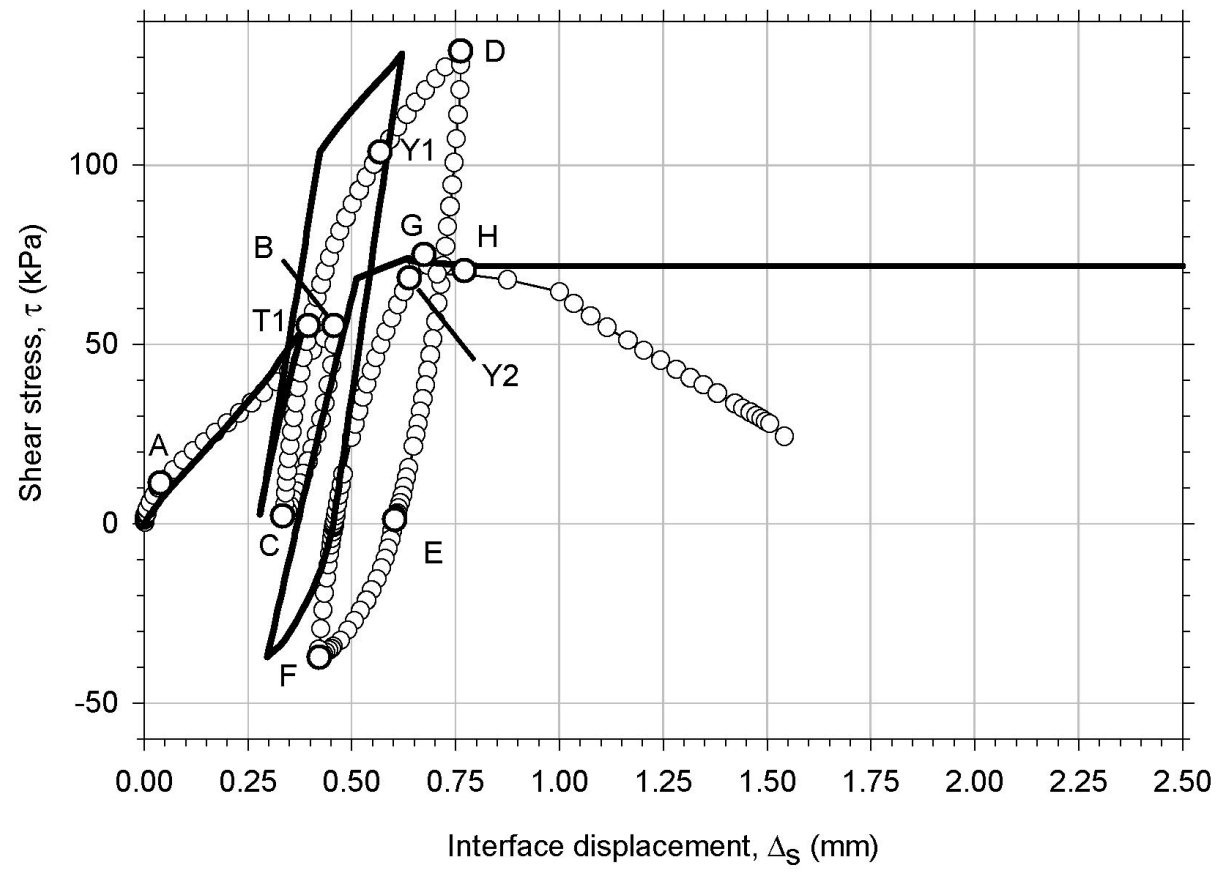

b. Comparison between Version I for unloading-reloading and test data

Figure 3-3. Comparison between the extended hyperbolic model and data from multidirectional stress path test T2005 performed on the dense Blacksburg Sand-to-concrete interface (Continued) 


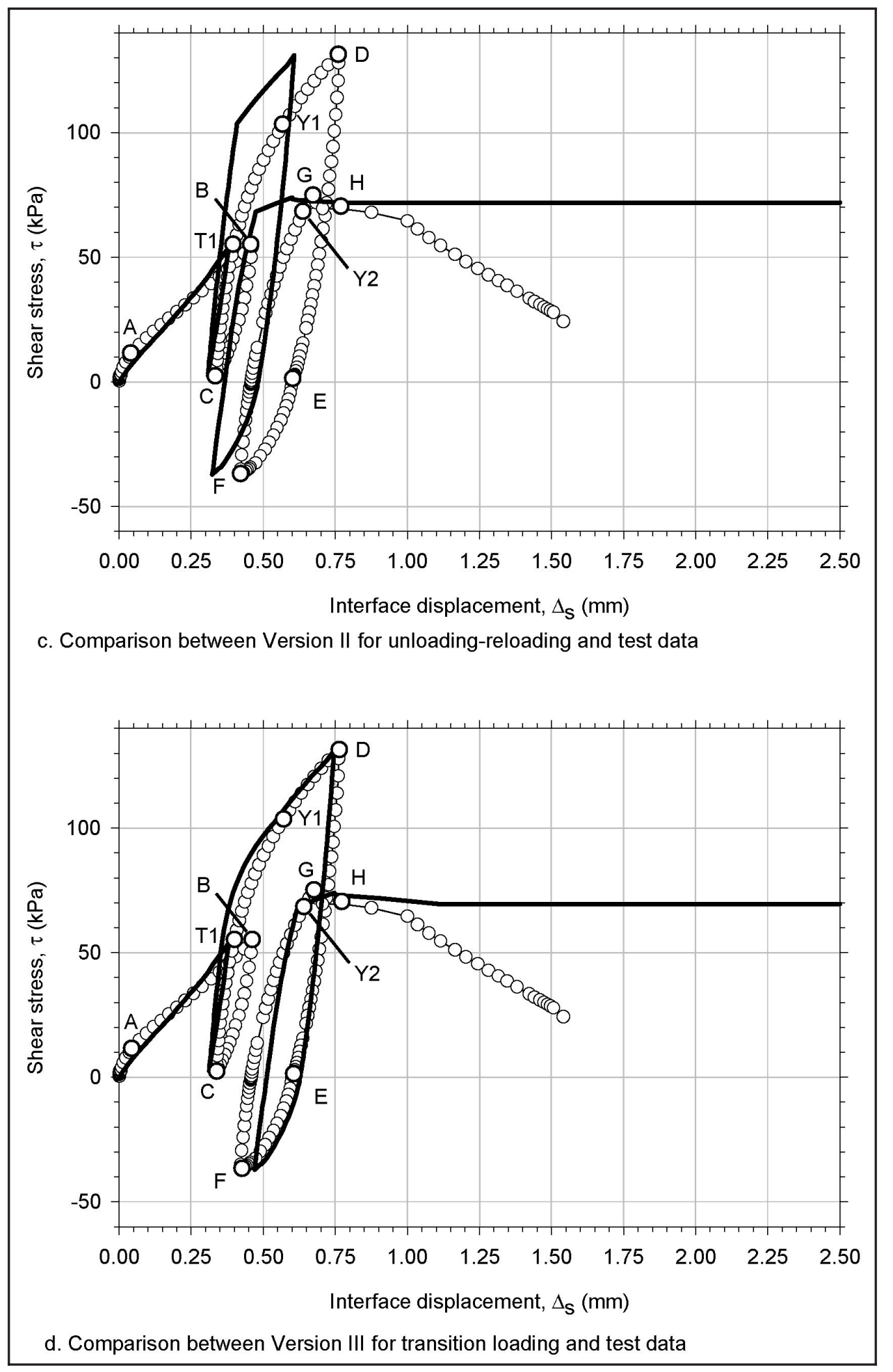

Figure 3-3. (Concluded) 
The interface response estimated using Version I for unloadingreloading from $D$ to $E$ and from $F$ to $Y 2$ is linear and does not model the interface response accurately. Versions II and III capture the nonlinearity of the interface response.

It can be seen that the formulation for yield-inducing shear provides accurate estimates of the interface response in the first and fourth quadrants for all directions of the stress path applied during this test. It is important to note that, during shearing between points $G$ and $H$, the measured interface response shows stiffness values that are lower than zero. That is, interface displacement increases as shear stresses decrease. This negative stiffness is not due to post-peak softening of the interface because it takes place before the stress path intersects the interface strength envelope. Negative values of interface stiffness can occur for certain inclinations of the stress path (see Figure 4-16 in Gómez, Filz, and Ebeling 2000). As can be seen in Figure 3-3, the formulation for interfaces at yield of the extended hyperbolic model captures this feature of the interface response.

For shearing beyond point $\mathrm{H}$ (Figure 3-3), once failure of the interface is attained, the model does not provide accurate estimates of the interface response because the stiffness is assumed to be zero at failure in the model.

In summary, comparison of the model calculations to the results of interface test T2005 confirms the accuracy of the extended hyperbolic model in the prediction of the response of sand-to-concrete interfaces subjected to a variety of complex stress paths.

\subsection{Input of Model Parameters in SOILSTRUCT-ALPHA}

The formulation for yield-inducing shear and Version II of the formulation for unloading-reloading of the Gómez-Filz-Ebeling model were implemented into the finite element program SOILSTRUCT-ALPHA. Table 3-11 summarizes the soil and interface parameters required as input for SOILSTRUCT-ALPHA analyses. 


\section{Table 3-11 \\ Summary of Soils and Interface Material Properties Required as Input for SOILSTRUCT-ALPHA Analyses}

\begin{tabular}{|c|c|}
\hline Materials & Input Parameters $^{1}$ \\
\hline Soils & $\begin{aligned} K & =\text { modulus number } \\
n & =\text { modulus exponent } \\
K_{u r} & =\text { modulus number for unloading-reloading } \\
R_{f} & =\text { failure ratio } \\
\phi & =\text { internal friction angle } \\
V_{\text {nom }} & =\text { nominal Poisson's ratio } \\
K_{o} & =\text { at-rest earth pressure coefficient } \\
\gamma_{\text {moist }} \gamma_{\text {sat }} & =\text { moist and saturated unit weight, respectively }\end{aligned}$ \\
\hline Interface & $\begin{aligned} K_{l} & =\text { stiffness number } \\
n_{j} & =\text { stiffness exponent } \\
R_{f j} & =\text { failure ratio } \\
\delta & =\text { interface friction angle }\end{aligned}$ \\
\hline
\end{tabular}

\subsubsection{Soil parameter input}

The values of parameters $K, n, K_{u r}, R_{f}$, and $\phi$ for soils can be determined experimentally from the results of triaxial tests, or they can be estimated using values reported in the literature.

Values of the unload-reload modulus number, $K_{u r}$, for soils are not readily available in the literature. According to Duncan et al. (1980), the value of $K_{u r}$ is always larger than the value of the modulus number $K$ for primary loading. For stiff soils such as dense sands, $K_{u r}$ may be 20 percent greater than $K$. For soft soils such as loose sands, $K_{u r}$ may be three times as large as $K$. The value of the modulus exponent $n$ is always very similar for primary loading and unloading, and is often assumed to be the same.

Many granular soils present strength envelopes that are curvilinear and cannot be defined by a single value of $\phi$. In these cases, a value of secant friction angle $\phi$ can be assigned to the soil that corresponds to the range of confining stresses expected to occur. This value of secant friction angle can be calculated using the following equation:

$$
\phi=\phi_{o}-\Delta \phi \cdot \log _{10}\left(\frac{\sigma_{3}^{\prime}}{p_{a}}\right)
$$

Table A2 summarizes values of $K, n, R_{f}, \phi_{o}$, and $\Delta \phi$ for several types of soils at varying relative densities. These values were extracted from Table 5 in Duncan et al. (1980). They can be used as a basis for selection of parameters when triaxial test results are not available, or for confirmation of the experimental parameter values. 
Values for the nominal Poisson's ratio $v_{\text {nom }}$ are determined from a onedimensional (1-D) column analysis as described by Ebeling and Wahl (1997). In the 1-D column analysis, the horizontal earth pressure coefficient $K_{h}$ resulting from incremental backfill placement of the soil column is related to $v_{n o m}$, as described in Ebeling and Wahl (1997).

The at-rest earth pressure coefficient, $K_{o}$, input as a material property in SOILSTRUCT-ALPHA is assigned only to newly placed fill lifts. Because newly placed lifts are usually assumed to behave as a dense fluid, the value of $K_{o}$ for input in SOILSTRUCT-ALPHA is often assumed equal to 1.

\subsubsection{Interface parameter input}

The values of parameters $K_{I}, n_{j}, R_{f j}$, and $\delta$ for soil-to-structure interfaces can be determined experimentally, or they can be estimated using values available in the literature. Table 3-8 summarizes parameter values for several types of interfaces. These values can be used as the basis for assigning interface properties when test results are not available, or for verification of experimental parameter values.

It must be noted that, in SOILSTRUCT-ALPHA analyses, it is not necessary to introduce the values for unload-reload parameters $K_{u r j}$ and $\alpha$. They are estimated internally using the criteria in Tables 3-5 and 3-6, the input values for $K_{I}$ and $R_{f j}$, and Equation 3-14.

\subsection{Summary and Conclusions}

The extended hyperbolic model developed by Gómez, Filz, and Ebeling (2000) was evaluated against the results of shear tests performed at the interface between a coarse, well-graded sand and concrete. It was confirmed that the model can predict accurately the response of interfaces between sand and concrete. Principal advantages of the model are these:

a. It has a simple mathematical formulation.

b. Hyperbolic parameter values for different types of interfaces are available in the literature.

$c$. It captures the main features of the interface response under simultaneous changes in shear and normal stress and during unloadingreloading.

d. It provides accurate estimates of the response of a variety of soil-toconcrete interfaces subjected to complex stress paths.

$e$. It is relatively easy to implement in SSI analyses. 
f. It establishes a framework for future work on plasticity-based interface models.

The formulations for yield-inducing shear, and for unloading-reloading Version II of the extended hyperbolic model, were implemented by Gómez, Filz, and Ebeling (2000) in the finite element program SOILSTRUCTALPHA. This program is commonly used by the Corps of Engineers for analyses of earth-retaining structures. Through finite element analyses of a pilot-scale lock wall simulation, Gómez, Filz, and Ebeling (2000) found that these formulations could be used for predicting vertical shear forces in retaining structures.

The model has several limitations:

$a$. It does not model displacements normal to the interface, and the interface thickness is implicitly assumed as zero. Consequently, in finite element analyses, a large normal stiffness must be assigned to interface elements in order to reduce overlapping of adjacent twodimensional elements. In addition, it cannot model the generation of normal stresses due to restrained dilation of the interface during shear between two stiff, rough media. This may not be important for analyses of stiff structures retaining relatively compressible soils.

$b$. It does not model displacement softening of the interface. According to the experimental data collected during this investigation, displacement softening may take place in interfaces subjected to relative displacements of 6 to $20 \mathrm{~mm}$. Therefore, in cases where larger magnitudes of interface displacement take place, the model cannot provide accurate predictions of the displacement-softening interface response.

c. The model predicts interface stiffness values that are zero or negative for certain loading combinations. For implementation of the model in finite element programs, it is then necessary to use appropriate stiffness values and numerical procedures (see Stankowsky, Runesson, and Sture 1993, for example) in order to prevent numerical problems. It was found during this investigation that negative stiffness values do occur for certain stress path inclinations. However, if finite element analyses of multi-anchored systems show that these types of loading are common, it may be necessary to perform additional experimental work to verify the accuracy of the model predictions.

$d$. The model has not yet been used for routine analyses of multianchored systems. However, it was used successfully by Gómez, Filz, and Ebeling (2000) to estimate vertical shear forces in a pilotscale lock wall simulation. 


\section{Summary and Conclusions}

Soil-to-structure interfaces in multi-anchored systems may be subjected to complex stress paths, which may include simultaneous changes in shear and normal stress and unloading-reloading. Accurate modeling of the interface response to this type of loading may be required to develop improved design procedures of multi-anchored systems. Gómez, Filz, and Ebeling (2000) developed the extended hyperbolic model for interfaces. Based on comparisons between model predictions and results of laboratory interface tests, they showed that the model provides accurate estimates of the response of interfaces between fine sands and concrete subjected to a variety of stress paths.

Gómez, Filz, and Ebeling (2000) implemented the extended hyperbolic model in the finite element program SOILSTRUCT-ALPHA, which is commonly used for analyses of Corps of Engineers structures, such as lock walls. They also performed a pilot-scale lock wall simulation using a fine sand backfill. The simulation was conceived to model placement and compaction of the backfill in a lock wall, surcharge application, and inundation of the backfill. SOILSTRUCT-ALPHA analyses were performed to model the different stages of the simulation. Comparisons between SOILSTRUCT-ALPHA calculations and test measurements suggested that the model can accurately predict the magnitude of the downdrag force developed at the wall-backfill interface in lock walls.

However, the applicability and accuracy of the model for other types of interfaces were not evaluated. The main objectives of this investigation were the validation of the model against results of tests performed at the interface between coarse sand and concrete, and the expansion of the available database on interface hyperbolic parameters.

To accomplish these objectives, it was necessary to perform the following laboratory activities:

a. Select a coarse sand specimen for interface testing.

b. Perform grain size distribution, minimum/maximum density, specific gravity, consolidation, and triaxial testing on Blacksburg Sand. 
c. Conduct initial loading tests to determine the hyperbolic parameter values of the interface between concrete and dense Blacksburg Sand.

d. Perform multidirectional stress path test to obtain data for validating the extended hyperbolic model.

A coarse, well-graded sand (Blacksburg Sand) was selected for interface testing. The basic properties of the sand were determined from a series of laboratory tests, such as minimum/maximum density and grain size analyses. CD triaxial tests were also performed to determine sets of hyperbolic parameter values for this soil (Appendix A). These hyperbolic parameter values are consistent with values reported by Duncan et al. (1980) for soils of similar gradation.

Initial loading tests were performed at the interface between concrete and a coarse, well-graded sand. The hyperbolic parameter values for the interface were determined based on the results of these tests. A multidirectional stress path test was performed on the coarse sand against concrete interface. The purpose of this test was to obtain data for evaluating the accuracy of the extended hyperbolic model.

Comparisons between model calculations and the results of the multidirectional stress path test confirmed that the Gómez-Filz-Ebeling model can predict accurately the response of a variety of soil-to-concrete interfaces. The principal advantages of the model are:

a. It has a simple mathematical formulation.

$b$. Hyperbolic parameter values for different types of interfaces are available in the literature.

c. It captures the main features of the interface response under simultaneous changes in shear and normal stress and unloading-reloading.

$d$. It provides accurate estimates of the response of a variety of soil-toconcrete interfaces subjected to complex stress paths.

$e$. It is relatively easy to implement in SSI analyses.

f. It establishes a framework for future work on plasticity-based interface models.

The model has several limitations:

$a$. It does not model displacements normal to the interface, and the interface thickness is implicitly assumed as zero.

$b$. It does not model displacement softening of the interface.

$c$. The model predicts interface stiffness values that are zero or negative for certain loading combinations. Although it appears that negative stiffness values do occur for certain loading combinations, they may 
induce numerical problems in finite element analyses. Therefore, implementation of the model in finite element programs requires the use of appropriate stiffness values and numerical procedures (see Stankowsky, Runesson, and Sture 1993, for example) to prevent these numerical problems.

$d$. The model has not yet been used for routine analyses of multianchored systems. However, it was used successfully by Gómez, Filz, and Ebeling (2000) to estimate vertical shear forces in a pilotscale lock wall simulation. 


\section{References}

American Society for Testing and Materials. (1978). "Standard test method for laboratory compaction characteristics of soil using standard effort $\left(12,400 \mathrm{ft}-\mathrm{lbf} / \mathrm{ft}^{3}\left(600 \mathrm{kN}-\mathrm{m} / \mathrm{m}^{3}\right)\right)$," ASTM D698-78, West Conshohocken, PA.

(1991). "Standard test method for minimum index density and unit weight of soils and calculation of relative density," ASTM D4254-91, West Conshohocken, PA.

. (1992). "Standard test method for specific gravity of soils," ASTM D854-92, West Conshohocken, PA.

. (1993a). "Standard classification of soils for engineering purposes (Unified Soil Classification System)," ASTM D2487-93, West Conshohocken, PA.

(1993b). "Standard practice for description and identification of soils (visual-manual procedure)," ASTM D2488-93, West Conshohocken, PA.

. (1993c). "Standard test methods for maximum index density and unit weight of soils using a vibratory table," ASTM D4253-93, West Conshohocken, PA.

Brandon, T. L., Duncan, J. M., and Gardner, W. S. (1990). "Hydrocompression settlement of deep fills," Journal of Geotechnical Engineering ASCE 116(10), 1536-48.

Clough, G. W., and Duncan, J. M. (1969). "Finite element analyses of Port Allen and Old River Locks," Contract Report S-69-6, U.S. Army Engineer Waterways Experiment Station, Vicksburg, MS.

Clough, G. W., and Duncan, J. M. (1971). "Finite element analyses of retaining wall behavior," Journal of the Soil Mechanics and Foundations Division ASCE 97(SM12), 1657-73. 
Desai, C. S., Drumm, E. C., and Zaman, M. M. (1985). "Cyclic testing and modeling of interfaces," Journal of Geotechnical Engineering ASCE 111(6), 793-815.

Desai, C. S., Muqtadir, A., and Scheele, F. (1986). "Interaction analyses of anchor-soil systems," Journal of Geotechnical Engineering ASCE 112(5), 537-53.

Duncan, J .M., Byrne, P., Wong, K. S., and Mabry, P. (1980). "Strength, stress-strain and bulk modulus parameters for finite element analyses of stresses and movements in soil masses," Report UCB/GT/80-01, Department of Civil Engineering, University of California, Berkeley.

Ebeling, R. M., and Mosher, R. L. (1996). "Red River U-Frame Lock No. 1 backfill-structure-foundation interaction," Journal of Geotechnical Engineering ASCE 122(3), 216-25.

Ebeling, R. M., and Wahl, R. E. (1997). "Soil-structure-foundation interaction analysis of new roller-compacted concrete, north lock wall at McAlpine Locks," Technical Report ITL-97-5, U.S. Army Engineer Waterways Experiment Station, Vicksburg, MS.

Ebeling, R. M., Mosher, R. L., Abraham, K., and Peters, J. F. (1993). "Soil-structure interaction study of Red River Lock and Dam No. 1 subjected to sediment loading," Technical Report ITL-93-3, U.S. Army Engineer Waterways Experiment Station, Vicksburg, MS.

Ebeling, R. M., Pace, M. E., and Morrison, E. E., Jr. (1997). "Evaluating the stability of existing massive concrete gravity structures founded on rock," Technical Report REMR-CS-54, U.S. Army Engineer Waterways Experiment Station, Vicksburg, MS.

Ebeling, R. M., Peters, J. F., and Mosher, R. L. (1997). “The role of nonlinear deformation analyses in the design of a reinforced soil berm at Red River U-frame Lock No. 1," International Journal for Numerical and Analytical Methods in Geomechanics 21, 753-87.

Gómez, J. E., Filz, G. M., and Ebeling, R. M. (2000). "Development of an improved numerical model for concrete-to-soil interfaces in soilstructure interaction analyses; Report 2, Final Study," Technical Report ITL-99-1, U.S. Army Engineer Research and Development Center, Vicksburg, MS

Goodman, R. E., Taylor, R. L., and Brekke, T. L. (1968). "A model for the mechanics of jointed rock," Journal of the Soil Mechanics and Foundations Division ASCE 94(SM3), 637-59.

Idriss, I. M., and Duncan, J. M. (1988). "Earthquake response analysis of embankment dams." Chap 8, Advanced dam engineering for design, construction and rehabilitation. R. J. Jansen, ed., Van Nostrand Reinhold, New York. 
Lee, P. A., Kane, W. F., Drumm, E. C., and Bennett, R. M. (1989). "Investigation and modeling of soil-structure interface properties." Foundation engineering: Current principles and practice, ASCE Geotechnical Special Publication 22. Reston, VA, 580-87.

Matsui, T., and San, K. C. (1989). "An elastoplastic joint element with its application to reinforced slope cutting," Soils and Foundations 29(3), 95-104.

Maurseth, J., and Sedey, J. S. (1992). "Slurry constructed diaphragm guard wall, Bonneville Navigation Lock." Corps of Engineers structural engineering conference. St. Johns County, FL, 8-12 July 1991. 1, 251-60.

Mosher, R. L., and Knowles, V. R. (1990). "Finite element study of tieback wall for Bonneville Navigation Lock," Technical Report ITL-904, U.S. Army Engineer Waterways Experiment Station, Vicksburg, MS.

Munger, D. F., Jones, P. T., and Johnson, J. (1990). “Temporary tieback wall, Bonneville Navigation Lock," ASCE specialty conference on design and performance of earth retaining structures. Cornell University, June 18-21. ASCE Special Publication 25, Reston, VA. 778-93.

Munger, D. F., Jones, P. T., and Johnson, J. (1992). "Temporary tieback wall, Bonneville Navigation Lock," Corps of Engineers structural engineering conference. St. Johns County, FL, 8-12 July 1991. 1, 359-73.

Peterson, M. S., Kulhawy, F. H., Nucci, L. R., and Wasil, B. A. (1976). "Stress-deformation behavior of soil-concrete interfaces," Contract Report B-49, Niagara Mohawk Power Corporation, Syracuse, NY.

Stankowski, T., Runesson, K., and Sture, S. (1993). "Fracture and slip of interfaces in cementitious composites; I, Characteristics," Journal of Engineering Mechanics ASCE 119(2), 292-314.

Stark, T. D., Ebeling, R. M., and Vettel, J. J. (1994). "Hyperbolic stressstrain parameters for silts," Journal of Geotechnical Engineering ASCE 120(2), 420-41.

Wong, P. C., Kulhawy, F. H., and Ingraffea, A. R. (1989). "Numerical modeling of interface behavior for drilled shaft foundations under generalized loading." Foundation engineering: Current principles and practice, ASCE Geotechnical Special Publication 22. Reston, VA, 565-79.

Zaman, M. M., Desai, C. S., and Drumm, E. C. (1984). "Interface model for dynamic soil-structure interaction," Journal of Geotechnical Engineering ASCE 110(9), 1257-73. 


\section{Appendix A Results of Triaxial and Consolidation Tests and Determination of Hyperbolic Parameter Values}

Triaxial and consolidation tests were performed on dense specimens of Blacksburg Sand. The objectives of these tests were to

a. Determine the internal friction angle of the sand.

b. Determine the hyperbolic parameter values of the sand.

c. Evaluate hydrocompression strains during inundation.

\section{A.1 Triaxial Tests}

The soil used for all the tests described herein is a coarse, well-graded sand, commercially available for the preparation of concrete in Blacksburg, VA. This sand was also used for the interface tests described in Chapter 2 and Appendix B of this report. A more complete description of the properties of Blacksburg Sand is presented in Chapter 2.

Drained triaxial (CD) tests were performed to determine the internal friction angle and hyperbolic parameter values of dense Blacksburg Sand. Three specimens were compacted to a relative density of 80 percent. Each specimen was subjected to an internal manometric pressure of -15 to $-20 \mathrm{kPa}$, which was gradually removed during application of the cell pressure. The samples were de-aired using carbon dioxide, inundated with de-aired distilled water, and back-pressure saturated. The specimens were consolidated under effective confining pressures ranging from 69 to $276 \mathrm{kPa}$. Shearing was performed at a strain rate of 0.25 percent per minute, which was found to be appropriate for pore pressure dissipation during previous trials. 
The results of the tests are presented graphically in Figure A1. All the specimens exhibited dilation during shear and strain-softening after mobilization of the peak strength. Because the peak strength envelopes of both soils are curved, the value of peak secant friction angle, $\phi$, for a given confining stress, $\sigma_{3}^{\prime}$, can be calculated from the following expression (Duncan et al. 1980):

$$
\phi=\phi_{o}-\Delta \phi \cdot \log _{10}\left(\frac{\sigma_{3}^{\prime}}{p_{a}}\right)
$$

where

$$
\begin{aligned}
\phi_{o}= & \text { peak secant friction angle at a confining pressure of } \\
& 101.4 \mathrm{kPa}(1 \mathrm{~atm}) \\
\Delta \phi= & \text { reduction in the peak secant friction angle value for a } 10 \text {-fold } \\
& \text { increase in } \sigma_{3}^{\prime}
\end{aligned}
$$

Determination of the values of friction parameters $\phi_{o}$ and $\Delta \phi$ is done using diagrams of secant friction angle versus normalized confining pressure $\sigma_{3}{ }^{\prime} / p_{a}$, as shown in Figure A1c.

\section{A.2 Consolidation Testing}

Consolidation tests were performed on dense specimens of Blacksburg Sand to provide additional data on their mechanical properties and determine their susceptibility to hydrocompression (Brandon, Duncan, and Gardner 1990).

Two specimens of Blacksburg Sand were prepared by compaction to a relative density of 75 percent in a dry condition. Each specimen was consolidated under a series of vertical stress increments. Once a predetermined stress was reached, the specimen was inundated after primary consolidation was attained. The results of these tests are presented as strain versus stress diagrams in Figure A2.

During inundation, compressive vertical strain was observed in both specimens. The strain that takes place during inundation includes deformation due to secondary compression of the sand and collapse of the structure due to inundation. In retaining walls subject to changes in the water elevation inside the backfill, hydrocompression-induced settlements may introduce additional shear stresses at the backfill-wall interface. Estimates on the magnitudes of hydrocompression-induced settlements in retaining walls can be done as outlined in Appendix A of Gómez, Filz, and Ebeling (2000). The results presented in Figure A2 add to the database on hydrocompression properties of soils. 


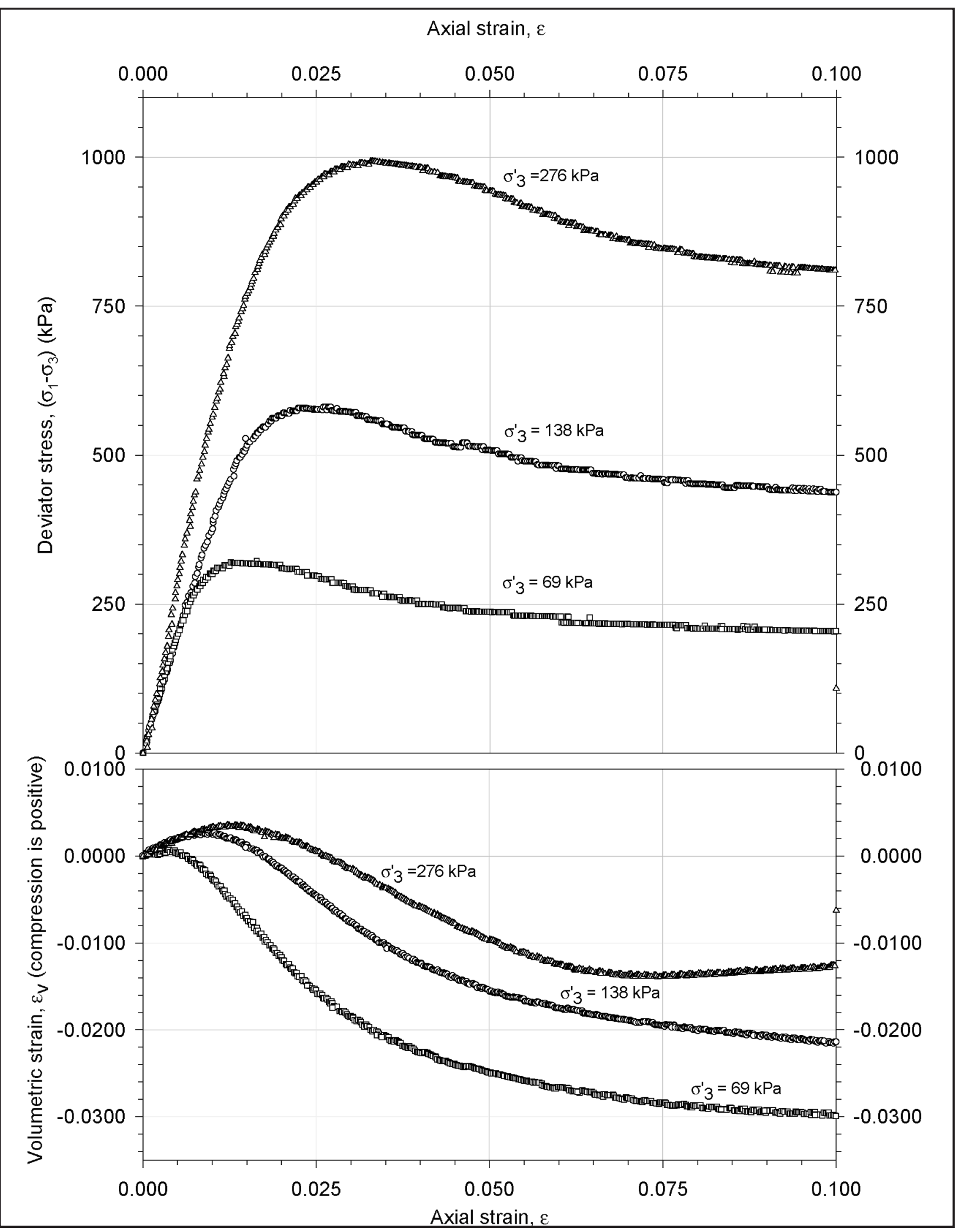

a. Stress-strain and volumetric strain data

Figure A1. Results of CD triaxial tests on dense Blacksburg Sand (Sheet 1 of 3 ) 


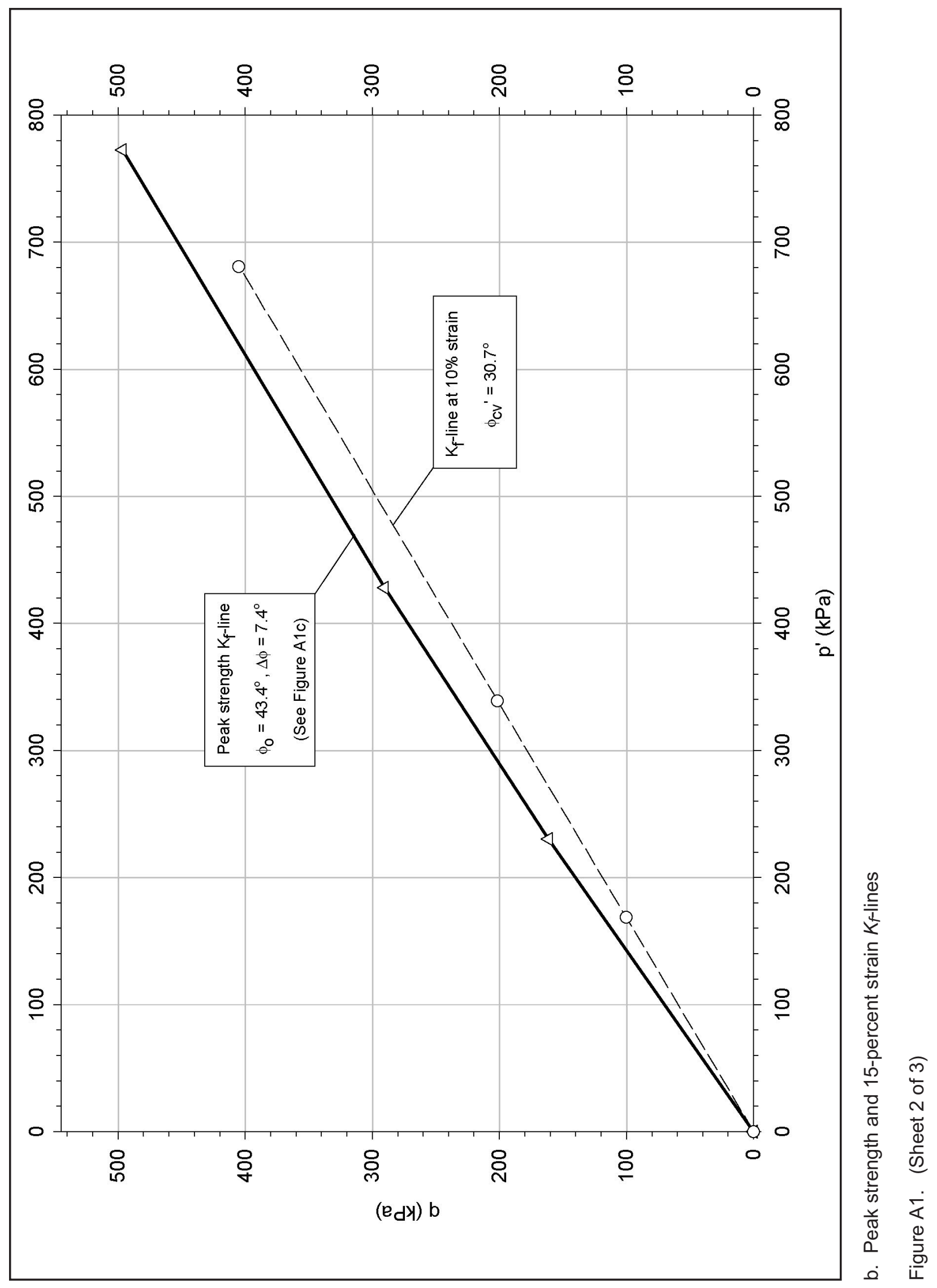




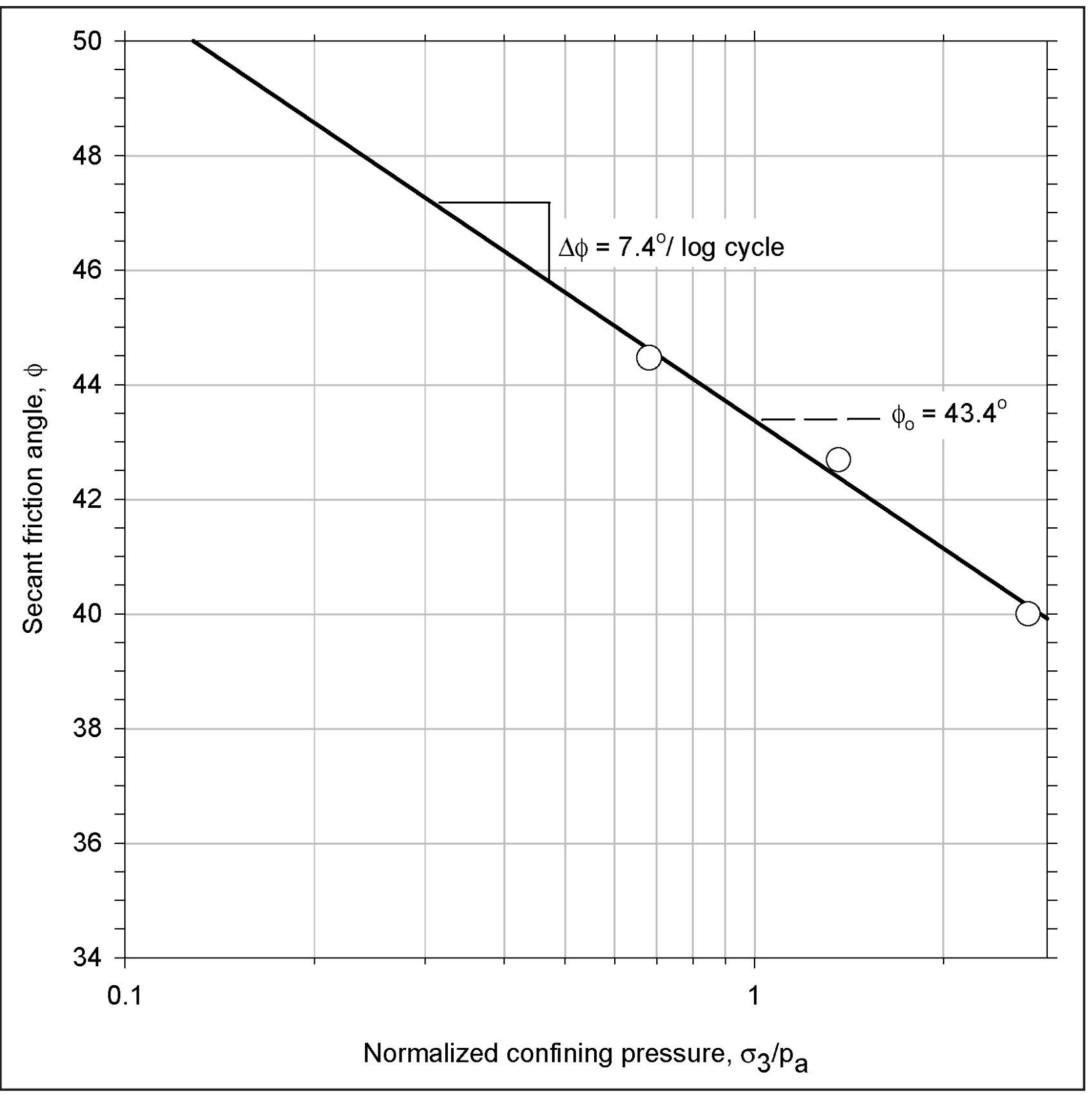

C. Determination of strength parameters $\phi_{0}$ and $\Delta \phi$

Figure A1. (Sheet 3 of 3 ) 


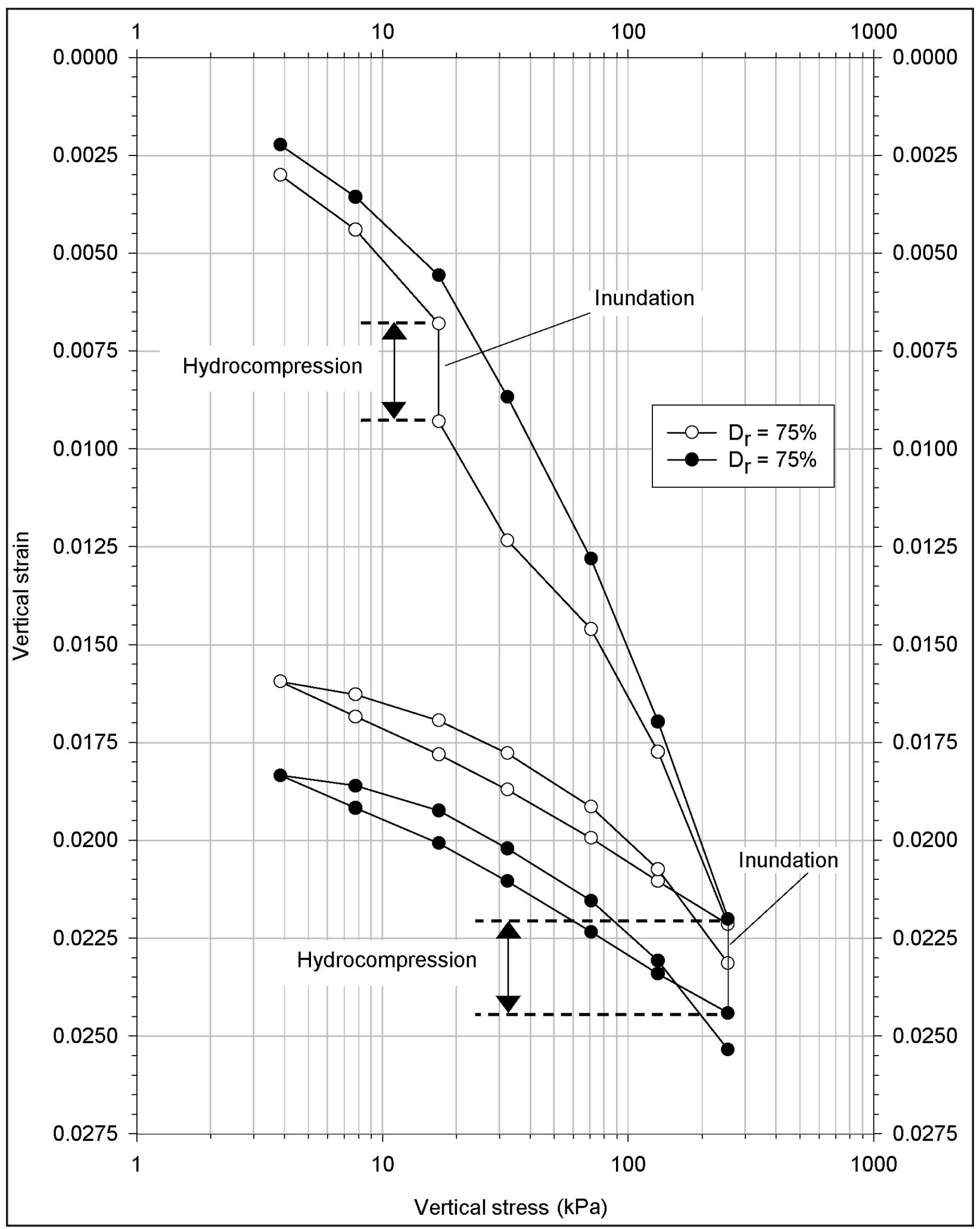

Figure A2. Results of consolidation tests on dense Blacksburg Sand 


\section{A.3 Hyperbolic Parameter Values for Dense Blacksburg Sand}

This section contains a description of the procedure suggested by Duncan et al. (1980) for the determination of hyperbolic parameter values for soils from results of triaxial tests. Hyperbolic parameter values for dense Blacksburg Sand are determined based on the results of the triaxial tests presented previously in this appendix.

\section{A.3.1 Determination of hyperbolic parameter values}

The first step in the determination of hyperbolic parameter values is checking for inconsistencies in the data from the CD triaxial tests. Figure A3 shows the results of the tests performed on dense Blacksburg Sand. The data points shown in the figure are identical to those shown in Figure A1. To minimize inconsistencies in the data, a smooth response of the soil to triaxial testing was assumed for determination of the hyperbolic parameter values. This assumed response corresponds to the solid lines in Figure A3.

The next step is determination of the deviator stress at failure $\left(\sigma_{1}-\sigma_{3}\right)_{f}$ for each confining stress. The values of $\left(\sigma_{1}-\sigma_{3}\right)_{f}$ can be determined from the plots of deviator stress $\left(\sigma_{1}-\sigma_{3}\right)$ versus axial strain $\varepsilon$. Column 2 in the table presented in Figure A4 contains the values of deviator stress at failure determined from Figure A3. The values of $\left(\sigma_{1}-\sigma_{3}\right)$ corresponding to 70 and 95 percent of $\left(\sigma_{1}-\sigma_{3}\right)_{f}$ are calculated as shown in columns 3 and 6 , respectively.

The values of axial strain $\varepsilon$ corresponding to 70 and 95 percent of the strength are determined from the $\left(\sigma_{1}-\sigma_{3}\right)$ versus $\varepsilon$ plots. Columns 4 and 7 in Figure A4 contain the axial strain values determined as shown in Figure A3.

The values in columns 2, 3, 4, 6, and 7 are the basis for the determination of the values of initial Young's modulus $E_{i}$ and failure ratio $R_{f}$. The sequence of calculations leading to the determination of the values of $E_{i}$ and $R_{f}$ is shown in Figure A4.

The value of failure ratio $R_{f}$ to be used for modeling is the average of the values determined in Figure A4. The values of $K$ and $n$ are determined by plotting the normalized values of initial Young's modulus against the normalized confining stress in logarithmic scale as shown in Figure A5.

Figures A3 and A4 also illustrate the determination of the values of bulk modulus $B$ from the triaxial test data. If the plot of volumetric strain

$\varepsilon_{v}$ versus axial strain $\varepsilon$ does not reach a horizontal tangent before mobilization of 70 percent of the strength, the $\varepsilon_{v}$ value corresponding to 70 percent 


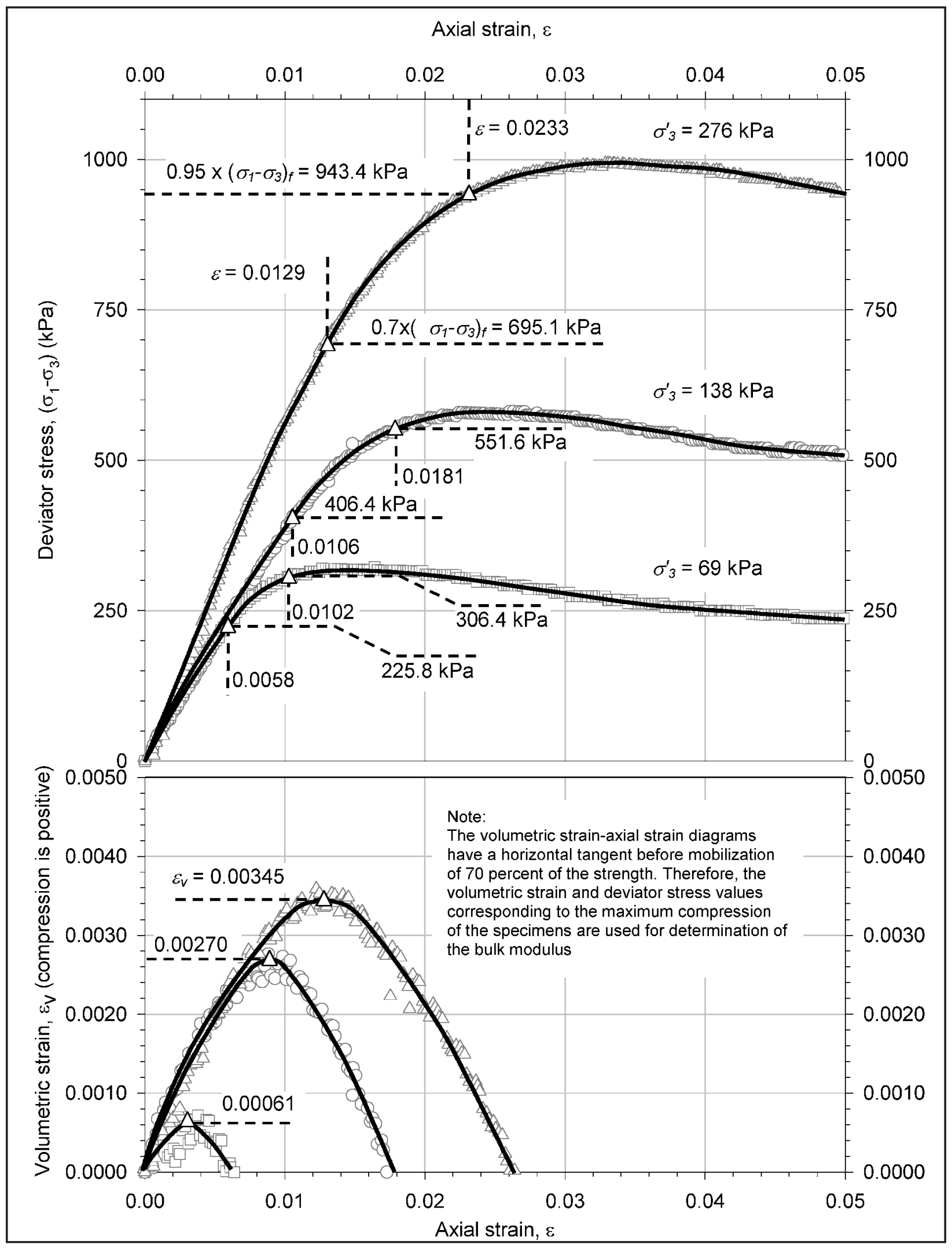

Figure A3. Determination of axial and volumetric strain values at 70 and 95 percent of strength. Data from CD triaxial tests on dense Blacksburg Sand 


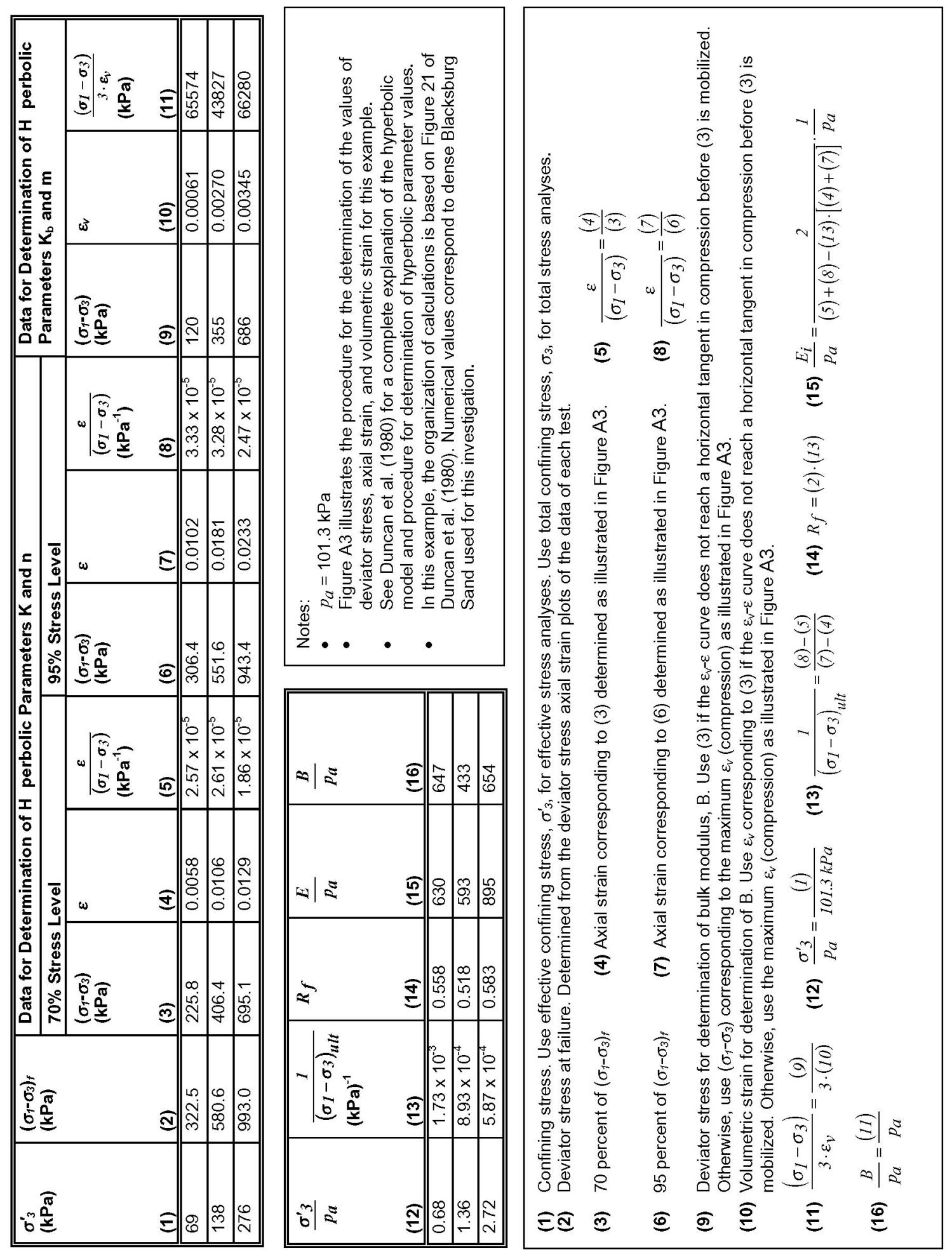

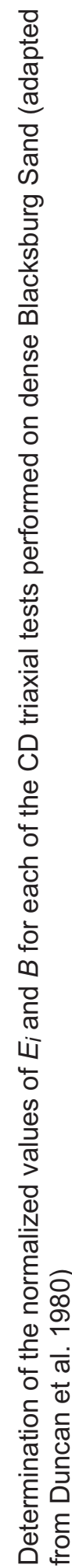

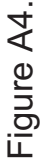

Appendix A Results of Triaxial and Consolidation Tests and Determination of Hyperbolic Parameter Values 


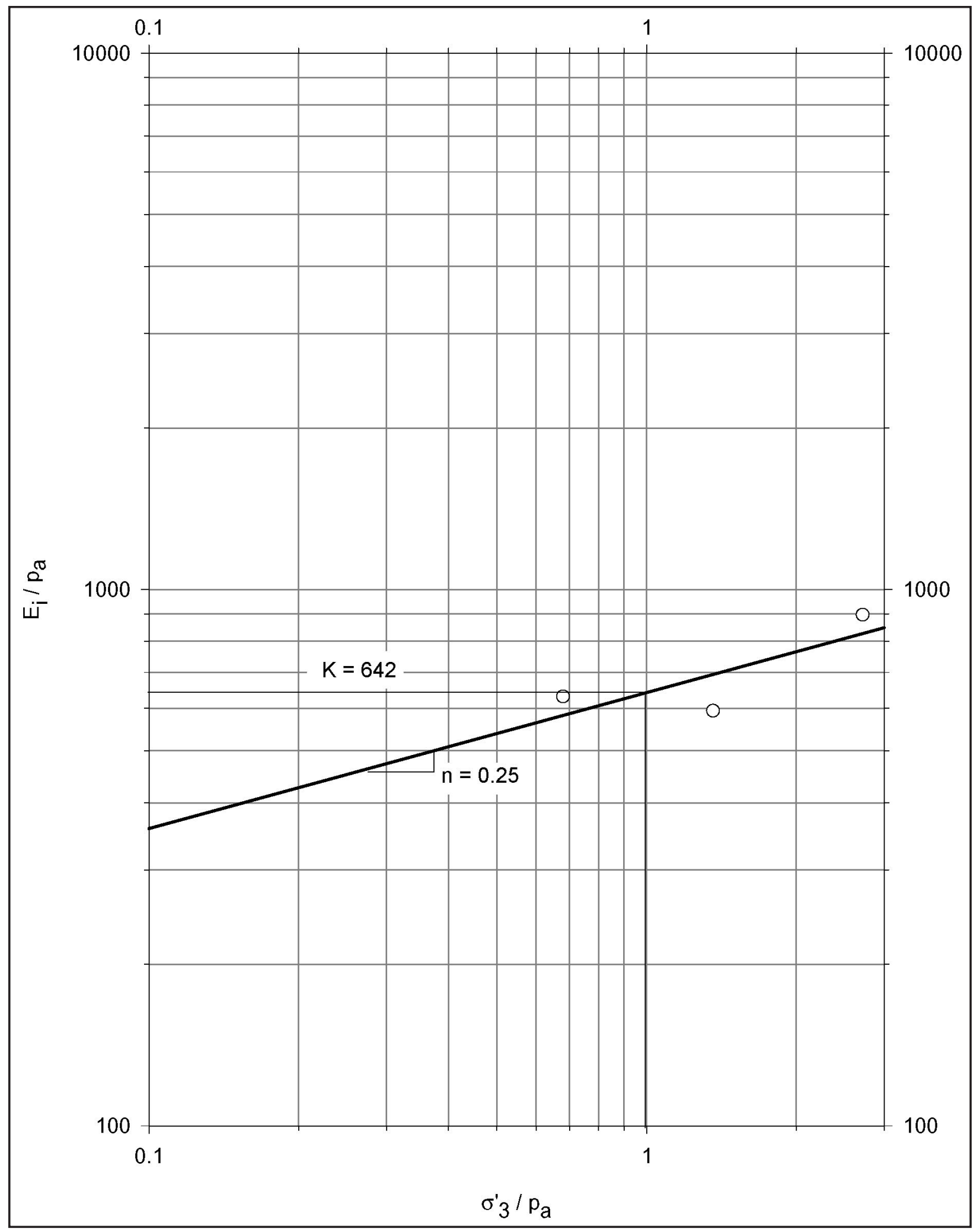

Figure A5. Determination of hyperbolic parameters $K$ and $n$ for dense Blacksburg Sand 
of the strength is used for the determination of $B$. If the $\varepsilon_{v}$ versus $\varepsilon$ plot reaches a horizontal tangent before mobilization of 70 percent of the strength, the maximum value of $\varepsilon_{v}$ is used for the determination of $B$.

The $\varepsilon_{v}$ versus $\varepsilon$ plots of dense Light Castle Sand shown in Figure A3 reach a horizontal tangent before mobilization of 70 percent of the strength. The maximum values of volumetric strain $\varepsilon_{v}$ are determined as shown in the figure. They are copied to column 10 of the table presented as Figure A4. The deviator stress $\left(\sigma_{1}-\sigma_{3}\right)$ corresponding to the point of maximum volumetric strain is also determined from the figure and copied to column 9 in Figure A4. These two values are used to determine the value of $B$ for each of the confining stresses applied. The values of $K_{b}$ and $m$ are determined from a logarithmic plot of normalized bulk modulus versus normalized confining stress, as shown in Figure A6.

Table A1 summarizes the values of the hyperbolic parameters $K, n, R_{f}$, $K_{b}$, and $m$ for dense Blacksburg Sand, as well as the values of $\phi_{o}$ and $\Delta \phi$ determined from the triaxial tests data, as described previously in this appendix. Parameter values obtained from the results of drained CD triaxial tests on a variety of soils are reported in Table 5 of Duncan et al. (1980). These values are reproduced in Section A.3.3.

\section{Table A1 \\ Hyperbolic Parameter Values for Dense Blacksburg Sand $\left(D_{r}=80 \%\right)$}

\begin{tabular}{||l|l|}
\hline \hline Parameter $^{1}$ & Value \\
\hline \hline$K$ & 642 \\
\hline$R_{f}$ & 0.25 \\
\hline$K_{b}$ & 0.55 \\
\hline$m$ & 567 \\
\hline$\phi_{o}$, deg & 0.01 \\
\hline$\Delta \phi$, deg & 43.4 \\
\hline \hline 1 Parameters are listed and defined in the notation (Appendix C). \\
\hline
\end{tabular}

As discussed in Chapter 2 of this report, the values of the hyperbolic parameters for dense Blacksburg Sand appear consistent with those reported by Duncan et al. (1980).

\section{A.3.2 Comparison of model to test data}

The stress-strain response from the model is calculated using the following expression: 


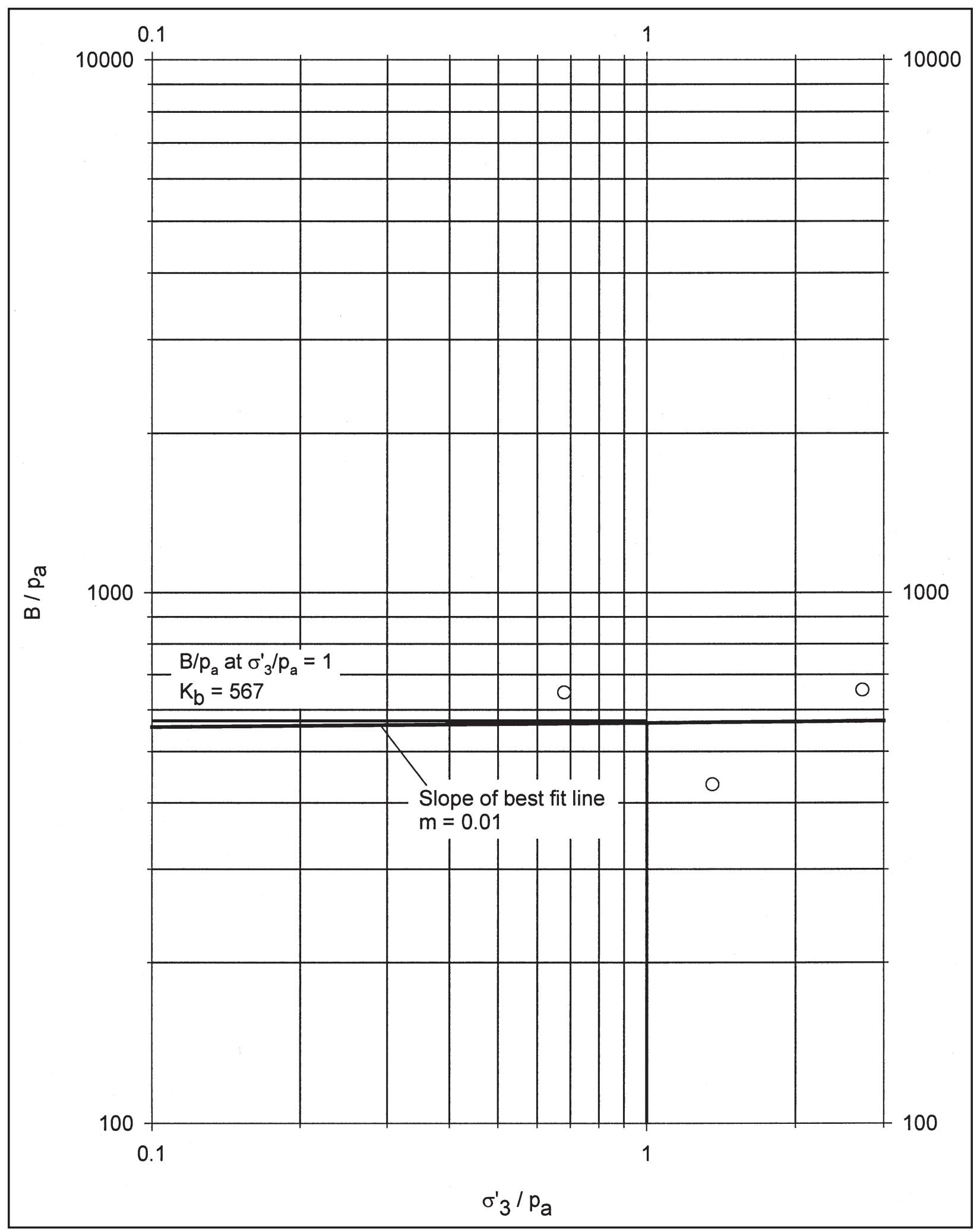

Figure A6. Determination of hyperbolic parameters $K_{b}$ and $m$ for dense Blacksburg Sand 


$$
\left(\sigma_{1}-\sigma_{3}\right)=\frac{\varepsilon}{K \cdot p_{a} \cdot\left(\frac{\sigma_{3}^{\prime}}{p_{a}}\right)^{n}+R_{f} \cdot \frac{\varepsilon}{\left(\sigma_{1}-\sigma_{3}\right)_{f}}}
$$

The deviator stress at failure $\left(\sigma_{1}-\sigma_{3}\right)_{f}$ is calculated from the following expression:

$$
\left(\sigma_{1}-\sigma_{3}\right)_{f}=2 \frac{\sigma_{3}^{\prime} \cdot \sin \phi}{1-\sin \phi}
$$

where $\phi$ can be determined from Equation A1.

The volumetric strain-axial strain response is calculated using the following expression:

$$
\varepsilon_{v}=\frac{\left(\sigma_{1}-\sigma_{3}\right)}{3 \cdot K_{b} \cdot p_{a} \cdot\left(\frac{\sigma_{3}^{\prime}}{p_{a}}\right)^{m}}
$$

The hyperbolic stress-strain and volumetric strain-axial strain response of dense Blacksburg Sand was calculated using Equations A2, A3, and A4 and the hyperbolic parameters determined following the procedure described previously. Figure A7 shows a comparison between the test data and the calculated hyperbolic response. In the figure, the stress-strain hyperbolas are interrupted at the value of deviator stress at failure $\left(\sigma_{1}-\sigma_{3}\right)$. A horizontal stress-strain relationship (i.e., zero Young's modulus) is used to model the response of the soil at failure.

It can be seen that the hyperbolic model provides an accurate approximation of the stress-strain response measured during the tests. The volumetric strain-axial strain response calculated using the hyperbolic model also provides a good approximation of the test data for the initial stages of shear, in which compression takes place. It does not model subsequent dilation of the soil. 


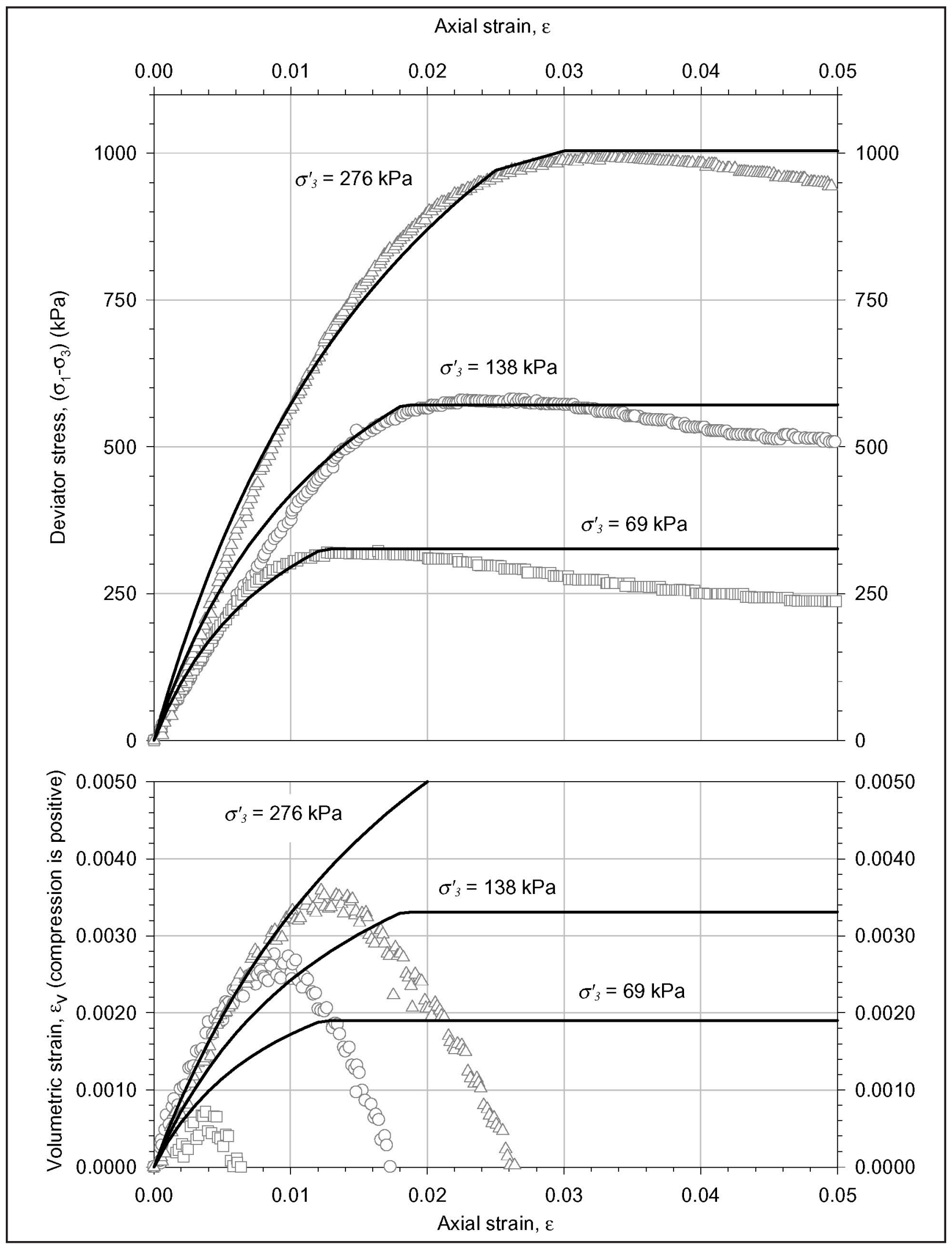

Figure A7. Hyperbolic model for dense Blacksburg Sand and comparison to CD test data 


\section{A.3.3 Selection of hyperbolic parameter values for soils under drained conditions}

A summary of property values for different types of soils tested under drained conditions is presented by Duncan et al. (1980). The summary is reproduced in Table A2. Additionally, Stark, Ebeling, and Vettel (1994) provide hyperbolic stress-strain parameters for freshly deposited, normally consolidated silts and clayey silts, which are reproduced in Tables A3 and A4. Note that the unit weight given in Tables A3 and A4 for the kaolinite-silt and montmorillonite-silt specimens is the dry unit weight,

$\gamma_{\text {dry }}$. The moist unit weight, $\gamma_{\text {moist }}$, is computed using $\gamma_{\text {moist }}=\gamma_{d r y}(1+w)$ where the water content, $w$, is specified as a fraction.

The data contained in this section are not intended to replace sitespecific testing on high-quality soil specimens, but are for use as interim guidance prior to the availability of laboratory test results. The data in Tables A2 through A4 can be used as an aid for selecting hyperbolic parameter values for analysis when test results are not available.

Average hyperbolic parameter values for coarse soils were determined from the data in Table A2 and are presented in Table A5. The table also indicates the number of data points from Table A2 that were used for the determination of the average values for each soil type. To provide an idea of the variability of hyperbolic parameter values, the standard deviation is also indicated in parentheses after the average value for each of the parameters.

Based on the data reproduced in Table A2, Duncan et al. (1980) presented a conservative interpretation of parameter values for various types of soils at different degrees of compaction relative to Standard Proctor. These values are reproduced in Table A6. The original 1980 version of the table provides modulus and strength values that are relatively low, and unit weights (single value) that are relatively high for the types of materials listed. Consequently, the use of these values in finite element analyses may tend to provide conservative (large) deformation values. This table was updated by Idriss and Duncan (1988) to include ranges of unit weights, and these ranges are also listed in Table A6.

Table A7 provides ranges of hyperbolic parameter values for coarse soils. These ranges are based on the data presented in Table A2, combined with the judgment and experience of the authors of this report. In the interim and until data from laboratory tests are available, Table A7 may be used as a starting point for selecting soil property values for soil-structure interaction analyses. However, it is recommended that the analyst also refer directly to Table A2 when selecting property values because factors such as mineralogy, angularity, etc., which are not reflected in Table A7, can influence soil behavior. Further, the purposes of the analyses and the nature of the applied loading should be considered when selecting property values. One of the best procedures, when feasible, is to calibrate property values and analysis procedures with observed performance. 


\begin{tabular}{|c|c|c|c|c|c|c|c|c|}
\hline \multicolumn{9}{|c|}{$\begin{array}{l}\text { Table A2 } \\
\text { Stress-Strain and Strength Parameters for Soils Tested Under Drained Conditions (After } \\
\text { Table 5, Duncan et al. 1980) }\end{array}$} \\
\hline \multirow{2}{*}{$\begin{array}{l}\text { Row } \\
\text { No. }\end{array}$} & \multirow[b]{2}{*}{ Soil } & \multirow[b]{2}{*}{ Group } & \multirow[b]{2}{*}{ Soil Description [Reference] $^{1}$} & \multicolumn{3}{|c|}{ Grain Size $(\mathrm{mm})$} & \multirow[b]{2}{*}{ LL } & \multirow[b]{2}{*}{$\mathbf{P I}$} \\
\hline & & & & D60 & D30 & D10 & & \\
\hline 1 & GW & GW-1 & Conglomerate Rockfill (Netzahu. Dam) [16] & 47. & 7.5 & 0.9 & & \\
\hline 2 & GW & GW-2 & Granitic Gneiss Rockfill (Mica Dam) $[5,15]$ & 79. & 24. & 4. & & \\
\hline 3 & GW & GW-3 & Quartzite Rockfill (Furnas Dam Shell) [5] & 10. & -- & -- & & \\
\hline 4 & GW & GW-4 & Quartzite Rockfill (Furnas Dam Transition) [5] & 25. & & & & \\
\hline 5 & GW & GW-5 & Furnas Dam Transition [5] & 10. & & & & \\
\hline 6 & GW & GW-6 & Pinzandapan Gravel [16] & 21. & 2.7 & 0.25 & & \\
\hline 7 & GW & GW-7 & Diorite Rockfill (El Infiernillo Dam) [16] & 93. & 42. & 17. & & \\
\hline 8 & GP & GP-2 & Sandy Gravel (Mica Dam Shell) [5] & 22. & 1.2 & 0.23 & & \\
\hline 9 & GP & GP-3 & Basalt Rockfill $[5,15]$ & 19. & 3.6 & 1. & & \\
\hline 10 & GP & GP-6 & Silty Sandy Gravel (Oroville Dam) [9] & 18. & 4.8 & 0.4 & 21 & 3 \\
\hline 11 & GP & GP-7 & Amphibolite Gravel (Oroville Dam Shell) [14] & 13.2 & 4.6 & 0.36 & & \\
\hline 12 & GP & GP-11 & Crushed Basaltic Rock (Round Butte Dam) [17] & 15. & 12. & 6. & & \\
\hline 13 & GP & GP-13 & Sandy Gravel (Rowallan Dam) [4] & 10. & 3. & 0.6 & & \\
\hline 14 & GC & GC-1 & Clayey Gravel (New Hogan Dam Core) [2] & 12. & 0.6 & -- & 51 & 30 \\
\hline 15 & sw & SW-1 & Argillite Rockfill (Pyramid Dam Shell) [14] & 4.1 & 1.8 & 0.6 & & \\
\hline 16 & sw & SW-2 & Crushed Olivine Basalt [14] & 4.1 & 1.8 & 0.6 & & \\
\hline 17 & sw & SW-3 & Silty Sand, Some Gravel (Round Butte Dam) [17] & 1.7 & 0.09 & 0.009 & NP & NP \\
\hline 18 & sw & SW-5 & Venato Sandstone (0.5 in. max. size) [1] & 0.17 & 0.07 & 0.025 & NP & NP \\
\hline 19 & $\mathrm{SP}$ & SP-3 & Glacial Cutwash Sand [10] & 0.03 & 0.4 & 0.14 & & \\
\hline 20 & $\mathrm{SP}$ & SP-4A & Sacramento River Sand [13] & 0.22 & 0.17 & 0.15 & & \\
\hline 21 & $\mathrm{SP}$ & SP-4B & Sacramento River Sand [13] & 0.22 & 0.17 & 0.15 & & \\
\hline 22 & $\mathrm{SP}$ & $\mathrm{SP}-4 \mathrm{C}$ & Sacramento River Sand [13] & 0.22 & 0.17 & 0.15 & & \\
\hline 23 & SP & $S P-4 D$ & Sacramento River Sand [13] & 0.22 & 0.17 & 0.15 & & \\
\hline 24 & $\mathrm{SP}$ & SP-5A & Ham River Sand [3] & 0.25 & 0.17 & 0.15 & & \\
\hline 25 & $\mathrm{SP}$ & SP-5B & Ham River Sand [3] & 0.25 & 0.17 & 0.15 & & \\
\hline 26 & $\mathrm{SP}$ & SP-7A & Poorly Graded Sand (Port Allen Lock) [20] & 0.2 & 0.17 & 0.12 & NP & NP \\
\hline 27 & $\mathrm{SP}$ & SP-7B & Poorly Graded Sand (Port Allen Lock) [20] & 0.2 & 0.17 & 0.12 & NP & NP \\
\hline 28 & $\mathrm{SP}$ & SP-7C & Poorly Graded Sand (Port Allen Lock) [20] & 0.2 & 0.17 & 0.12 & NP & $\mathrm{NP}$ \\
\hline & & & & & & & She & of 7 \\
\hline
\end{tabular}




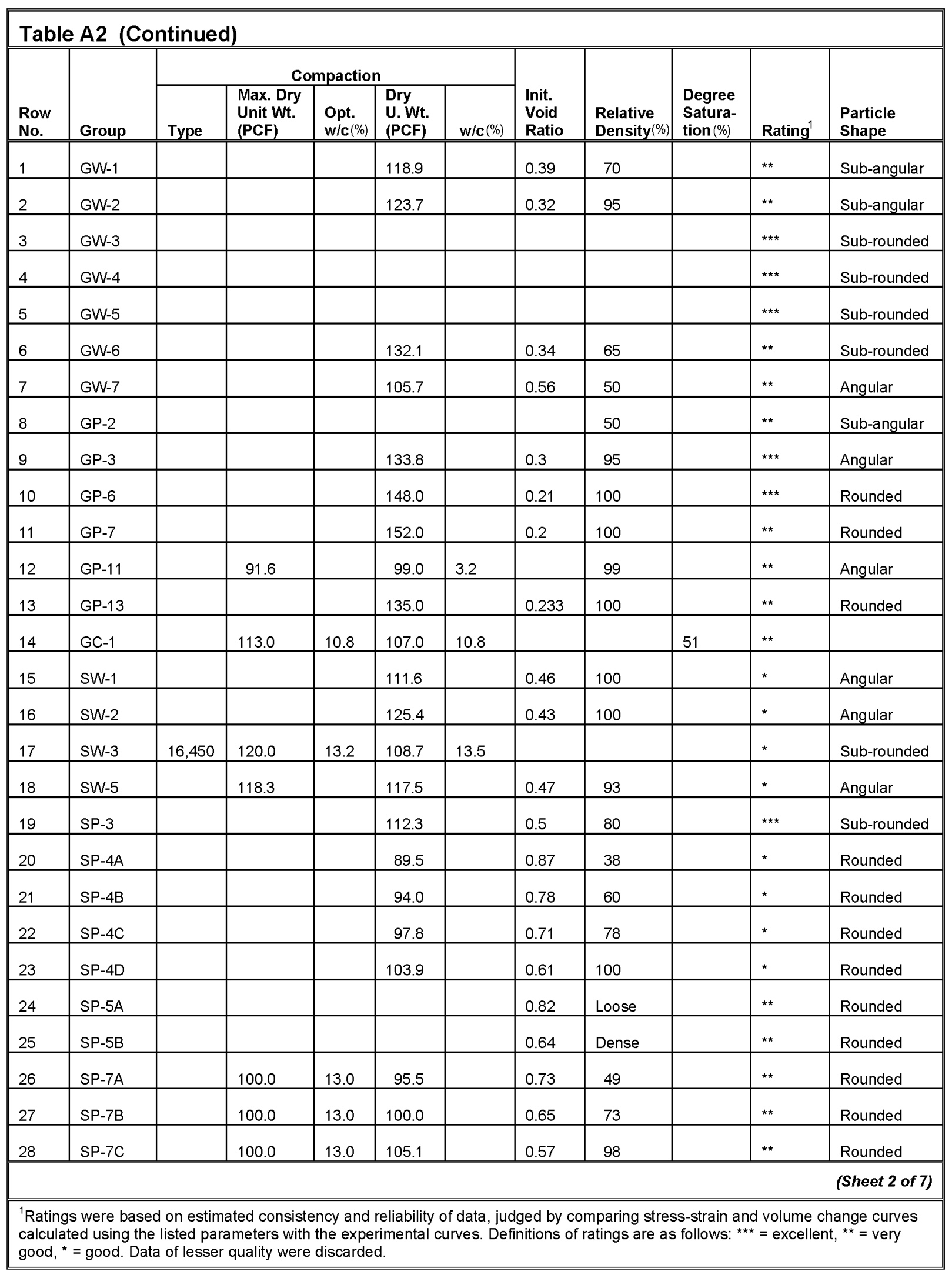

Appendix A Results of Triaxial and Consolidation Tests and Determination of Hyperbolic Parameter Values 


\begin{tabular}{|c|c|c|c|c|c|c|c|c|c|c|}
\hline $\begin{array}{l}\text { Row } \\
\text { No. }\end{array}$ & Group & $\begin{array}{l}\text { Stress } \\
\text { Range } \\
\text { (TSF) } \\
\end{array}$ & $\begin{array}{l}\text { No. } \\
\text { Tests } \\
\end{array}$ & $C$ (TSF) & $\begin{array}{c}\text { Friction } \\
\text { Angle } \\
\text { (deg) } \\
\end{array}$ & $\mathrm{K}$ & $\mathrm{n}$ & $\mathbf{R}_{\mathrm{f}}$ & $\mathbf{K}_{\mathrm{b}}$ & $\mathbf{m}$ \\
\hline 1 & GW-1 & $1.9-25.5$ & 3 & 0 & $50(10)$ & 540 & 0.43 & 0.64 & 135 & 0.34 \\
\hline 2 & GW-2 & $5.1-25.6$ & 3 & 0 & $44(9)$ & 210 & 0.51 & 0.64 & 100 & 0.34 \\
\hline 3 & GW-3 & $4.1-36.9$ & 4 & 0 & $49(6)$ & 560 & 0.48 & 0.65 & 330 & 0.33 \\
\hline 4 & GW-4 & $4.1-36.9$ & 4 & 0 & $53(7)$ & 950 & 0.52 & 0.59 & 470 & 0.52 \\
\hline 5 & GW-5 & $4.1-36.9$ & 4 & 0 & $50(7)$ & 690 & 0.57 & 0.51 & 360 & 0.57 \\
\hline 6 & GW-6 & $0.4-26.5$ & 6 & 0 & $51(9)$ & 690 & 0.45 & 0.59 & 170 & 0.22 \\
\hline 7 & GW-7 & $0.4-17.0$ & 7 & 0 & $46(9)$ & 340 & 0.28 & 0.71 & 52 & 0.18 \\
\hline 8 & GP-2 & $7.2-32.5$ & 3 & 0 & $41(3)$ & 420 & 0.50 & 0.78 & 125 & 0.46 \\
\hline 9 & GP-3 & $5.1-25.6$ & 3 & 0 & $52(10)$ & 450 & 0.37 & 0.61 & 255 & 0.18 \\
\hline 10 & GP-6 & $9.0-46.8$ & 4 & 0 & $53(8)$ & 1300 & 0.40 & 0.72 & 900 & 0.22 \\
\hline 11 & GP-7 & $2.2-28.6$ & 4 & 0 & $51(6)$ & 1780 & 0.39 & 0.67 & 1300 & 0.16 \\
\hline 12 & GP-11 & $2.0-14.1$ & 3 & 0 & $51(14)$ & 410 & 0.21 & 0.71 & 195 & 0 \\
\hline 13 & GP-13 & $1.8-10.8$ & 4 & 0 & $58(10)$ & 2500 & 0.21 & 0.75 & 1400 & 0 \\
\hline 14 & GC-1 & $1.1-4.3$ & 3 & 0.28 & 19 & 99 & 0.70 & 0.86 & 45 & 0 \\
\hline 15 & sW-1 & $2.2-46.8$ & 4 & 0 & $53(9)$ & 1600 & 0.08 & 0.72 & 600 & 0 \\
\hline 16 & sW-2 & $2.2-46.8$ & 4 & 0 & $55(10)$ & 1000 & 0.22 & 0.70 & 390 & 0.14 \\
\hline 17 & sW-3 & $2.0-14.0$ & 3 & 0 & $38(3)$ & 260 & 0.50 & 0.76 & 100 & 0.5 \\
\hline 18 & SW-5 & $2.2-28.6$ & 4 & 0 & $43(4)$ & 330 & 0.46 & 0.51 & 110 & 0.46 \\
\hline 19 & SP-3 & 1.0-41.1 & 6 & 0 & $44(4)$ & 190 & 0.70 & 0.57 & 190 & 0.35 \\
\hline 20 & SP-4A & $1.0-41.1$ & 8 & 0 & $35(2)$ & 430 & 0.27 & 0.84 & 230 & 0.02 \\
\hline 21 & SP-4B & $1.0-13.0$ & 4 & 0 & $37(2)$ & 410 & 0.69 & 0.90 & 260 & 0.15 \\
\hline 22 & SP-4C & 1.0-41.1 & 8 & 0 & $41(5)$ & 1100 & 0.36 & 0.85 & 900 & 0 \\
\hline 23 & SP-4D & $3.0-41.1$ & 6 & 0 & $45(7)$ & 1200 & 0.48 & 0.85 & 1500 & 0 \\
\hline 24 & SP-5A & $7.2-287.9$ & 4 & 0 & $31(2)$ & 890 & 0.26 & 0.78 & 360 & 0.11 \\
\hline 25 & SP-5B & 7.2-71.3 & 3 & 0 & $47(9)$ & 1100 & 0.57 & 0.86 & 2250 & 0 \\
\hline 26 & SP-7A & $0.9-3.9$ & 3 & 0 & $39(0)$ & 410 & 0.65 & 0.84 & & \\
\hline 27 & SP-7B & $0.9-3.9$ & 3 & 0 & $40(1)$ & 400 & 0.49 & 0.77 & & \\
\hline 28 & SP-7C & $0.9-3.9$ & 3 & 0 & $44(3)$ & 750 & 0.77 & 0.83 & & \\
\hline
\end{tabular}




\begin{tabular}{|c|c|c|c|c|c|c|c|c|}
\hline \multirow{2}{*}{$\begin{array}{l}\text { Row } \\
\text { No. } \\
\end{array}$} & \multirow[b]{2}{*}{ Soil } & \multirow[b]{2}{*}{ Group } & \multirow[b]{2}{*}{ Soil Description [Reference] ${ }^{1}$} & \multicolumn{3}{|c|}{ Grain Size $(\mathrm{mm})$} & \multirow[b]{2}{*}{ LL } & \multirow[b]{2}{*}{ PI } \\
\hline & & & & D60 & D30 & D10 & & \\
\hline 29 & $\mathrm{SP}$ & SP-12 & Coarse to Fine Sand (Round Butte Dam) [17] & \multicolumn{3}{|c|}{ minus No. 4 sieve } & NP & NP \\
\hline 30 & $\mathrm{SP}$ & $\mathrm{SP}-13$ & Pumicecus Sand (Round Butte Dam) [17] & 0.85 & 0.41 & 0.24 & & \\
\hline 31 & $\mathrm{SP}$ & SP-14 & Pumicecus Sand (Round Butte Dam) [19] & 1.0 & 0.5 & 0.24 & & \\
\hline 32 & $\mathrm{SP}$ & SP-16A & Fine Silica Sand (Loose) [8] & 0.27 & 0.2 & 0.165 & & \\
\hline 33 & $\mathrm{SP}$ & SP-16B & Fine Silica Sand (Dense) [8] & 0.27 & 0.2 & 0.165 & & \\
\hline 34 & $\mathrm{SP}$ & SP-17A & Monterey No. O Sand (Cylind. specimen) [12] & 0.43 & 0.37 & 0.29 & $\mathrm{NP}$ & NP \\
\hline 35 & $\mathrm{SP}$ & SP-17B & Monterey No. O Sand (Cubical specimen) [12] & 0.43 & 0.37 & 0.29 & NP & NP \\
\hline 36 & $\mathrm{SP}$ & SP-17C & Monterey No. O Sand (Cylind. specimen) [12] & 0.43 & 0.37 & 0.29 & NP & NP \\
\hline 37 & $\mathrm{SP}$ & SP-17D & Monterey No. O Sand (Cubical specimen) [12] & 0.43 & 0.37 & 0.29 & NP & NP \\
\hline 38 & $\mathrm{SP}$ & $\mathrm{SP}-18$ & Basaltic Sand (Round Butte Dam) [18] & 3. & 9. & 0.13 & & \\
\hline 39 & SM & SM-4 & Silty Sand (Chatfield Dam) [21] & 0.62 & 0.16 & 0.026 & 20 & 0 \\
\hline 40 & SM & SM-5 & Silty Gravelly Sand (Chatfield Dam) [21] & 1.15 & 0.28 & 0.05 & NP & NP \\
\hline 41 & SM & SM-6 & Silty Sand w/Pebbles (Round Butte Dam) [17] & 0.31 & 0.1 & 0.04 & NP & NP \\
\hline 42 & SM & SM-9 & Silty Sand w/Pumice (Round Butte Dam) [17] & 0.15 & 0.054 & 0.013 & NP & NP \\
\hline 43 & SM & SM-13 & Silty Sand (Round Butte Dam) [19] & 0.27 & 0.027 & 0.0022 & & \\
\hline 44 & SM & SM-16 & Silty Sand and Gravel (Round Butte Dam) [18] & 0.45 & 0.052 & 0.012 & & \\
\hline 45 & SM-SC & SM-SC-1A & Silty Clayey Sand (Mica Dam Core) $[5,11]$ & 0.34 & 0.03 & 0.002 & 21 & 4 \\
\hline 46 & SM-SC & SM-SC-1B & Silty Clayey Sand (Mica Dam Core) $[5,11]$ & 0.34 & 0.03 & 0.002 & 21 & 4 \\
\hline 47 & SM-SC & SM-SC-1C & Silty Clayey Sand (Mica Dam Core) $[5,11]$ & 0.34 & 0.03 & 0.0002 & 21 & 4 \\
\hline 48 & $\mathrm{ML}$ & $\mathrm{ML}-1$ & Cannonsville Silt (Undisturbed) [10] & 0.033 & 0.018 & 0.005 & & \\
\hline 49 & $\mathrm{ML}$ & $\mathrm{ML}-4$ & Sandy Silty w/Pumice (Round Butte Dam) [17] & 0.078 & 0.032 & 0.0064 & NP & NP \\
\hline 50 & $\mathrm{ML}$ & ML-5 & Sandy Silty w/Pumice (Round Butte Dam) [17] & 0.1 & 0.025 & 0.0052 & NP & NP \\
\hline 51 & $\mathrm{CL}$ & CL-29C & Silty Clay (Canyon Dam) [7] & 0.037 & 0.008 & -- & 34 & 19 \\
\hline 52 & $\mathrm{CL}$ & CL-29D & Silty Clay (Canyon Dam) [7] & 0.037 & 0.008 & -- & 34 & 19 \\
\hline 53 & $\mathrm{CL}$ & CL-30E & Silty Clay (Canyon Dam) [7] & 0.037 & 0.008 & -- & 34 & 19 \\
\hline 54 & $\mathrm{CL}$ & CL-30F & Silty Clay (Canyon Dam) [7] & 0.037 & 0.008 & -- & 34 & 19 \\
\hline 55 & $\mathrm{CL}$ & CL-34E & Silty Clay (Canyon Dam) [6] & 0.037 & 0.008 & -- & 34 & 19 \\
\hline & & & & & & & Shee & of 7 \\
\hline
\end{tabular}




\begin{tabular}{|c|c|c|c|c|c|c|c|c|c|c|c|}
\hline \multirow[b]{2}{*}{$\begin{array}{l}\text { Row } \\
\text { No. }\end{array}$} & \multirow[b]{2}{*}{ Group } & \multicolumn{5}{|c|}{ Compaction } & \multirow[b]{2}{*}{$\begin{array}{l}\text { Init. } \\
\text { Void } \\
\text { Ratio } \\
\end{array}$} & \multirow[b]{2}{*}{$\begin{array}{l}\text { Relative } \\
\text { Density } \\
\text { (\%) }\end{array}$} & \multirow[b]{2}{*}{\begin{tabular}{|l|} 
Degree \\
Saturation \\
$(\%)$
\end{tabular}} & \multirow[b]{2}{*}{ Rating $^{1}$} & \multirow[b]{2}{*}{$\begin{array}{l}\text { Particle } \\
\text { Shape }\end{array}$} \\
\hline & & Type & $\begin{array}{l}\text { Max. Dry } \\
\text { Unit Wt. } \\
\text { (PCF) }\end{array}$ & $\begin{array}{l}\text { Opt. } \\
\text { w/c } \\
(\%) \\
\end{array}$ & $\begin{array}{l}\text { Dry } \\
\text { U. Wt. } \\
\text { (PCF) } \\
\end{array}$ & $\begin{array}{l}\text { w/c } \\
(\%)\end{array}$ & & & & & \\
\hline 29 & SP-12 & & & & 74.8 & & 1.22 & 70 & & ** & Angular \\
\hline 30 & SP-13 & & 87.4 & & 84.2 & 18.0 & & 77 & & * & Angular \\
\hline 31 & SP-14 & & 80.7 & & 76.9 & 25.0 & & 71 & & * & Angular \\
\hline 32 & SP-16A & & & & & & 0.65 & 38 & & $\star \star * *$ & Rounded \\
\hline 33 & SP-16B & & & & & & 0.54 & 100 & & $\star \star \star \star ~$ & Rounded \\
\hline 34 & SP-17A & & & & & & 0.78 & 27 & & 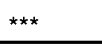 & Rounded \\
\hline 35 & SP-17B & & & & & & 0.78 & 27 & & $\star \star$ & Rounded \\
\hline 36 & SP-17C & & & & & & 0.57 & 98 & & $* * *$ & Rounded \\
\hline 37 & SP-17D & & & & & & 0.57 & 98 & & ** & Rounded \\
\hline 38 & SP-18 & & 120.1 & 9.5 & 120.0 & 9.5 & & & & ** & Angular \\
\hline 39 & SM-4 & Std.AASHO & 123.0 & 9.5 & 116.7 & 9.4 & & & & $\star \star$ & Sub-rounded \\
\hline 40 & SM-5 & Std.AASHO & 132.0 & 8.1 & 124.5 & 7.53 & & & & * & Sub-rounded \\
\hline 41 & SM-6 & 16,450 & 110.6 & 17.5 & 108.1 & 17.5 & & & & *** & Angular \\
\hline 42 & SM-9 & 16,450 & 91.7 & 19.5 & 88.4 & 19.0 & & & & ** & Angular \\
\hline 43 & SM-13 & & 105.6 & 16.4 & 104.5 & 15.0 & & & & * & Sub-angular \\
\hline 44 & SM-16 & & 109.3 & 12.9 & 109.0 & 12.0 & & & & $\star \star$ & Sub-angular \\
\hline 45 & SM-SC-1A & Std.AASHO & 136.0 & 9.8 & 131.1 & 7.7 & & & & ** & \\
\hline 46 & SM-SC-1B & Std.AASHO & 136.0 & 9.8 & 134.0 & 9.7 & & & & $\star \star *$ & \\
\hline 47 & SM-SC-1C & Std.AASHO & 136.0 & 9.8 & 128.2 & 11.9 & & & & $* * *$ & \\
\hline 48 & ML-1 & & & & 108.0 & & 0.57 & & & * & \\
\hline 49 & $\mathrm{ML}-4$ & 16,450 & 97.0 & 19.0 & 92.8 & 17.7 & & & & * & \\
\hline 50 & ML-5 & 16,450 & 102.5 & 16.5 & 99.2 & 17.0 & & & & $\star \star$ & \\
\hline 51 & CL-29C & Harvard & 116.2 & 15.2 & 111.2 & 13.1 & & & 69 & ** & \\
\hline 52 & CL-29D & Harvard & 116.2 & 15.2 & 116.2 & 13.3 & & & 79 & ** & \\
\hline 53 & CL-30E & Harvard & 112.8 & 16.7 & 115.1 & 15.2 & & & 88 & ** & \\
\hline 54 & CL-30F & Harvard & 112.8 & 16.7 & 110.0 & 17.4 & & & 88 & ** & \\
\hline 55 & CL-34E & Harvard & 105.6 & 19.8 & 106.3 & 19.0 & & & 87 & * & \\
\hline & & & & & & & & & & & (Sheet 5 of 7) \\
\hline $\begin{array}{l}{ }^{1} \mathrm{Rat} \\
\text { calc } \\
\text { goo }\end{array}$ & $\begin{array}{l}\text { were bas } \\
\text { d using th }\end{array}$ & $\begin{array}{l}\text { n estimated } \\
\text { ted parame }\end{array}$ & $\begin{array}{l}\text { sistency } \\
\text { with the }\end{array}$ & d relial & $\begin{array}{l}\text { ity of da } \\
\text { al curve }\end{array}$ & $\begin{array}{l}\text {, judgec } \\
\text { Definiti }\end{array}$ & by con & $\begin{array}{l}\text { ring stre } \\
\text { as are a }\end{array}$ & $\begin{array}{l}\text { ss-strain anc } \\
\text { follows: }{ }^{* \star *}\end{array}$ & $\begin{array}{l}\text { volume } \\
=\text { excell }\end{array}$ & $\begin{array}{l}\text { lange curves } \\
t,{ }^{* \star}=\text { very }\end{array}$ \\
\hline
\end{tabular}




\begin{tabular}{|c|c|c|c|c|c|c|c|c|c|c|}
\hline $\begin{array}{l}\text { Row } \\
\text { No. }\end{array}$ & Group & $\begin{array}{l}\text { Stress } \\
\text { Range } \\
\text { (TSF) } \\
\end{array}$ & $\begin{array}{l}\text { No. } \\
\text { Tests }\end{array}$ & C (TSF) & $\begin{array}{l}\text { Friction } \\
\text { Angle } \\
\text { (deg) }\end{array}$ & $\mathbf{K}$ & $\mathbf{n}$ & $\mathbf{R}_{\mathrm{f}}$ & $\mathbf{K}_{\mathrm{b}}$ & $\mathrm{m}$ \\
\hline 29 & $\mathrm{SP}-12$ & $2.0-14.0$ & 3 & 0 & $39(6)$ & 280 & 0.37 & 0.71 & 95 & 0.21 \\
\hline 30 & SP-13 & $2.0-14.1$ & 3 & 0 & $48(10)$ & 340 & 0.45 & 0.70 & 230 & 0.06 \\
\hline 31 & SP-14 & 2.0-14.1 & 3 & 0 & $49(12)$ & 650 & 0.38 & 0.77 & 380 & 0.05 \\
\hline 32 & SP-16A & $1.0-5.1$ & 3 & 0 & $30(0)$ & 280 & 0.65 & 0.93 & 110 & 0.65 \\
\hline 33 & SP-16B & $1.0-5.1$ & 3 & 0 & $37(0)$ & 1400 & 0.74 & 0.90 & 1080 & 0.15 \\
\hline 34 & SP-17A & $0.3-1.2$ & 3 & 0 & $35(0)$ & 920 & 0.79 & 0.96 & 465 & 0.32 \\
\hline 35 & SP-17B & $0.3-1.2$ & 3 & 0 & $39(0)$ & 510 & 0.51 & 0.97 & 370 & 0.22 \\
\hline 36 & SP-17C & $0.3-1.2$ & 3 & 0 & $45(3)$ & 3200 & 0.78 & 0.92 & 1400 & 0.45 \\
\hline 37 & SP-17D & $0.3-1.2$ & 3 & 0 & $47(5)$ & 1500 & 0.76 & 0.91 & 1100 & 0.52 \\
\hline 38 & SP-18 & $2.0-14.0$ & 3 & 0 & $39(13)$ & 1600 & 0.08 & 0.63 & 750 & 0 \\
\hline 39 & SM-4 & $6.0-10.0$ & 3 & 0 & $37(0)$ & 100 & 1.07 & 0.62 & & \\
\hline 40 & SM-5 & $6.0-10.0$ & 3 & 0 & $41(0)$ & 530 & 0.51 & 0.62 & 640 & 0 \\
\hline 41 & SM-6 & $2.0-14.0$ & 3 & 0 & $46(8)$ & 700 & 0.35 & 0.75 & & \\
\hline 42 & SM-9 & $2.0-13.7$ & 3 & 0 & $43(8)$ & 670 & 0.25 & 0.72 & 500 & 0 \\
\hline 43 & SM-13 & 2.0-14.1 & 3 & 0 & $36(5)$ & 530 & 0.28 & 0.74 & 470 & 0 \\
\hline 44 & SM-16 & $2.0-14.0$ & 3 & 0 & $36(11)$ & 800 & 0.20 & 0.67 & 600 & 0 \\
\hline 45 & SM-SC-1A & 3.6-32.4 & 6 & 0.31 & 33 & 700 & 0.37 & 0.80 & 280 & 0.19 \\
\hline 46 & SM-SC-1B & $3.6-18.0$ & 4 & 0.85 & 34 & 425 & 0.58 & 0.70 & 205 & 0.44 \\
\hline 47 & SM-SC-1C & 3.6-32.4 & 6 & 0.40 & 34 & 160 & 0.81 & 0.63 & 65 & 0.81 \\
\hline 48 & $\mathrm{ML}-1$ & $1.5-7.4$ & 4 & 0 & $45(6)$ & 200 & 1.07 & 0.57 & 200 & 0.89 \\
\hline 49 & $\mathrm{ML}-4$ & $2.0-13.9$ & 2 & 0 & $42(7)$ & 500 & 0.45 & 0.82 & 400 & 0 \\
\hline 50 & ML-5 & $2.0-13.9$ & 3 & 0 & $36(1)$ & 530 & 0.35 & 0.71 & 520 & 0.23 \\
\hline 51 & $C L-29 C$ & 1.0-8.2 & 4 & 0.17 & 30 & 550 & -0.05 & 0.82 & & \\
\hline 52 & CL-29D & $1.0-8.2$ & 4 & 0.59 & 29 & 690 & 0.10 & 0.71 & & \\
\hline 53 & CL-30E & $1.0-8.2$ & 4 & 0.51 & 33 & 150 & 0.62 & 0.61 & 360 & 0 \\
\hline 54 & CL-30F & $1.0-4.0$ & 4 & 0.39 & 30 & 160 & 0.50 & 0.63 & 210 & 0 \\
\hline 55 & CL-34E & $0.5-8.0$ & 5 & 0.26 & 31 & 130 & 0.59 & 0.72 & 45 & 0.59 \\
\hline \multicolumn{11}{|c|}{ (Sheet 6 of 7 ) } \\
\hline
\end{tabular}




\section{Table A2 (Concluded)}

[1] Becker, E., Chan, C. K., and Seed, H. Bolton. (1972). "Strength and deformation characteristics of rockfill materials in plane strain and triaxial compression tests," Report TE-72-3, Office of Research Services, University of California, Berkeley.

[2] Bird, J. M. (1961). "Uncertainties in earth dam design," Journal of the Soil Mechanics and Foundations Division, ASCE 87(SM3), 33-68.

[3] Bishop, A. W. (1966). "The strength of soils as engineering materials," Geotechnique 16(2), 89-130.

[4] Broughton, N. O. (1970). "Elastic analysis for behavior of rockfill," Journal of the Soil Mechanics and Foundations Division, ASCE (Sep), 1715-33.

[5] Casagrande, A. (1965). "Hohe staudamme," No. 6 (Dec), Mitteilungen des Institutes fur Grundbau und Bodenmechanik, Technische Hochschule, Vienna.

[6] Casagrande, A., and Hirschfeld, R. C. (1962). "Second progress report on investigation of stress-deformation and strength characteristics of compacted clays," Soil Mechanics Series No. 65 (Apr), Harvard University, Cambridge, MA.

[7] Casagrande, A., Hirschfeld, R. C., and Poulos, S. J. (1963). "Third progress report on investigation of stress-deformation and strength characteristics of compacted clays," Soil Mechanics Series No. 70 (Nov), Harvard University, Cambridge, MA.

[8] Duncan, J. M., and Change, C.-Y. (1970). "Nonlinear analysis of stress and strain in soils," Journal of the Soil Mechanics and Foundations Division, ASCE 96(SM5, Sep).

[9] Hall, E. B., and Gordon, B. B. (1963). "Triaxial testing with large-scale high pressure equipment," STP 361-Laboratory shear testing of soils, American Society for Testing and Materials, West Conshohocken, PA, 315-28.

[10] Hirschfeld, R. C., and Poulos, S. J. (1963). "High-pressure triaxial tests on a compacted sand and an undisturbed silt," STP 361-Laboratory shear testing of soils, American Society for Testing and Materials, West Conshohocken, PA, 329-39.

[11] Insley, A. E., and Hillis, S. T. (1965). "Triaxial shear characteristics of a compacted glacial till under unusually high confining pressures," Proceedings, 6th international conference on soil mechanics and foundation engineering, Vol 1, Montreal, Canada, 244-48.

[12] Lade, P. (1971). "The stress-strain and strength characteristics of cohesionless soils," Ph.D. diss., University of California Berkeley.

[13] Lee, K. L. (1965). "Triaxial compressive strength of saturated sand under seismic loading conditions," Ph.D. diss., University of California, Berkeley.

[14] Marachi, N. (1969). "Strength and deformation characteristics of rockfill materials," Ph.D. diss., University of California, Berkeley.

[15] Marsal, R. J. (1967). "Large scale testing of rockfill materials," Journal of the Soil Mechanics and Foundations Division, ASCE 93(SM2, Mar), 27-43.

[16] Marsal, R. J., Gomez, E. M., Nunez, A., Cuellar, R., and Ramos, R. M. (1965, Feb). "Research on the behavior of granular materials and rockfill samples," Mission Federal de Electricidad, Mexico, D.F.

[17] Shannon and Wilson Soil Mechanics and Foundation Engineers. (1961, Jul). "Report on soil tests: Round Butte Dam project," Seattle, WA.

[18] ___ (1963). "Report on construction control and record tests for Round Butte Dam," Seattle, WA.

[19] _____ (1964). "Report on construction control and record tests for Round Butte Dam," Seattle, WA.

[20] Sherman, W. C., and Trahan, C. C. (1968). "Analysis of data from instrumentation program, Port Allen Lock," Technical Report S-68-7, U.S. Army Engineer Waterways Experiment Station, Vicksburg, MS

[21] U.S. Army Engineer District, Omaha. (1968). "Chatfield Dam and Reservoir: Design Memorandum No. PC-24," Omaha, NE. 


\section{Table A3 \\ Drained Hyperbolic Stress-Strain Parameters for Kaolinite-Silt Mixtures from Isotropically Consolidated Drained Triaxial Tests Listed in Table 3 of Stark, Ebeling, and Vettel (1994)}

\begin{tabular}{|c|c|c|c|c|c|c|c|c|c|c|c|}
\hline $\begin{array}{l}\text { Percent } \\
\text { clay } \\
\text { mineral }^{\mathrm{a}} \\
\text { (1) }\end{array}$ & $\begin{array}{l}\text { Standard } \\
\text { Proctor } \\
\text { relative } \\
\text { compaction } \\
(\%) \\
(2)\end{array}$ & $\begin{array}{l}\text { Average } \\
\text { initial } \\
\text { dry unit } \\
\text { weight } \\
\left(\mathrm{kN} / \mathrm{m}^{3}\right) \\
(3)\end{array}$ & $\begin{array}{l}\text { Average } \\
\text { initial } \\
\text { water } \\
\text { content } \\
\text { (percent) } \\
\text { (4) }\end{array}$ & $\begin{array}{l}\text { Range of } \\
\text { triaxial } \\
\text { consolidation } \\
\text { pressure } \\
(\mathrm{kPa}) \\
(5)\end{array}$ & $\begin{array}{l}\text { Effective } \\
\text { stress } \\
\text { cohesion } \\
(\mathrm{kPa}) \\
(6)\end{array}$ & $\begin{array}{l}\text { Effective } \\
\text { stress } \\
\text { friction } \\
\text { angle } \\
\text { (deg) } \\
\text { (7) }\end{array}$ & $\begin{array}{l}\text { Modulus } \\
\text { number } \\
K \\
(8)\end{array}$ & $\begin{array}{l}\text { Modulus } \\
\text { exponent } \\
n \\
(9)\end{array}$ & \begin{tabular}{|l|} 
Bulk \\
modulus \\
number \\
$K_{b}$ \\
$(10)$
\end{tabular} & \begin{tabular}{|l|} 
Bulk \\
modulus \\
exponent \\
$m$ \\
$(11)$
\end{tabular} & $\begin{array}{l}\text { Failure } \\
\text { ratio } \\
R_{f} \\
(12)\end{array}$ \\
\hline 0\% Kao & 100 & 15.4 & 27 & $1,120-1,740$ & 0 & 40 & 270 & 1.0 & 115 & 1.00 & 0.75 \\
\hline $0 \%$ Kao & 95 & 15.2 & 27 & $755-1,725$ & 0 & 37 & 150 & 1.0 & 65 & 1.00 & 0.70 \\
\hline $0 \%$ Kao & 90 & 15.1 & 28 & $765-1,585$ & 0 & 35 & 120 & 1.0 & 50 & 1.00 & 0.65 \\
\hline $0 \%$ Kao & 85 & $N / A^{b}$ & $\mathrm{~N} / \mathrm{A}$ & N/A & $\mathrm{N} / \mathrm{A}$ & N/A & $\mathrm{N} / \mathrm{A}$ & N/A & $\mathrm{N} / \mathrm{A}$ & N/A & $\mathrm{N} / \mathrm{A}$ \\
\hline $10 \%$ Kao & 100 & 16.3 & 23 & $940-1,630$ & 0 & 37 & 240 & 1.0 & 85 & 1.00 & 0.85 \\
\hline $10 \% \mathrm{Kao}$ & 95 & 16.2 & 23 & $1,120-1,665$ & 0 & 35 & 125 & 1.0 & 55 & 1.00 & 0.80 \\
\hline $10 \%$ Kao & 90 & 16.2 & 23 & $295-1,475$ & 0 & 34 & 100 & 1.0 & 40 & 1.00 & 0.75 \\
\hline $10 \%$ Kao & 85 & 16.0 & 24 & $300-1,390$ & 0 & 33 & 75 & 1.0 & 30 & 1.00 & 0.70 \\
\hline $30 \%$ Kao & 100 & 18.1 & 17 & $980-1,685$ & 0 & 33 & 105 & 1.0 & 35 & 1.00 & 0.80 \\
\hline $30 \%$ Kao & 95 & 18.1 & 17 & $795-1,485$ & 0 & 31 & 70 & 1.0 & 30 & 1.00 & 0.75 \\
\hline $30 \% \mathrm{Kao}$ & 90 & 17.9 & 17 & $395-1,520$ & 0 & 30 & 65 & 1.0 & 25 & 1.00 & 0.70 \\
\hline $30 \%$ Kao & 85 & 17.9 & 18 & $300-1,660$ & 0 & 29 & 60 & 1.0 & 20 & 1.00 & 0.65 \\
\hline $50 \%$ Kao & 100 & 17.4 & 18 & $880-1,670$ & 0 & 28 & 65 & 1.0 & 30 & 1.00 & 0.75 \\
\hline $50 \%$ Kao & 95 & 17.1 & 19 & $785-1,475$ & 0 & 27 & 60 & 1.0 & 25 & 1.00 & 0.70 \\
\hline $50 \%$ Kao & 90 & 17.0 & 20 & $390-1,275$ & 0 & 26 & 55 & 1.0 & 20 & 1.00 & 0.65 \\
\hline $50 \%$ Kao & 85 & 16.8 & 21 & $350-1,280$ & 0 & 25 & 50 & 1.0 & 15 & 1.00 & 0.60 \\
\hline
\end{tabular}


Table A4

Drained Hyperbolic Stress-Strain Parameters for Montmorillonite-Silt Mixtures from Isotropically Consolidated Drained Triaxial Tests Listed in Table 5 of Stark, Ebeling, and Vettel (1994)

\begin{tabular}{|c|c|c|c|c|c|c|c|c|c|c|c|}
\hline $\begin{array}{l}\text { Percent } \\
\text { clay } \\
\text { mineral }^{\mathrm{a}} \\
\text { (1) }\end{array}$ & \begin{tabular}{|l|} 
Standard \\
Proctor \\
relative \\
compaction \\
$(\%)$ \\
$(2)$
\end{tabular} & $\begin{array}{l}\text { Average } \\
\text { initial } \\
\text { dry unit } \\
\text { weight } \\
\left(\mathrm{kN} / \mathrm{m}^{3}\right) \\
(3)\end{array}$ & $\begin{array}{l}\text { Average } \\
\text { initial } \\
\text { water } \\
\text { content } \\
(\%) \\
(4)\end{array}$ & $\begin{array}{l}\text { Range of } \\
\text { triaxial } \\
\text { consolidation } \\
\text { pressure } \\
(\mathrm{kPa}) \\
(5)\end{array}$ & $\begin{array}{l}\text { Effective } \\
\text { stress } \\
\text { cohesion } \\
(\mathrm{kPa}) \\
(6)\end{array}$ & $\begin{array}{l}\text { Effective } \\
\text { stress } \\
\text { friction } \\
\text { angle } \\
\text { (deg) } \\
\text { (7) }\end{array}$ & \begin{tabular}{|l|} 
Modulus \\
number \\
$K$ \\
$(8)$
\end{tabular} & $\begin{array}{l}\text { Modulus } \\
\text { exponent } \\
n \\
(9)\end{array}$ & \begin{tabular}{|l|} 
Bulk \\
modulus \\
number \\
$K_{b}$ \\
$(10)$
\end{tabular} & \begin{tabular}{|l} 
Bulk \\
modulus \\
exponent \\
$m$ \\
$(11)$
\end{tabular} & $\begin{array}{l}\text { Failure } \\
\text { ratio } \\
R_{f} \\
(12)\end{array}$ \\
\hline $0 \%$ Mont & 100 & 15.4 & 27 & $200-1,640$ & 0 & 40 & 270 & 1.0 & 115 & 1.0 & 0.75 \\
\hline $\begin{array}{l}10 \% \\
\text { Mont }\end{array}$ & 100 & 16.0 & 24 & $1,080-1,620$ & 0 & 35 & 90 & 1.0 & 50 & 1.0 & 0.75 \\
\hline $\begin{array}{l}30 \% \\
\text { Mont }\end{array}$ & 100 & 15.7 & 26 & $990-1,620$ & 0 & 20 & 55 & 1.0 & 20 & 1.0 & 0.75 \\
\hline $\begin{array}{l}50 \% \\
\text { Mont }\end{array}$ & 100 & 14.8 & 30 & $840-1,485$ & 0 & 14 & 35 & 1.0 & 15 & 1.0 & 0.75 \\
\hline
\end{tabular}

\section{Table A5}

Average Property Values of Coarse and Fine Soils in Drained Condition

\begin{tabular}{|c|c|c|c|c|c|c|c|c|c|c|}
\hline $\begin{array}{l}\text { Unified } \\
\text { Classification }\end{array}$ & $\begin{array}{l}\text { Number } \\
\text { of data } \\
\text { points }\end{array}$ & $\begin{array}{l}D_{r} \\
\text { (percent) }\end{array}$ & $\begin{array}{l}\phi \\
\text { (deg) }\end{array}$ & $\begin{array}{l}\Delta \phi \\
\text { (deg) }\end{array}$ & $\begin{array}{l}c \\
(\mathrm{kPa})\end{array}$ & $K$ & $n$ & $\boldsymbol{R}_{f}$ & $K_{b}$ & $m$ \\
\hline \multirow[t]{3}{*}{ GW, GP, SW, SP } & 8 & $20-50$ & $\begin{array}{l}37 \\
(5)\end{array}$ & $\begin{array}{l}2 \\
(3)\end{array}$ & 0 & $\begin{array}{l}525 \\
(245)\end{array}$ & $\begin{array}{l}0.49 \\
(0.20)\end{array}$ & $\begin{array}{l}0.85 \\
(0.09)\end{array}$ & $\begin{array}{l}245 \\
(155)\end{array}$ & $\begin{array}{l}0.28 \\
(0.22)\end{array}$ \\
\hline & 9 & $50-85$ & $\begin{array}{l}44 \\
(5)\end{array}$ & $\begin{array}{l}7 \\
(4)\end{array}$ & 0 & $\begin{array}{l}510 \\
(275)\end{array}$ & $\begin{array}{l}0.48 \\
(0.13)\end{array}$ & $\begin{array}{l}0.72 \\
(0.11)\end{array}$ & $\begin{array}{l}295 \\
(260)\end{array}$ & $\begin{array}{l}0.17 \\
(0.13)\end{array}$ \\
\hline & 15 & $85-100$ & $\begin{array}{l}48 \\
(5)\end{array}$ & $\begin{array}{l}7 \\
(4)\end{array}$ & 0 & $\begin{array}{l}1250 \\
(820)\end{array}$ & $\begin{array}{l}0.46 \\
(0.23)\end{array}$ & $\begin{array}{l}0.75 \\
(0.12)\end{array}$ & $\begin{array}{l}899 \\
(650)\end{array}$ & $\begin{array}{l}0.19 \\
(0.19)\end{array}$ \\
\hline
\end{tabular}

Notes:

Symbols are defined in the notation (Appendix C).

Numbers in parentheses indicate the standard deviation. 
Table A6

Property Values for Compacted Soils Listed in Table 7 of Duncan et al. (1980)

\begin{tabular}{|c|c|c|c|c|c|c|c|c|c|c|c|c|}
\hline $\begin{array}{l}\text { Unified } \\
\text { Classification }\end{array}$ & $\begin{array}{l}D_{r} \\
(\%)^{1}\end{array}$ & $\begin{array}{l}\text { RC } \\
(\%)\end{array}$ & $\begin{array}{l}\gamma_{m} \\
\left(\mathbf{k N} / \mathrm{m}^{3}\right)\end{array}$ & $\begin{array}{l}\text { Range }^{1} \\
\text { in } \gamma_{m} \\
\left(\mathrm{kN} / \mathrm{m}^{3}\right)\end{array}$ & $\begin{array}{l}\phi_{0} \\
\text { (deg) }\end{array}$ & $\begin{array}{l}\Delta \phi \\
\text { (deg) }\end{array}$ & $\begin{array}{l}C \\
(\mathrm{kPa})\end{array}$ & $K$ & $n$ & $R_{f}$ & $K_{b}$ & $m$ \\
\hline GW, GP, SW, SP & $\begin{array}{r}100 \\
75 \\
50 \\
25\end{array}$ & $\begin{array}{r}105 \\
100 \\
95 \\
90\end{array}$ & $\begin{array}{l}23.6 \\
22.8 \\
22.0 \\
21.2\end{array}$ & $\begin{array}{l}16.5-23.6 \\
15.7-22.8 \\
14.9-22.0 \\
14.1-21.2\end{array}$ & $\begin{array}{l}42 \\
39 \\
36 \\
33\end{array}$ & $\begin{array}{l}9 \\
7 \\
5 \\
3\end{array}$ & $\begin{array}{l}0 \\
0 \\
0 \\
0\end{array}$ & $\begin{array}{l}600 \\
450 \\
300 \\
200\end{array}$ & $\begin{array}{l}0.4 \\
0.4 \\
0.4 \\
0.4\end{array}$ & $\begin{array}{l}0.7 \\
0.7 \\
0.7 \\
0.7\end{array}$ & $\begin{array}{r}175 \\
125 \\
75 \\
50\end{array}$ & $\begin{array}{l}0.2 \\
0.2 \\
0.2 \\
0.2\end{array}$ \\
\hline SM & $\begin{array}{l}- \\
- \\
-\end{array}$ & $\begin{array}{r}100 \\
95 \\
90 \\
85\end{array}$ & $\begin{array}{l}21.2 \\
20.4 \\
19.6 \\
18.9\end{array}$ & $\begin{array}{l}17.3-21.2 \\
16.5-20.4 \\
15.7-19.6 \\
14.9-18.9\end{array}$ & $\begin{array}{l}36 \\
34 \\
32 \\
30\end{array}$ & $\begin{array}{l}8 \\
6 \\
4 \\
2\end{array}$ & $\begin{array}{l}0 \\
0 \\
0 \\
0\end{array}$ & $\begin{array}{l}600 \\
450 \\
300 \\
150\end{array}$ & $\begin{array}{l}0.25 \\
0.25 \\
0.25 \\
0.25\end{array}$ & $\begin{array}{l}0.7 \\
0.7 \\
0.7 \\
0.7\end{array}$ & $\begin{array}{l}450 \\
350 \\
250 \\
150\end{array}$ & $\begin{array}{l}0.0 \\
0.0 \\
0.0 \\
0.0\end{array}$ \\
\hline SM-SC & $\begin{array}{l}- \\
- \\
-\end{array}$ & $\begin{array}{r}100 \\
95 \\
90 \\
85\end{array}$ & $\begin{array}{l}21.2 \\
20.4 \\
19.6 \\
18.9\end{array}$ & \begin{tabular}{|l|}
$18.1-21.2$ \\
$17.3-20.4$ \\
$16.5-19.6$ \\
$15.7-18.9$
\end{tabular} & $\begin{array}{l}33 \\
33 \\
33 \\
33\end{array}$ & $\begin{array}{l}0 \\
0 \\
0 \\
0\end{array}$ & $\begin{array}{l}0.5 \\
0.4 \\
0.3 \\
0.2\end{array}$ & $\begin{array}{l}400 \\
200 \\
150 \\
100\end{array}$ & $\begin{array}{l}0.6 \\
0.6 \\
0.6 \\
0.6\end{array}$ & $\begin{array}{l}0.7 \\
0.7 \\
0.7 \\
0.7\end{array}$ & $\begin{array}{r}200 \\
100 \\
75 \\
50\end{array}$ & $\begin{array}{l}0.5 \\
0.5 \\
0.5 \\
0.5\end{array}$ \\
\hline$C L$ & $\begin{array}{l}- \\
- \\
-\end{array}$ & $\begin{array}{r}100 \\
95 \\
90 \\
85\end{array}$ & $\begin{array}{l}21.2 \\
20.4 \\
19.6 \\
18.9\end{array}$ & $\begin{array}{l}18.1-21.2 \\
17.3-20.4 \\
16.5-19.6 \\
15.7-18.9\end{array}$ & $\begin{array}{l}30 \\
30 \\
30 \\
30\end{array}$ & $\begin{array}{l}0 \\
0 \\
0 \\
0\end{array}$ & $\begin{array}{l}0.4 \\
0.3 \\
0.2 \\
0.1\end{array}$ & $\begin{array}{r}150 \\
120 \\
90 \\
60\end{array}$ & $\begin{array}{l}0.45 \\
0.45 \\
0.45 \\
0.45\end{array}$ & $\begin{array}{l}0.7 \\
0.7 \\
0.7 \\
0.7\end{array}$ & $\begin{array}{r}140 \\
110 \\
80 \\
50\end{array}$ & $\begin{array}{l}0.2 \\
0.2 \\
0.2 \\
0.2\end{array}$ \\
\hline
\end{tabular}

Note:

Parameters are listed and defined in the notation (Appendix C).

$\mathrm{RC}$ refers to the relative compaction according to Standard Proctor: ASTM D698-78.

$\gamma_{\mathrm{m}}$ refers to moist unit weight.

${ }^{1}$ Listed in Table 8-1, Chapter 8 (Idriss and Duncan 1988).

\section{Table A7}

Proposed Ranges of Starting Property Values for Granular Soils in Drained Condition

\begin{tabular}{|c|c|c|c|c|c|c|c|c|c|}
\hline $\begin{array}{l}\text { Unified } \\
\text { Classification }\end{array}$ & $\begin{array}{l}D_{\mathrm{r}} \\
(\%)\end{array}$ & $\begin{array}{l}\phi_{0} \\
\text { (deg) }\end{array}$ & $\begin{array}{l}\Delta \phi \\
\text { (deg) }\end{array}$ & $\begin{array}{l}\text { C } \\
(\mathrm{kPa})\end{array}$ & $K$ & $n$ & $R_{f}$ & $K_{b}$ & $m$ \\
\hline \multirow[t]{3}{*}{ GW, GP, SW, SP } & $20-50$ & $30-40$ & $0-4$ & 0 & $200-600$ & $0.4-0.6$ & $0.7-0.9$ & $150-300$ & $0.1-0.4$ \\
\hline & $50-85$ & $35-45$ & $5-10$ & 0 & $400-800$ & $0.4-0.6$ & $0.7-0.9$ & $200-400$ & $0.1-0.4$ \\
\hline & $85-100$ & $40-50$ & $5-10$ & 0 & $500-1500$ & $0.4-0.6$ & $0.7-0.9$ & $400-1100$ & $0.1-0.4$ \\
\hline
\end{tabular}

Note: Symbols are defined in the notation (Appendix C). 
In SOILSTRUCT-ALPHA, the soil property values for primary loading required as input for analysis are the modulus number $K$, the modulus exponent $n$, the failure ratio $R_{f}$, the friction angle $\phi$, and the nominal Poisson's ratio $v_{n o m}$. Starting values of $K, n$, and $R_{f}$ can be determined using Table A7, and may be adjusted depending on the characteristics of the problem under analysis and the expected response of the soil. The value of the friction angle can be determined using Equation A1 and the values of $\phi_{o}$ and $\Delta \phi$ from Table $\mathrm{A} 7$, together with a representative value of confining stress.

The value of $v_{n o m}$ can be related to the bulk modulus number $K_{b}$ and modulus number $K$, following the procedure described in Appendix $\mathrm{C}$ of Ebeling, Pace, and Morrison (1997). This procedure provides a good starting value of $v_{n o m}$ that can be refined using the one-dimensional (1-D) column analysis procedure as described by Ebeling and Wahl (1997).

Before performing a 1-D column analysis, it is necessary to estimate the value of the coefficient of earth pressure at rest $K_{O}$. For a tall backfill of homogeneous granular fill where the overburden pressures exceed the compaction-induced preconsolidation pressures over the majority of the backfill, an adequate value of $K_{o}$ can be estimated using Jaky's relationship $\left(K_{o}=1-\sin \phi^{\prime}\right)$. In relatively short backfills or in backfills compacted with heavy equipment, the overburden pressures may not exceed the compaction-induced preconsolidation pressures over the majority of the backfill height and the value of $K_{o}$ may vary significantly over the height of the backfill. In these cases, the value of $K_{o}$ for analysis must account for overconsolidation of the backfill.

The value of $v_{n o m}$ is dependent on $K_{o}$ and the stress level $S L$. In a 1-D column analysis, the value of $v_{n o m}$ is adjusted until matching the target $K_{o}$ value determined from Jaky's relationship. A good initial approximation to the value of $v_{n o m}$ can be obtained solving Equation A1 from Appendix A of Ebeling and Wahl (1997), which is restated as Equation A5 below.

$$
K_{o}=\frac{1-\left(1-2 v_{\text {nom }}\right)\left[1-R_{f} \frac{(1-\sin \phi)\left(1-K_{o}\right)}{2 K_{o} \sin \phi}\right]^{2}}{1+\left(1-2 v_{\text {nom }}\right)\left[1-R_{f} \frac{(1-\sin \phi)\left(1-K_{o}\right)}{2 K_{o} \sin \phi}\right]^{2}}
$$

For the McAlpine lock wall analyses described by Ebeling and Wahl (1997), a value $K_{o}$ of 0.44 was estimated using Jaky's relationship with $\phi^{\prime}=34 \mathrm{deg}$. The value of failure ratio $R_{f}$ of the backfill was 0.7 . Using these values and solving Equation A1 in Ebeling and Wahl (1997) yielded a value of $v_{n o m}$ of 0.025 . In addition, 1-D column analyses of the backfill were performed using the backfill placement option incorporated in SOILSTRUCT-ALPHA. The value of $v_{\text {nom }}$ obtained from the 1-D column 
analyses was consistent with the value of 0.025 determined from Equation A5.

The value of Poisson's ratio $v$ corresponding to a given value of nominal Poisson's ratio $v_{n o m}$ can be determined using Equation A2 in Ebeling and Wahl (1997). According to this equation (restated as Equation A6 below), the value of $v$ depends on $v_{n o m}, R_{f}$, and the stress level $S L$. For $v_{\text {nom }}=0.025, R_{f}=0.7$, and $S L=0.51$, the value of Poisson's ratio $v$ is 0.3 .

$$
v=\frac{1-\left(1-2 v_{\text {nom }}\right) *\left(1-R_{f} S L\right)^{2}}{2}
$$

For unloading-reloading, SOILSTRUCT-ALPHA requires an additional property value, the unload-reload modulus $K_{u r}$. Values of the unload-reload modulus number $K_{u r}$ for soils are not readily available in the literature. According to Duncan et al. (1980), the value of $K_{u r}$ is always larger than the value of the modulus number $K$ for primary loading. For stiff soils such as dense sands, $K_{u r}$ may be 20 percent greater than $K$. For soft soils such as loose sands, $K_{u r}$ may be three times as large as $K$.

A more precise determination of the value of $K_{u r}$ can be achieved from the results of a 1-D consolidation test that includes one or more cycles of unloading-reloading. A procedure for the determination of $K_{u r}$ from 1-D unloading-reloading tests is presented in Chapter 5 of Clough and Duncan (1969). 


\section{Appendix B Results of Interface Tests and Determination of Interface Hyperbolic Parameter Values}

This appendix contains the results of the interface tests performed for this investigation. It also contains a brief description of the procedure developed by Clough and Duncan (1971) for the determination of hyperbolic parameter values for interfaces. Hyperbolic parameter values of the interface between concrete and dense Blacksburg Sand are determined based on the Clough and Duncan (1971) procedure.

\section{B.1 Results of Interface Tests}

The results of the interface tests performed for this investigation are presented in Figures B1 through B3. The results of initial loading tests T2001_5, T2002_10, T2003_20, and T2004_40 are presented in Figures B1 and B2. During these tests, the interface was sheared under constant normal stress until failure was attained. Determination of the interface hyperbolic parameter values, which is described in the following section, was done based on the results of these tests.

Figure B3 shows the results of multidirectional stress path test T2005. The test consisted of the application of a stress path that included simultaneous changes in shear and normal stresses and unloading-reloading. The purpose of this test was to provide a basis for a performance evaluation of the extended hyperbolic model under complicated loading paths. 


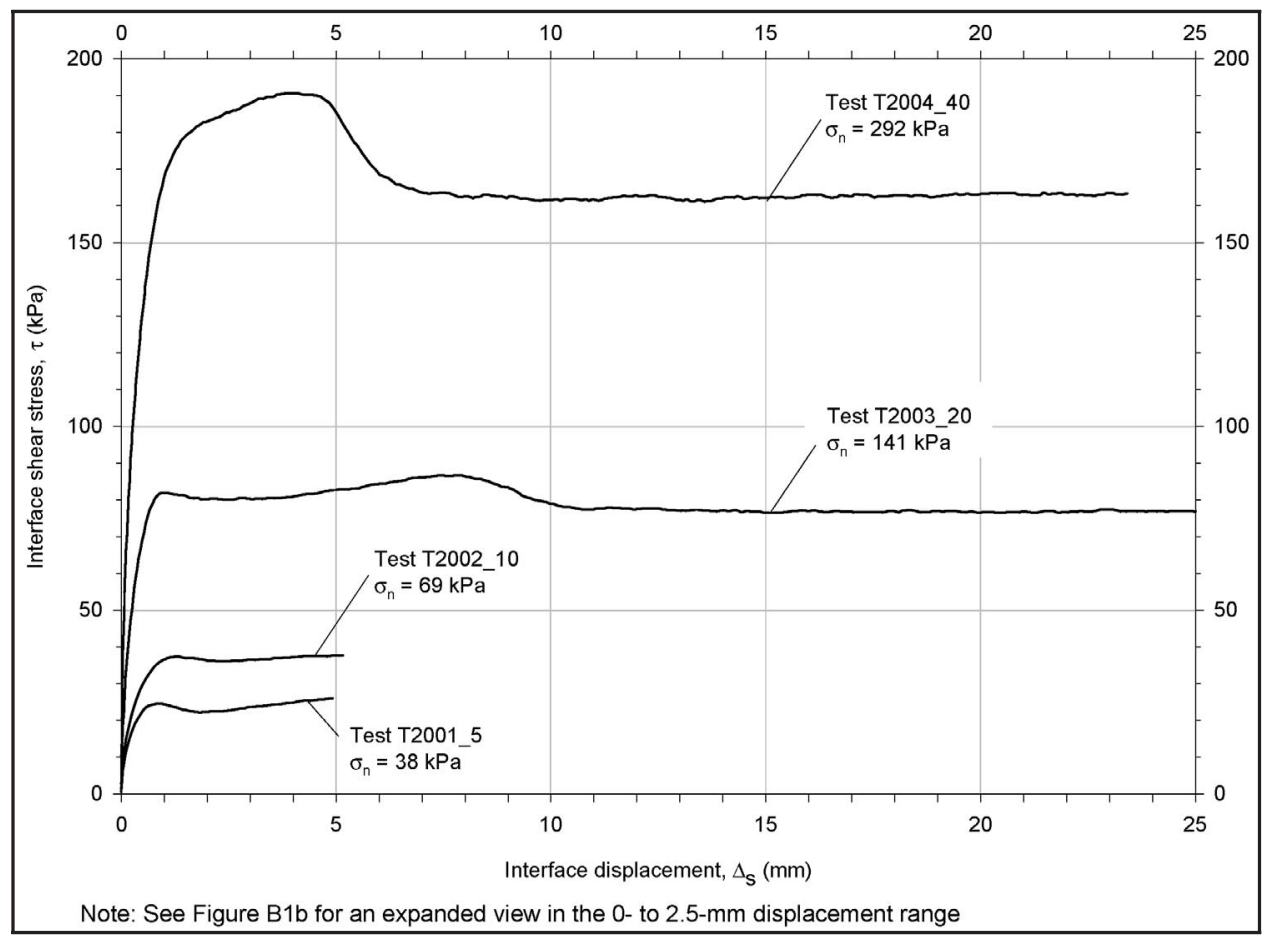

a. Shear stress versus interface displacement data

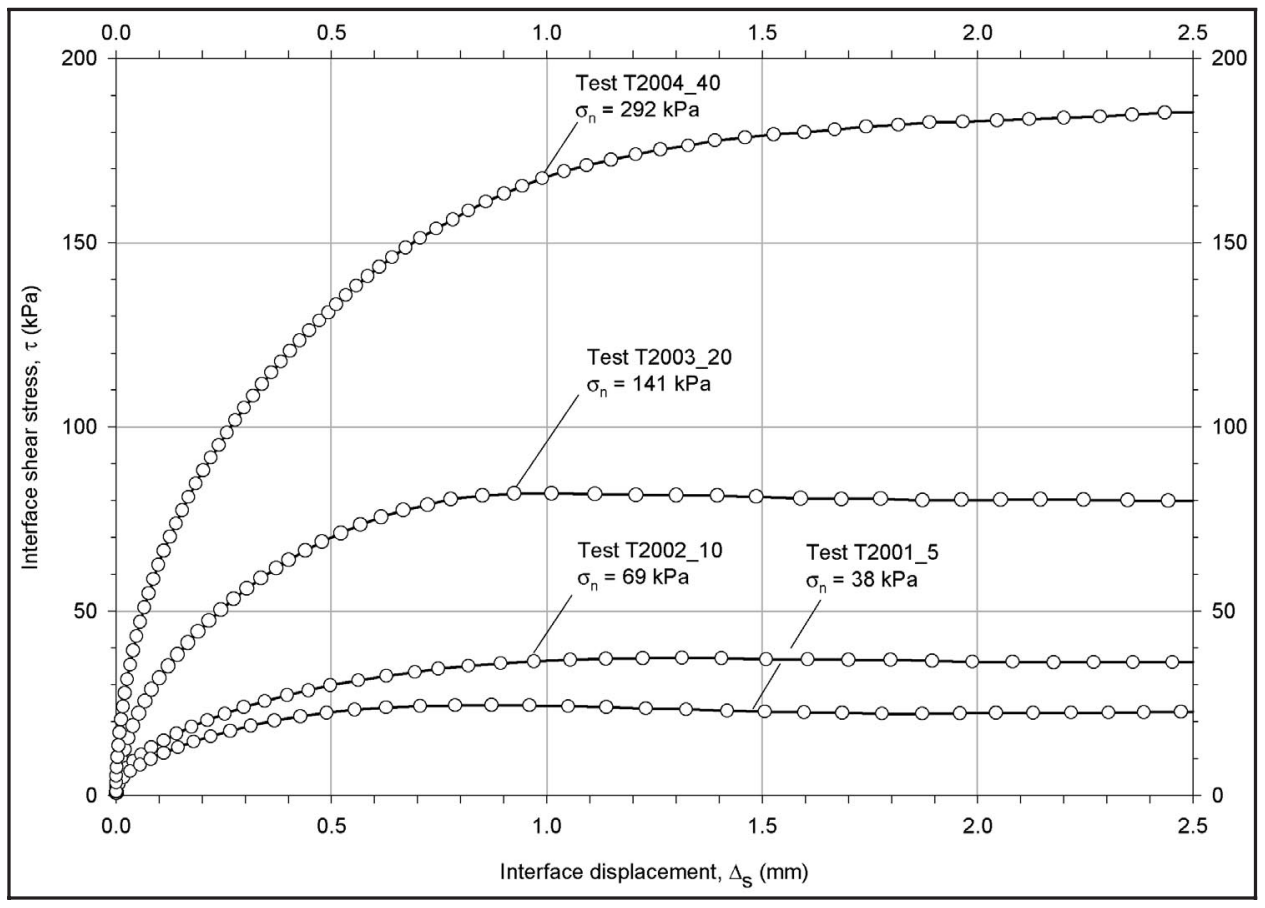

b. Enlargement of Figure B1a

Figure B1. Results of initial loading tests on dense Blacksburg Sand-toconcrete interface 


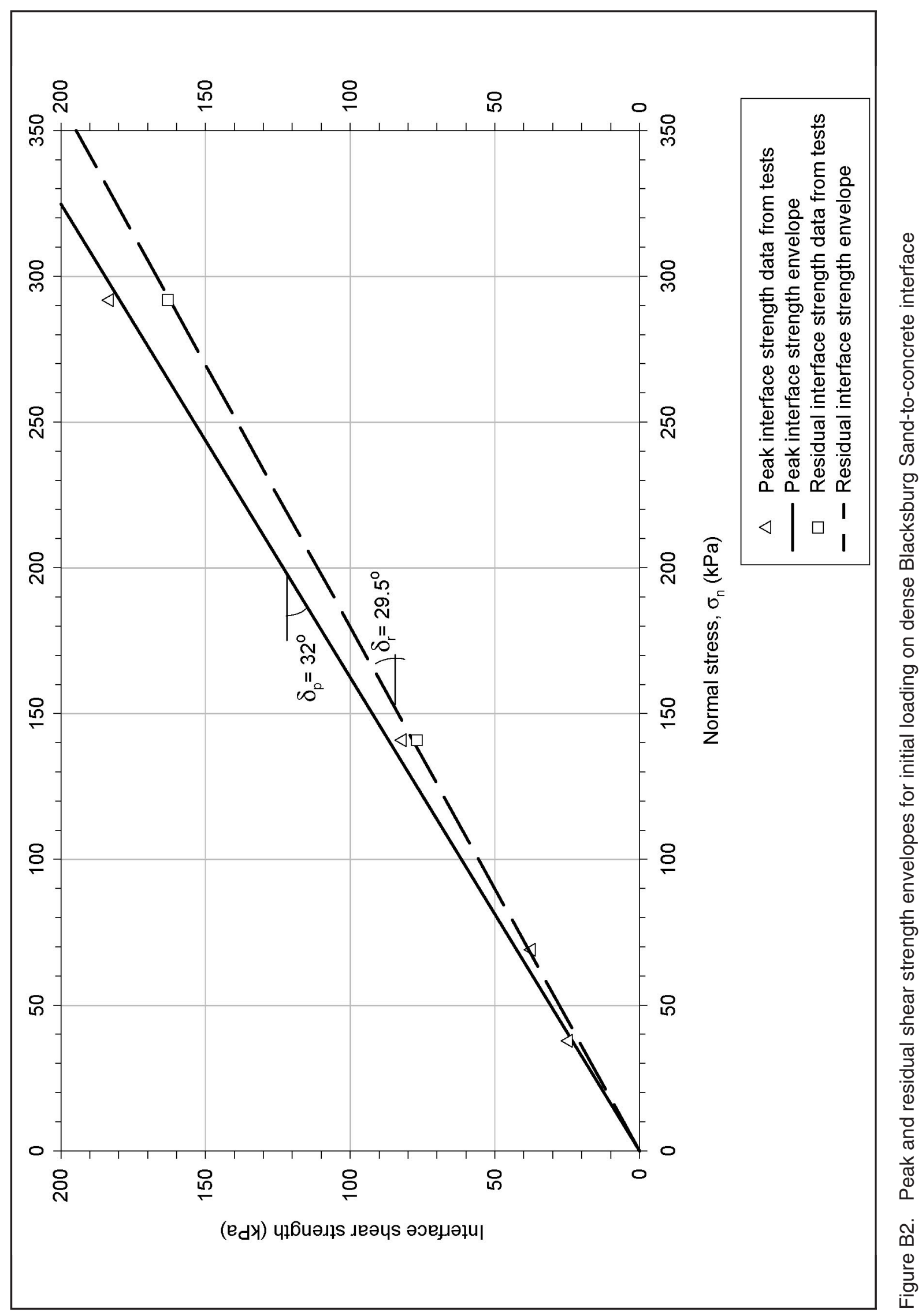

Appendix B Results of Interface Tests and Determination of Interface Hyperbolic Parameter Values 


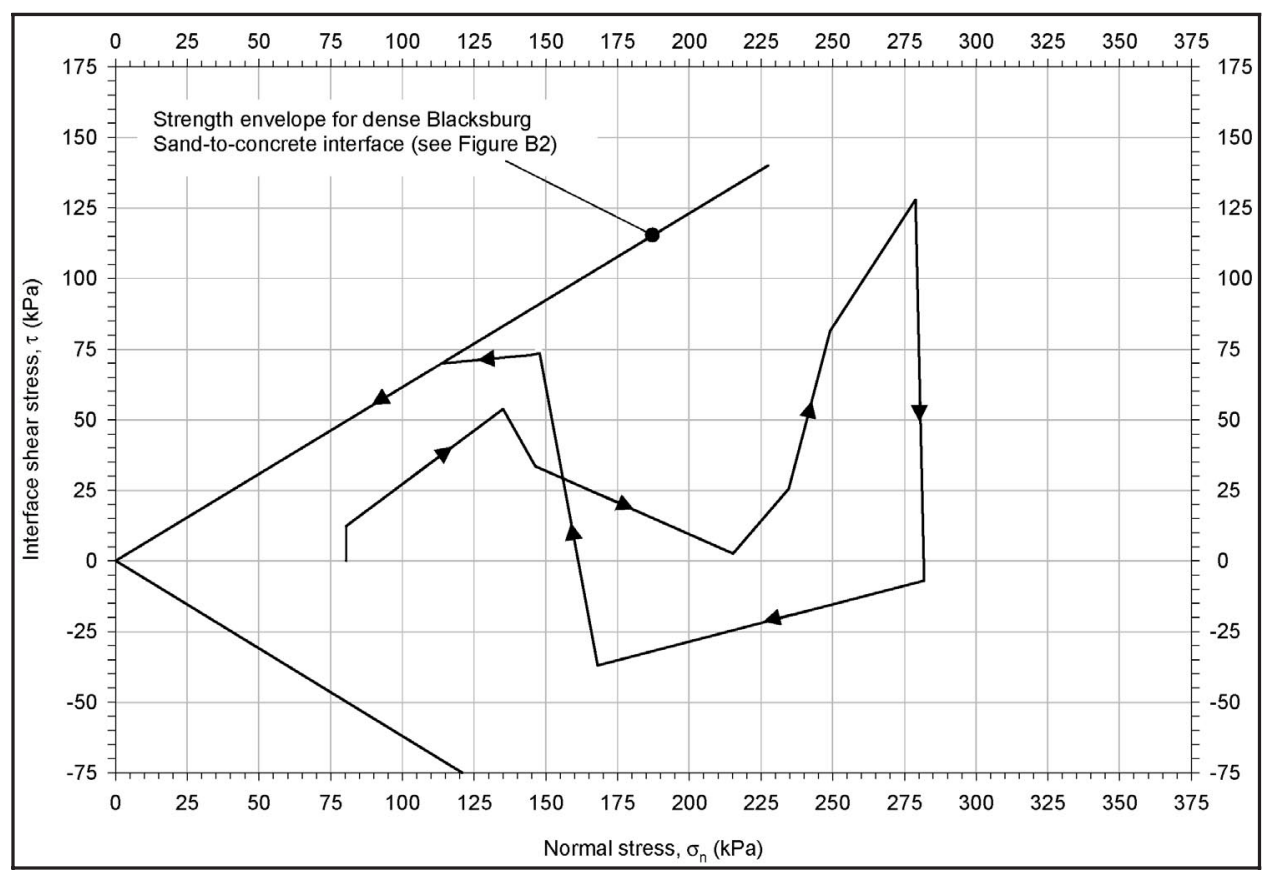

a. Stress path applied during test

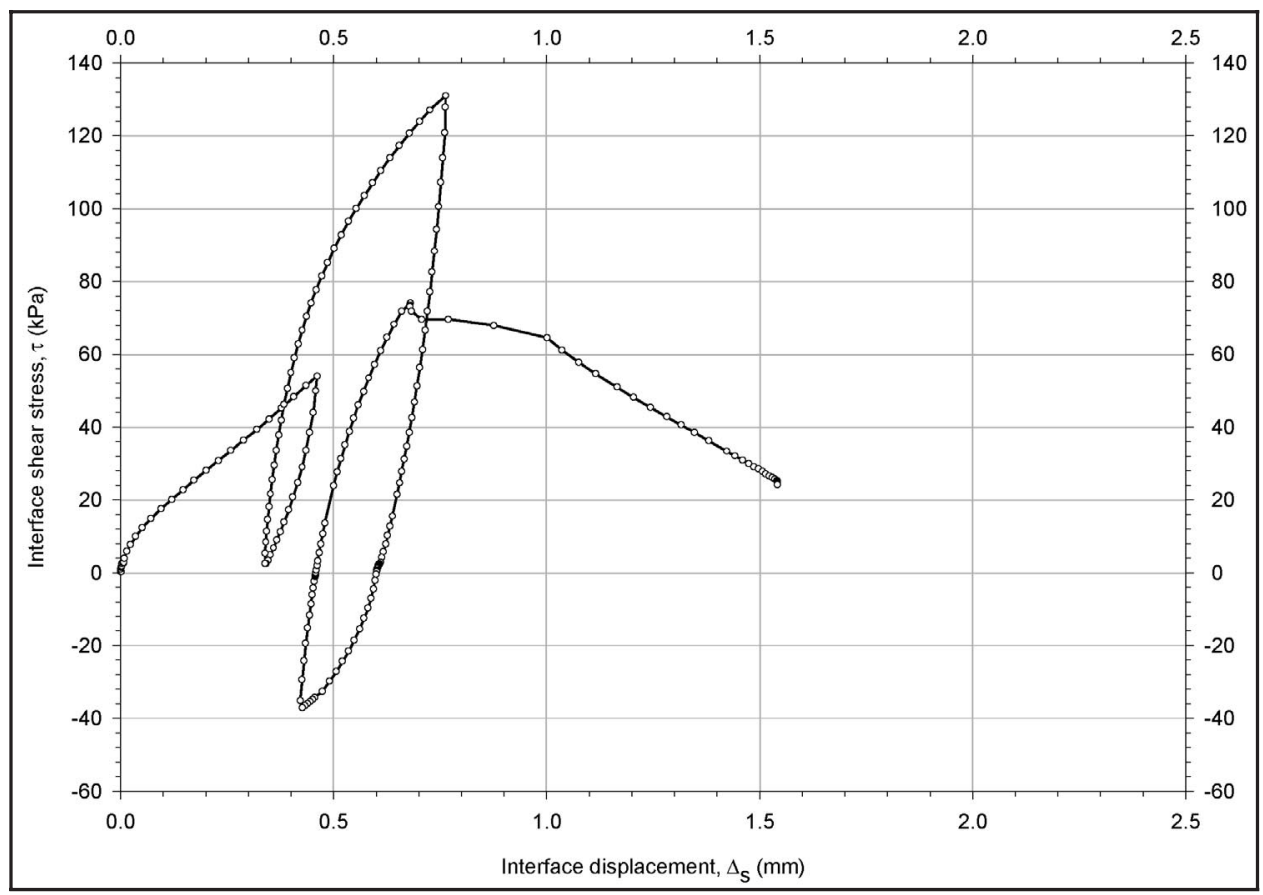

b. Shear stress versus interface displacement data

Figure B3. Multidirectional stress path test T2005 on dense Blacksburg Sand-to-concrete interface 


\section{B.2 Determination of Interface Hyperbolic Parameter Values}

The first step in the determination of hyperbolic parameter values is checking for inconsistencies in the data from the interface tests. Figure B4 shows the results of the tests performed on the dense Blacksburg Sand against concrete interface. The data points shown in the figure are identical to those shown in Figure B1. Frequently, data from interface tests may present some inconsistencies that can be minimized by developing an assumed shear stress-displacement response. The response assumed for the determination of the hyperbolic parameters in this example is represented as solid lines in Figure B4. Because of the good precision of displacement and shear stress measurements in these tests, few inconsistencies can be seen in the data, and the assumed response is practically identical to the measured response.

The next step is the determination of the shear stress at failure $\tau_{f}$ for each normal stress. The values of $\tau_{f}$ can be determined from the shear stress-displacement plots of the tests. Column 2 of the table presented as Figure B5 contains the values of shear stress at failure determined from Figure B4. The values of shear stress corresponding to 70 and 95 percent of $\tau_{f}$ are calculated as shown in columns 3 and 6 , respectively.

The values of interface displacement corresponding to 70 and 95 percent of the shear stress at failure are determined from the shear stressdisplacement plots. Columns 4 and 7 in Figure B5 contain the displacement values determined as shown in Figure B4.

The values in columns $2,3,4,6$, and 7 are the basis for the determination of the values of initial interface stiffness $K_{s i}$ and failure ratio $R_{f j}$. The sequence of calculations leading to the determination of the values of $K_{s i}$ and $R_{f j}$ is shown in Figure B5.

The value of failure ratio $R_{f j}$ to be used for modeling is the average of the values determined in Figure B5. The values of $K_{I}$ and $n_{j}$ are determined by plotting the normalized values of initial interface stiffness against the normalized normal stress in logarithmic scale, as shown in Figure B6.

Values of interface hyperbolic parameters, determined following the procedure outlined in this section, may require further adjustments when using the Gómez-Filz-Ebeling interface model (Gómez, Filz, and Ebeling 2000). As discussed in a subsequent section, only the value of $K_{I}$ for the interface between dense Blacksburg Sand and concrete required further adjustment. 


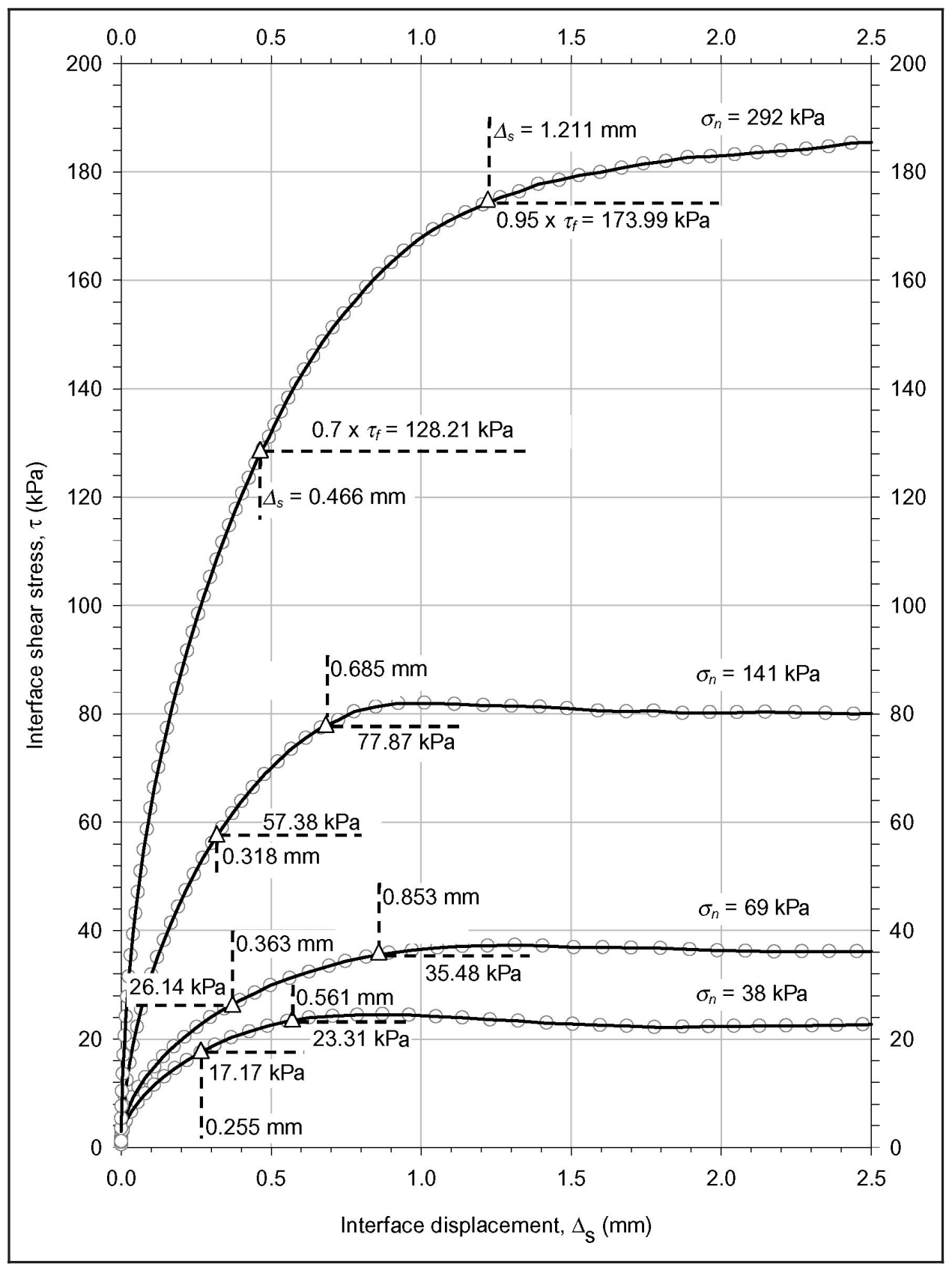

Figure B4. Example determination of interface displacements at 70 and 95 percent of strength data from interface tests on dense Blacksburg Sand 


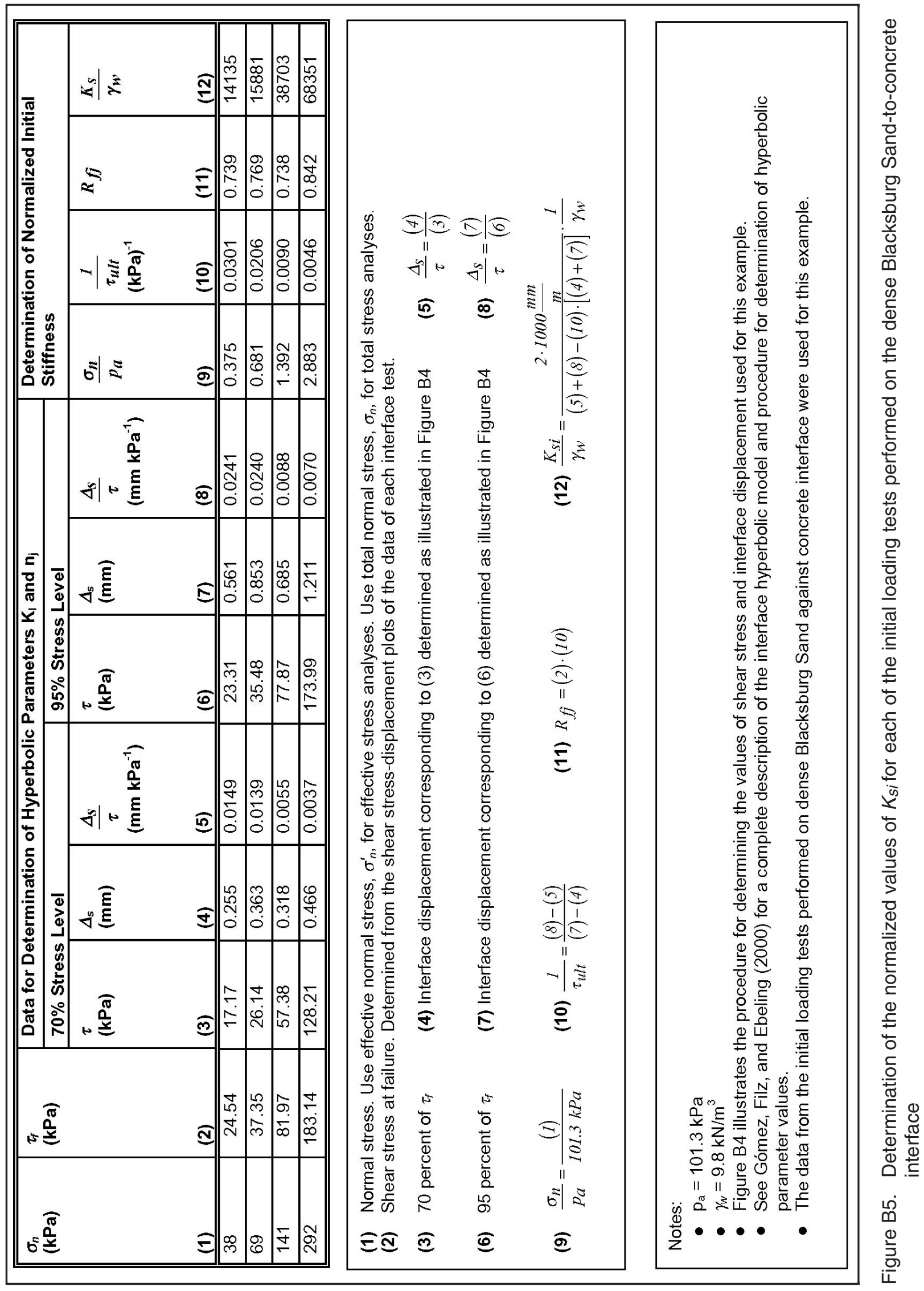

Appendix B Results of Interface Tests and Determination of Interface Hyperbolic Parameter Values 


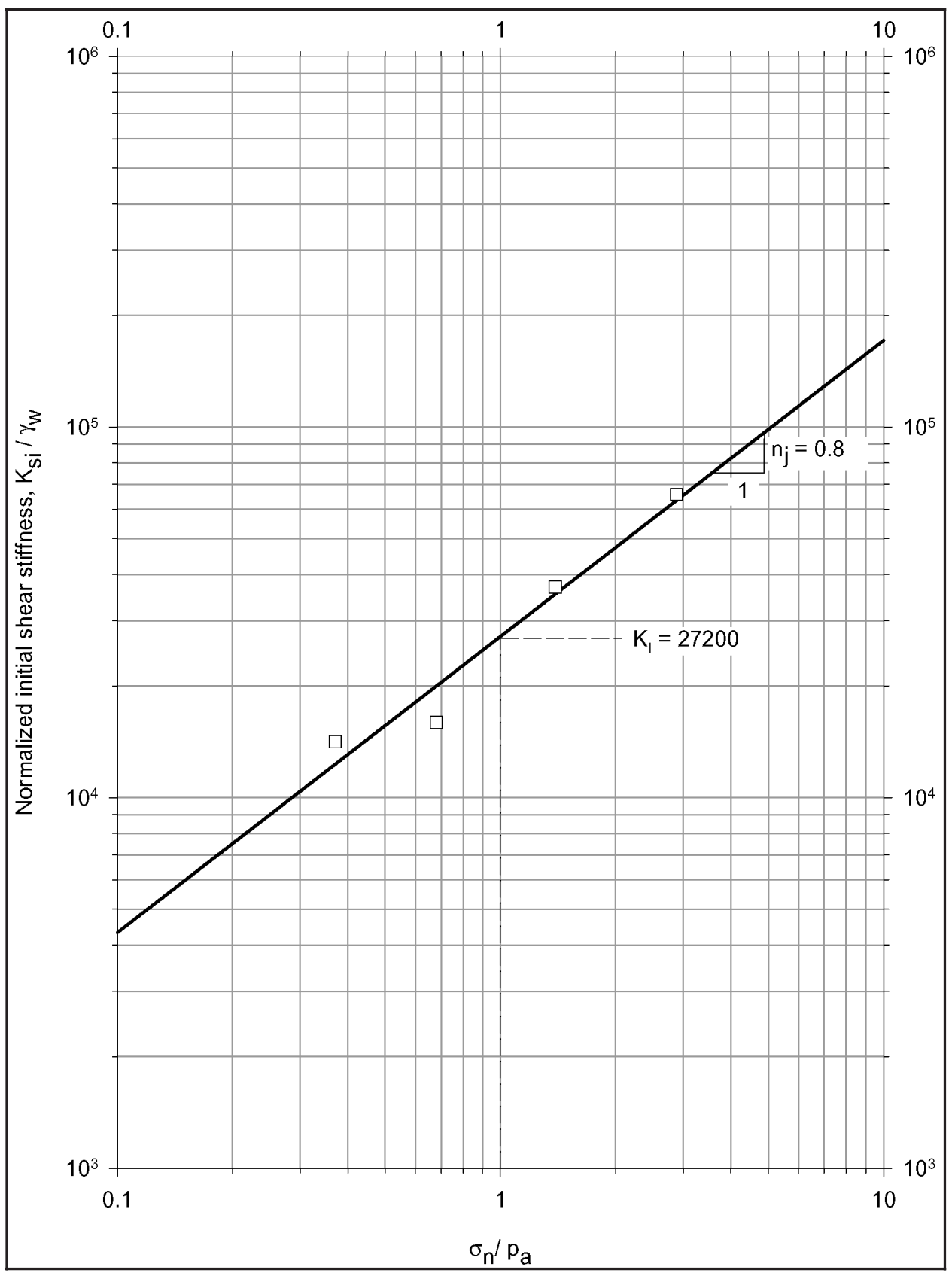
Figure B6. Determination of hyperbolic parameters $K_{l}$ and $n_{j}$ for dense
Blacksburg Sand-to-concrete interface 


\section{B.3 Comparison of Model to Test Data}

The shear stress-displacement response from the model is calculated using the following expression:

$$
\tau=\frac{\Delta_{s}}{K_{I} \cdot \gamma_{w} \cdot\left(\frac{\sigma_{n}}{p_{a}}\right)^{n_{j}}}+\frac{R_{f j} \cdot \Delta_{s}}{\sigma_{n} \cdot \tan \delta}
$$

where $\delta$ is the interface friction angle. This expression is valid for frictional interfaces with zero adhesion intercept.

The shear stress-displacement response of the interface between dense Blacksburg Sand and concrete was calculated using Equation B1 and the hyperbolic parameters determined as described previously. Figure B7 compares the test data and the calculated hyperbolic response. In the figure, the shear stress-displacement hyperbolas are interrupted at the value of shear stress at failure, $\tau_{f}$. A horizontal shear stress-displacement relationship (i.e., zero interface stiffness) is used to model the response of the soil after failure is attained. It can be seen that the hyperbolic model provides an accurate approximation of the interface response measured during each of the tests.

\section{B.4 Adjustment of the Hyperbolic Parameter Values}

As observed by Gómez, Filz, and Ebeling (2000), hyperbolic parameter values, determined according to the method outlined in the previous sections, are usually accurate enough for implementation of the Clough and Duncan (1971) hyperbolic model for interface shear under constant normal stress. However, for implementation of the Gómez-Filz-Ebeling model for interfaces, it may be necessary to improve the accuracy of the parameter values through an adjustment procedure.

The procedure for adjustment of hyperbolic parameter values is described in detail by Gómez, Filz, and Ebeling (2000). It is based on the normalization of the measured and calculated response of the interface during initial loading. The first step in this procedure is determination of the values of tangent interface stiffness $K_{s t}{ }^{\prime}$ from the test data using the following equation: 


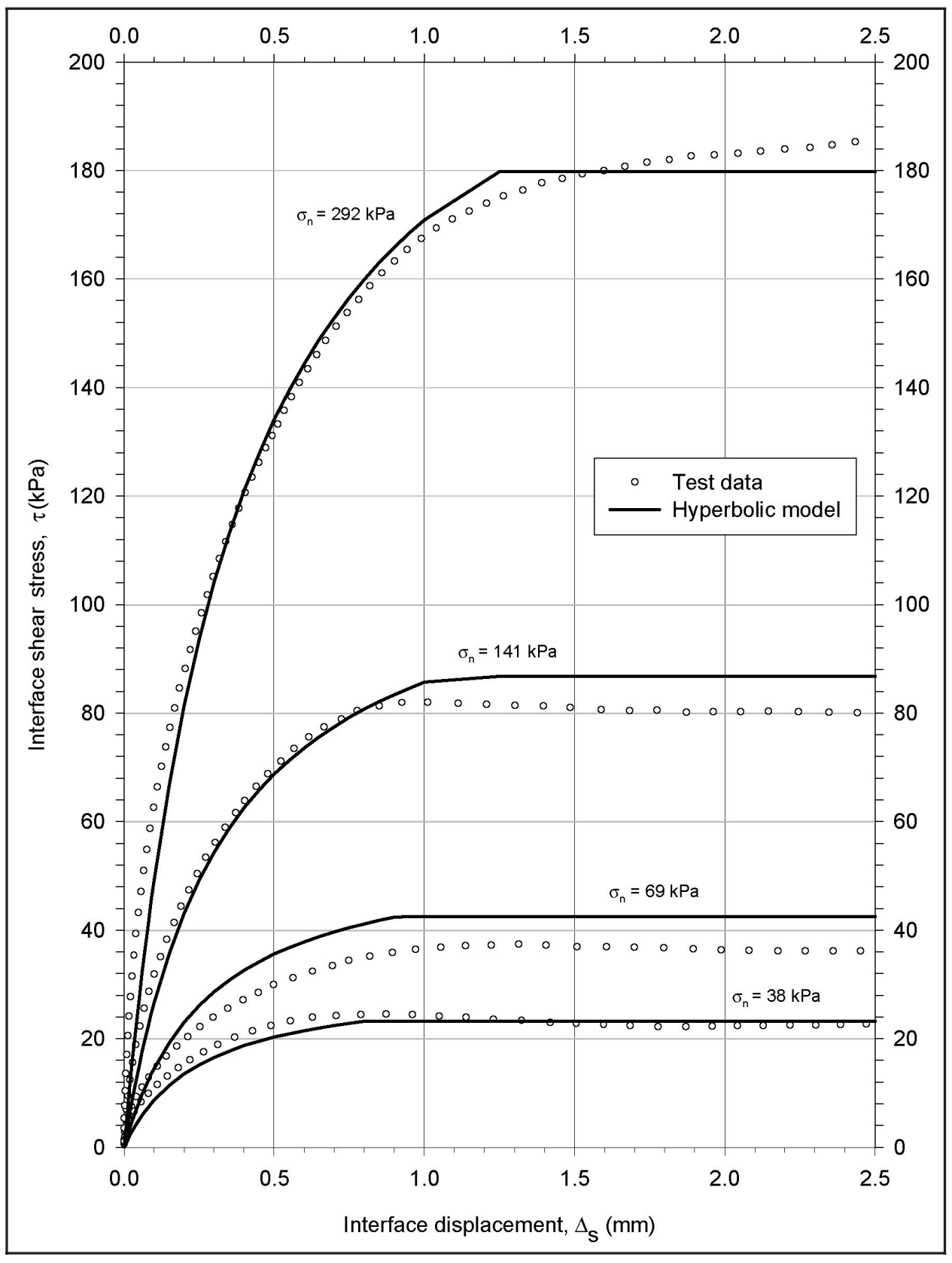

Figure B7. Comparison between the hyperbolic model and data from initial loading tests on dense Blacksburg Sand-to-concrete interface 


$$
K_{s t}^{\prime}=\frac{\tau^{i}-\tau^{i-1}}{\Delta_{s}^{i}-\Delta_{s}^{i-1}}
$$

where

$$
\tau^{i-1}, \tau^{i}=\text { consecutive shear stress readings }
$$

$\Delta_{s}^{i-1}, \Delta_{s}^{i}=$ consecutive interface displacement readings

The values of $K_{s t} t^{\prime}$ can be normalized according to the following expression:

$$
K_{s n}=\frac{K_{s t}^{\prime}}{\gamma_{w} \cdot\left(\frac{\sigma_{n}}{p_{a}}\right)^{n_{j}}}
$$

where $K_{s n}$ is the normalized stiffness of the interface. The parameter $n_{j}$ is the stiffness exponent in the Clough and Duncan (1971) hyperbolic model, which is determined as described previously in this appendix.

Figure B8 is a diagram of normalized stiffness, represented in logarithmic scale, versus stress level. The data points correspond to the initial loading tests performed on the interface between dense Blacksburg Sand and concrete.

Gómez, Filz, and Ebeling (2000) propose three adjustments to the hyperbolic parameter values. The first adjustment consists of finding the value of $n_{j}$ that minimizes the scatter of the data points in the diagram of normalized stiffness. Ideally, the adjusted value of $n_{j}$ would produce data points in the diagram that lie on a single trendline (Gómez, Filz, and Ebeling 2000). In practice, the optimal value of $n_{j}$ is that which minimizes the scatter of the data points.

For the interface between dense Blacksburg Sand and concrete, it was found that no adjustment was required for the $n_{j}$ value determined previously in this appendix.

The second and third adjustments require plotting the normalized hyperbolic stiffness $K_{s n}$, which is calculated from the following equation:

$$
K_{s n}=K_{I} \cdot\left(1-R_{f j} \cdot S L\right)^{2}
$$




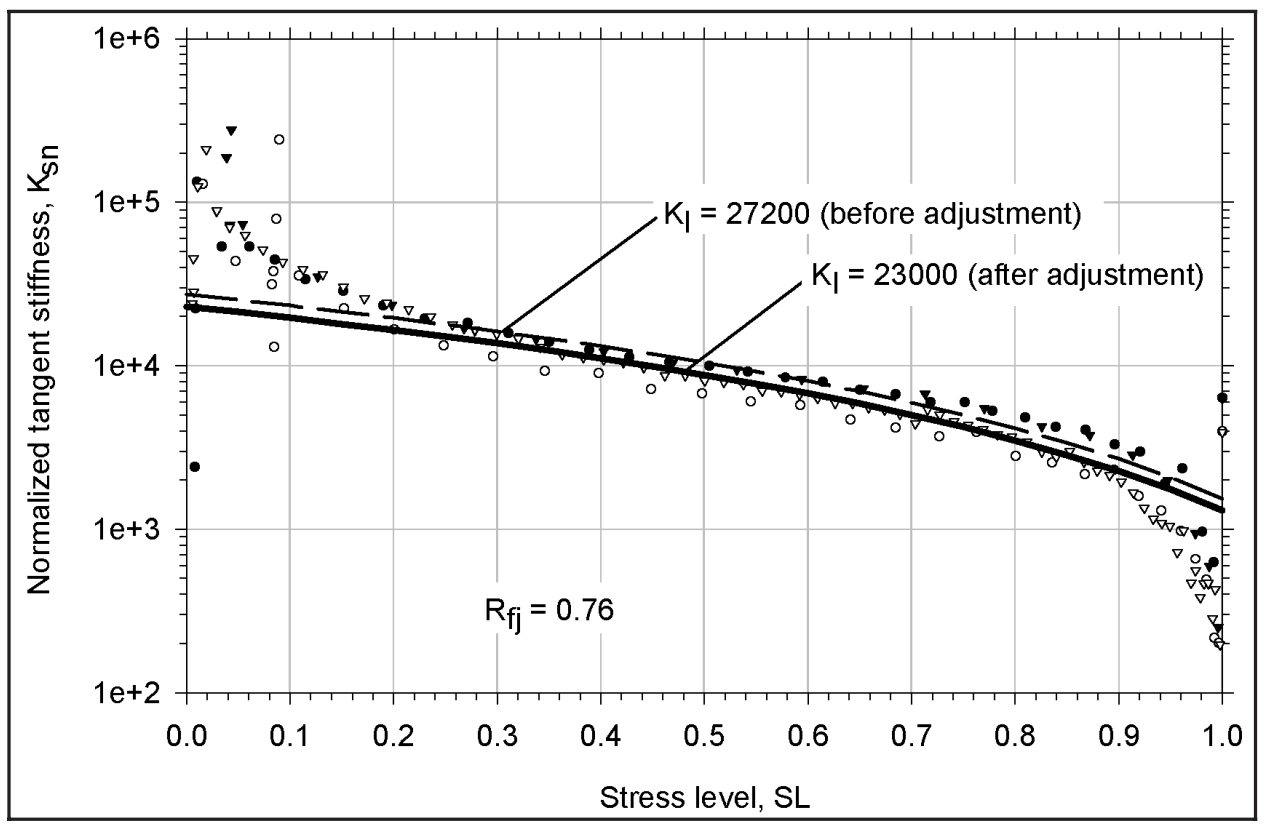

Figure B8. Adjustment of the value of stiffness number $K_{I}$ for the dense Blacksburg Sand-to-concrete interface

If the response of the interface is hyperbolic, accurate values of $K_{I}$ and $R_{f j}$ would produce a $K_{s n}$ versus $S L$ diagram that fits closely the normalized stiffness diagram of the test data. The dashed line in Figure B8 corresponds to the values of $K_{s n}$ before adjustment of the hyperbolic parameter values determined previously in this appendix. It is seen that, although it shows good agreement with the test data, the dashed line can be adjusted to slightly improve the accuracy of the model. By reducing the value of $K_{I}$, an excellent agreement with the test data is achieved. No adjustment was necessary for the value of $R_{f j}$ determined previously.

Table B1 summarizes the values of the hyperbolic parameters for the interface between dense Blacksburg Sand and concrete.

\section{Table B1}

Hyperbolic Parameter Values for the Interface Between Dense Blacksburg Sand and Concrete

\begin{tabular}{|l|l|}
\hline \hline Parameter $^{1}$ & Parameter Value \\
\hline \hline$K_{l}$ & 23000 (adjusted) \\
\hline$n_{j}$ & 0.8 \\
\hline$R_{f j}$ & 0.76 \\
\hline$\delta$, deg & 31.6 \\
\hline \hline
\end{tabular}




\section{Appendix C Notation}

$B$

$C_{c}$

$C_{k}$

$C_{u}$

$D_{r}$

$D_{1}$

$D_{2}$

$D_{10,30,60}$

$E_{i}$

$G_{S}$

$I$

K

$K_{b}$

$K_{f}$-line

$K_{I}$

$K_{o}$

$K_{s i}$
Bulk modulus of soil

Coefficient of curvature

Interface stiffness ratio

Uniformity coefficient

Relative density

Thickness of the backfill above the hydrostatic water table

Thickness of the submerged backfill above the heel of the wall

Particle size diameter corresponding to 10,30 , or 60 percent, respectively, passing in the grain size distribution curve

Initial tangent (Young's) modulus of the soil

Specific gravity

Correction factor for inclination of the stress path

Modulus number

Bulk modulus number

Line joining the points in the $\mathrm{p}^{\prime}-\mathrm{q}$ plane that correspond to failure

Dimensionless interface stiffness number for initial loading

At-rest pressure coefficient

Initial shear stiffness of the interface 


\begin{tabular}{|c|c|}
\hline$K_{s n}$ & Normalized shear stiffness of the interface \\
\hline$K_{s n}^{t s}$ & Transition stiffness number \\
\hline$K_{s n}^{y s}$ & Yield stiffness number \\
\hline$K_{s t}$ & $\begin{array}{l}\text { Interface tangent stiffness for vertical stress paths (as } \\
\text { defined in Clough and Duncan } 1971 \text { hyperbolic model } \\
\text { for interfaces) }\end{array}$ \\
\hline$K_{s t}^{\prime}$ & Interface tangent stiffness for stress paths of any orientation \\
\hline$K_{u r}$ & Unload-reload modulus \\
\hline$K_{u r j}$ & Unload-reload stiffness number for interfaces \\
\hline$m$ & Bulk modulus exponent \\
\hline$m_{k}$ & Stiffness degradation parameter \\
\hline$n$ & Modulus exponent \\
\hline$n_{j}$ & Interface stiffness exponent \\
\hline$p^{\prime}$ & $\left(\sigma_{1}^{\prime}+\sigma_{3}^{\prime}\right) / 2$ \\
\hline$p_{a}$ & Atmospheric pressure $=101.3 \mathrm{kPa}$ \\
\hline$q$ & Shear direction parameter; $\left(\sigma_{1}-\sigma_{3}\right) / 2$ \\
\hline$R_{f}$ & Failure ratio for soils \\
\hline$R_{f j}$ & Failure ratio for interfaces \\
\hline$S L$ & Stress level \\
\hline$S L_{o}$ & Stress level at the origin of unloading-reloading \\
\hline$S L^{t s}$ & Transition stress level \\
\hline$S L^{y s}$ & Stress level for current position of yield surface \\
\hline$\alpha$ & Scaling factor for unloading-reloading \\
\hline$\gamma_{\max }, \gamma_{\min }$ & Maximum and minimum density, respectively \\
\hline$\gamma_{w}$ & Unit weight of water $\left(9.8 \mathrm{kN} / \mathrm{m}^{3}\right)$ \\
\hline$\delta$ & Peak interface friction angle \\
\hline
\end{tabular}




\begin{tabular}{|c|c|}
\hline$\delta_{r}$ & Residual interface friction angle \\
\hline$\Delta_{s}$ & Displacement along the interface \\
\hline$\Delta_{s}^{i-1}, \Delta_{s}^{i}$ & Consecutive interface displacement readings \\
\hline$\Delta_{\text {so }}$ & Interface displacement at the origin of unloading-reloading \\
\hline$\Delta_{s p}$ & Interface displacement to peak \\
\hline$\Delta_{s r}$ & Interface displacement to residual \\
\hline$\Delta \phi$ & $\begin{array}{l}\text { Reduction in the peak secant friction angle value for a } \\
10 \text {-fold increase in } \sigma_{3}{ }^{\prime}\end{array}$ \\
\hline$\varepsilon$ & Axial strain \\
\hline$\varepsilon_{v}$ & Volumetric strain \\
\hline$\theta$ & Angle between the stress path direction and the $\tau$-axis \\
\hline$v$ & Poisson's ratio \\
\hline$v_{n o m}$ & Nominal Poisson's ratio \\
\hline$\sigma_{h}$ & Horizontal pressure \\
\hline$\sigma_{n}$ & Normal stress acting on the interface \\
\hline$\sigma_{n}^{t s}$ & $\begin{array}{l}\text { Normal stress corresponding to point TS where the stress } \\
\text { path intersects a transition surface }\end{array}$ \\
\hline$\sigma_{n o}$ & Normal stress at the origin \\
\hline$\sigma_{1}$ & Major principal total stress \\
\hline$\sigma_{1}^{\prime}$ & Major principal effective stress \\
\hline$\sigma_{3}$ & Minor principal total stress \\
\hline$\sigma_{3}^{\prime}$ & Minor principal effective stress \\
\hline$\left(\sigma_{1}-\sigma_{3}\right)$ & Deviator stress \\
\hline$\left(\sigma_{1}-\sigma_{3}\right)_{f}$ & Deviator stress at failure \\
\hline$\left.\sigma_{3}\right)_{u l t}$ & Asymptotic deviator stress \\
\hline
\end{tabular}


$\tau^{i-1}, \tau^{i} \quad$ Consecutive interface shear stress readings

$\tau^{t s} \quad$ Shear stress at point TS where the stress path intersects a transition surface

Interface shear strength

$\tau_{o}$

Interface shear stress at the origin of unloading-reloading

$\tau_{u l t}$

$\phi$

$\phi^{\prime}$

$\phi_{c v}$

$\phi_{o}$
Asymptotic interface shear stress

Peak secant internal friction angle of the soil

Effective peak secant friction angle of the soil

Friction angle at a strain of 15 percent

Peak secant friction angle at a confining pressure of $101.3 \mathrm{kPa}(1 \mathrm{~atm})$ 


\section{REPORT DOCUMENTATION PAGE}

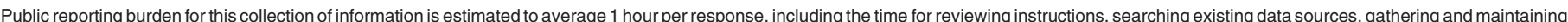

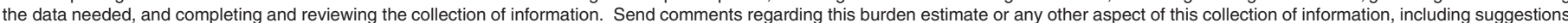

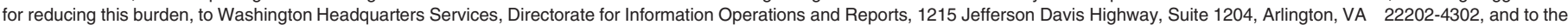
Office of Management and Budget, Paperwork Reduction Project (0704-0188), Washington, DC 20503

\begin{tabular}{|c|c|c|}
\hline 1. AGENCY USE ONLY (Leave blank) & $\begin{array}{ll}\text { 2. } & \text { REPORT DATE } \\
\text { December } 2000\end{array}$ & $\begin{array}{l}\text { 3. REPORT TYPE AND DATES COVERED } \\
\text { Final report }\end{array}$ \\
\hline
\end{tabular}

\section{TITLE AND SUBTITLE}

Extended Load/Unload/Reload Hyperbolic Model for Interfaces: Parameter Values and Model Performance for the Contact Between Concrete and Coarse Sand

6. AUTHOR(S)

Jesús E. Gómez, George M. Filz, Robert M. Ebeling

\section{FUNDING NUMBERS}

INP WU 33272

\section{PERFORMING ORGANIZATION NAME(S) AND ADDRESS(ES)}

Virginia Polytechnic Institute and State University, Blacksburg, VA 24061-0105; U.S. Army Engineer Research and Development Center, Information Technology Laboratory, 3909 Halls Ferry Road, Vicksburg, MS 39180-6199

9. SPONSORING/MONITORING AGENCY NAME(S) AND ADDRESS(ES)

U.S. Army Corps of Engineers, Washington, DC 20314-1000
8. PERFORMING ORGANIZATION REPORT NUMBER

ERDC/ITL TR-00-7

\section{SUPPLEMENTARY NOTES}

12a. DISTRIBUTION/AVAILABILITY STATEMENT

Approved for public release; distribution is unlimited. 12b. DISTRIBUTION CODE

13. ABSTRACT (Maximum 200 words)

The extended hyperbolic model for interfaces developed by Gómez, Filz, and Ebeling (Technical Report ITL-99-1; Report 2) can model the response of interfaces subjected to complex stress paths that may include simultaneous changes in shear and normal stresses and unloading-reloading. These types of loading can occur at soil-structure interfaces of multi-anchored systems used in navigation projects. Therefore, it is possible that finite element analyses of multi-anchored systems can be performed that incorporate the extended hyperbolic model for interfaces. Performance of the model is excellent for interfaces between fine sands and concrete. However, the model has not been evaluated against the results of shear tests between coarse sand and concrete.

In this investigation, a number of interface tests between coarse sand and concrete were performed. Comparisons were made between the calculated and measured interface response. These comparisons show that the extended hyperbolic model is also accurate for this type of interface and, therefore, that it can be used for a large variety of interfaces between granular soils and concrete.

14. SUBJECT TERMS Hyperbolic model Interface Interface model Interface testing
Reloading Retaining structure Retaining wall
Shear reversal

Staged shear

Unloading
15. NUMBER OF PAGES 97

16. PRICE CODE

\section{SECURITY CLASSIFICATION OF REPORT UNCLASSIFIED

\begin{tabular}{l|ll}
$\begin{array}{l}\text { SECURITY CLASSIFICATION } \\
\text { OF THIS PAGE }\end{array}$ & $\begin{array}{l}\text { 19. } \\
\text { SECURITY CLASSIFICATION } \\
\text { OF ABSTRACT }\end{array}$ \\
\hline UNCLASSIFIED &
\end{tabular}

NSN 7540-01-280-5500 